\title{
Continuous Improvement of Closures for PWR and BWR Simulations
}

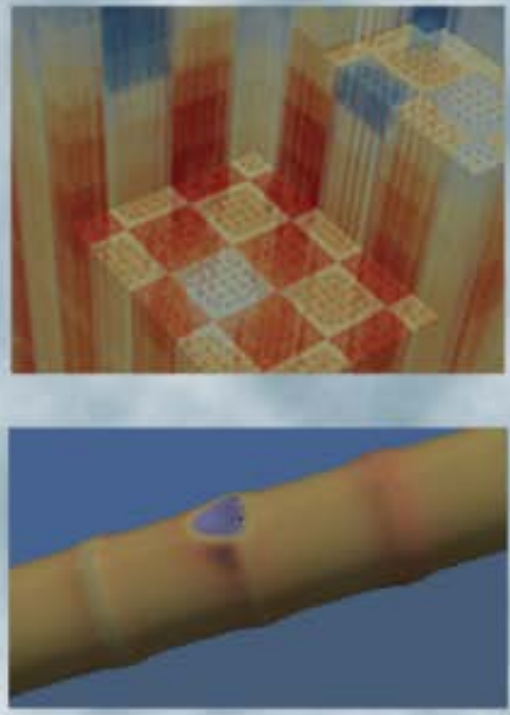

Michael Podowski, RPI

March 16, 2017

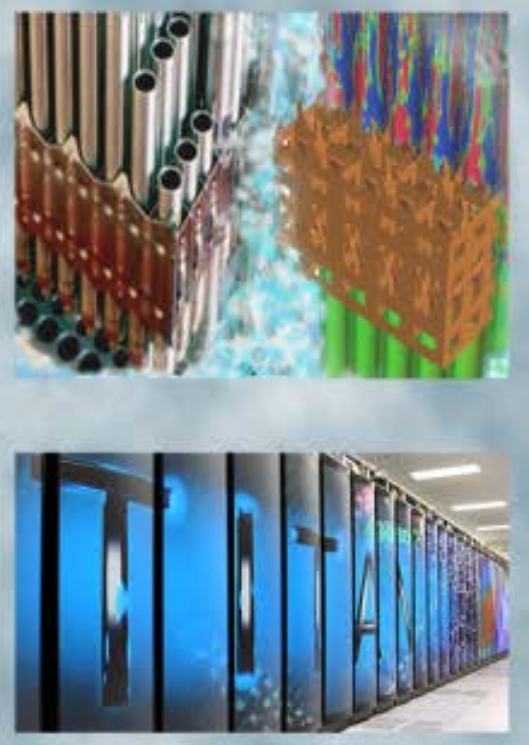


Please complete sections appropriate for this record.

REVISION LOG

\begin{tabular}{|c|c|c|l|}
\hline Revision & Date & Affected Pages & \multicolumn{1}{c|}{ Revision Description } \\
\hline 0 & $03 / 16 / 2017$ & All & Initial Release \\
\hline & & & \\
\hline & & & \\
\hline & & & \\
\hline
\end{tabular}

\section{Document pages that are:}

Export Controlled __ None

IP/Proprietary/NDA Controlled___None

Sensitive Controlled___ None

\section{Requested Distribution:}

To:

Copy:

This report was prepared as an account of work sponsored by an agency of the United States Government. Neither the United States Government nor any agency thereof, nor any of their employees, makes any warranty, express or implied, or assumes any legal liability or responsibility for the accuracy, completeness, or usefulness of any information, apparatus, product, or process disclosed, or represents that its use would not infringe privately owned rights. Reference herein to any specific commercial product, process, or service by trade name, trademark, manufacturer, or otherwise, does not necessarily constitute or imply its endorsement, recommendation, or favoring by the United States Government or any agency thereof. The views and opinions of authors expressed herein do not necessarily state or reflect those of the United States Government or any agency thereof. 


\title{
RPI L3 Milestone for FY 2017
}

\section{Continuous Improvement of Closures for PWR and BWR Simulations}

\author{
Progress Report \\ March 2017
}

\section{Executive Summary}

The purpose of the current report is to document the progress of research conducted at RPI between October 1, 2016 and February 28, 2017. The current RPI Milestone can be divided into two parts/tasks:

Task-1: Collect and document datasets to support the VUQ activities milestones for PWR and BWR.

Task-2: Continue the development and validation of mechanistic closure laws for twophase flow and heat transfer in reactor fuel assemblies.

The present report consists of four parts. They are:

Part A. Overview of the Information Collected by Brian Waite during a Visit to ETH-Zurich in January/February, 2017.

Part B. Bibliography on Forced Convection Boiling and CHF

Part C. Development of Improved Mechanistic Closure Laws for Boiling Heat Transfer

Part D. Development of Improved Models of Two-Phase Flow around Spacer Grids

Both Part A and Part B pertain to Task-1. The purpose of Part A is to provide a comprehensive summary of newly acquired information about SUBFLOW experimental facility. The importance of this document is in the fact that the SUBFLOW experiments constitute one of very few available sources of data for multiphase flow in multiple rod assemblies with spacers. The results of those experiments have been extensively used in the validation of RPI models and we expect it to be very valuable to other CASL researchers. 


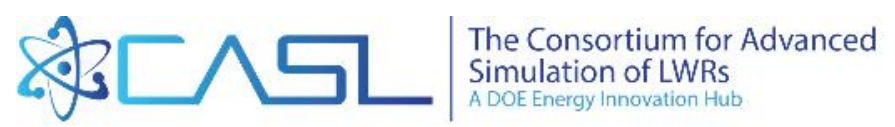

\section{(20) Rensselaer}

Whereas the SUBFLOW experiments are very useful as a reference for multiphase model validation, they are limited to adiabatic air/water flows. Since a major part of the investigations at RPI deals with boiling heat transfer, a list of publications in the area is shown as Part-B. They cover a broad range of issues, including subcooled and saturated boiling conditions, critical heat flux, and include both experimental and theoretical works. Again, whereas the positions listed in this document have been used in the studies performed at RPI, they should also be of significant interest to the CASL community as a whole/.

The purpose of Part C and Part D is to document the recent progress made at RPI in the formulation, testing and validation of new models of multiphase flow and heat transfer. Part $\mathrm{C}$ shows a full paper on the mechanistic modeling of boiling heat transfer which has been accepted for publication in the Proceedings of the ICAPP' 17 conference. Part D presents the abstract of a paper submitted to the NURETH-17 conference. A full paper is currently underway and will be completed and submitted to the conference office by the end of this month.

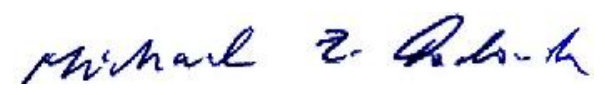

Michael Z. Podowski

Professor and Director, Center for Multiphase Research

Email: podowm@rpi.edu

Tel: 518-276-4000 


\section{Part A. Overview of the Information Collected by Brian Waite during a Visit to ETH- Zurich in January/February, 2017}

\section{Summary}

As a result of the agreement between Professor Michael Podowski and Professor Horst Michael Prasser, Head of the Laboratory for Nuclear Energy Systems (LNES) at ETH-Zurich, Switzerland, Brian Waite, Prof. Podowski's PhD advisee and a member of the RPI CASL team, traveled to Zurich between January 27 and February 7, 2017, to visit both LNES at ETH and the Laboratory of Thermal-Hydraulics at the Paul Scherrer Institute (PSI) [1] in Villigen, near Zurich. A general purpose of the trip was to get first-hand insight into the SUBFLOW experimental facility that was used before to provide multiphase flow data, and to obtain Professor Prasser's input in regard to the main characteristics and capabilities of the wire mesh sensor (WMS) system used in the experiments. This kind of information was deemed very important since the SUBFLOW experiments constitute one of very few available sources of data for multiphase flow in multiple rod assemblies with spacers. The results of those experiments have been used in the validation of RPI models and should also be very valuable to other CASL researchers.

The only information that had been available about the experiment before was that provided in the $\mathrm{PhD}$ Thesis of A. Ylönen [2], and it was basically limited to images (color contours) of the void fraction data for a few selected cases of the experiements performed with and without spacer grids in a 5 x 5 rod bundle. The discussions that Brian had during the visit with Professor Prasser and his associates, as well as the new references which have been provided, have painted a more complete picture of the experiments at SUBFLOW facility. Dr. Prasser agreed to share with CMR the raw void fraction and velocity data, in the understanding that our colloboration would continue.

\section{Description of Data Provided by ETH}

As mentioned before, the previously publicly available data [2] was only depicted as void fraction color contour images. Furthermore, the associated information and insight have been quite limited by the fact that it primarily focused on the single-phase mixing experiments with a salt tracer. The single phase mixing results have been also discussed extensively in a paper published in the Nuclear Engineering and Design Journal [3]. While the images of void fraction data with spacers do provide enough information for a qualitative comparison, they did not represent all of the cases run; furthermore, the information extracted from the images is somewhat unreliable. The raw post-processed data allows for plotting and visualizing the measurements in a variety of ways. The newly obtained data also includes the axial bubble velocity information for all cases, and the lateral bubble velocity information for cases with a spacer grid. It should be mentioned here that whereas the velocity measurements provide useful qualitative information about the flow, they may still be quantitatively inaccurate. Specifically, the intrusive method of the two-layer wire mesh sensor hinders the flow, and thus may cause errors in the velocity data. The cross-correlation factor method to determine bubble velocities is not tailored to each individual bubble and has trouble 
correcting for lateral bubble movement between the sensors, which introduces additional inaccuracies.

Table 1.1 shows an overview of all the conditions with data available. The locations of 50, 250, 450 and 650 refer to the distance (in millimeters) downstream from the spacer grid. A discussion of the analysis and results is given in following sections. It is important to note that all of the measurements have a fixed measuring location, as the wire mesh sensor is immovable. Instead, the spacer is moved to measure void fraction at different distances downstream from the spacer grid. This then implies the assumption that the inlet conditions to all five measurement runs are identical for the same flow rate, even though the inlet distance from the air injectors is different for each case. This assumption must be valid in the experiments to provide consistent information about the development of void fraction distribution downstream from the spacer grid.

Table 1.1: Overview of Flow Conditions and Data Provided

\begin{tabular}{|l|c|c|l|}
\hline Case & $\boldsymbol{j}_{\boldsymbol{l}}[\mathbf{m} / \mathbf{s}]$ & $\boldsymbol{j}_{\boldsymbol{l}}[\mathbf{m} / \mathbf{s}]$ & Data Locations \\
\hline Case 1-1 & 0.8 & 0.008 & No Spacer, $50 \mathrm{~mm}, 250 \mathrm{~mm}, 450 \mathrm{~mm}$, and $650 \mathrm{~mm}$ \\
\hline Case 1-2 & 0.8 & 0.020 & No Spacer, $50 \mathrm{~mm}, 250 \mathrm{~mm}, 450 \mathrm{~mm}$, and $650 \mathrm{~mm}$ \\
\hline Case 1-3 & 0.8 & 0.039 & No Spacer, $50 \mathrm{~mm}, 250 \mathrm{~mm}, 450 \mathrm{~mm}$, and $650 \mathrm{~mm}$ \\
\hline Case 1-4 & 0.8 & 0.059 & No Spacer \\
\hline Case 2-1 & 1.2 & 0.008 & No Spacer, $50 \mathrm{~mm}, 250 \mathrm{~mm}, 450 \mathrm{~mm}$, and $650 \mathrm{~mm}$ \\
\hline Case 2-2 & 1.2 & 0.020 & No Spacer, $50 \mathrm{~mm}, 250 \mathrm{~mm}, 450 \mathrm{~mm}$, and $650 \mathrm{~mm}$ \\
\hline Case 2-3 & 1.2 & 0.039 & No Spacer, $50 \mathrm{~mm}, 250 \mathrm{~mm}, 450 \mathrm{~mm}$, and $650 \mathrm{~mm}$ \\
\hline Case $2-4$ & 1.2 & 0.059 & No Spacer \\
\hline Case 3-1 & 1.6 & 0.008 & No Spacer, $50 \mathrm{~mm}, 250 \mathrm{~mm}, 450 \mathrm{~mm}$, and $650 \mathrm{~mm}$ \\
\hline Case 3-2 & 1.6 & 0.020 & No Spacer, $50 \mathrm{~mm}, 250 \mathrm{~mm}, 450 \mathrm{~mm}$, and $650 \mathrm{~mm}$ \\
\hline Case 3-3 & 1.6 & 0.039 & No Spacer, $50 \mathrm{~mm}, 250 \mathrm{~mm}, 450 \mathrm{~mm}$, and $650 \mathrm{~mm}$ \\
\hline Case 3-4 & 1.6 & 0.059 & No Spacer \\
\hline
\end{tabular}

\section{SUBFLOW Facility Overview}

The SUBFLOW facility is unique as it allows for conducting high-resolution spatial measurements of void fraction in rod bundles. This helps to get insights into how the spacer grid affects local void distribution, that are vital data to the benchmarking and validation of CFD models at developing flow conditions. All of the dimensions have been scaled up by 2.6 from a typical PWR bundle, what makes the hydraulic diameter in the experiment equal to $3.387 \mathrm{~cm}$. This was done to get more measurement locations, and the scaling factor of 2.6 represents the ratio of the critical bubble diameter at prototypical steam/water conditions to that at atmospheric air/water, according to the Tomiyama's lift correlation[4]. Figure 3.1 shows images of the SUBFLOW facility taken during the tour. The facility operates at atmospheric air/water conditions at about 23 
$\pm 1^{\circ} \mathrm{C}$. The duration of each measurement was 20 seconds with a $2.5 \mathrm{kHz}$ frequency corresponding to 50,000 frames. The air injector is located $1712 \mathrm{~mm}$ upstream from the wire mesh sensor (WMS). This allows a significant amount of time for the flow to develop before contacting the WMS. There is a simple support spacer grid $912 \mathrm{~mm}$ upstream from the WMS. A schematic of the support spacer is shown in Figure 3.2. This support spacer is only between the exterior acrylic rods, as the center rod is stainless steel. The support spacer is assumed to have little effect on the flow but this assumption can be verified based on computational fluid dynamics calculations.
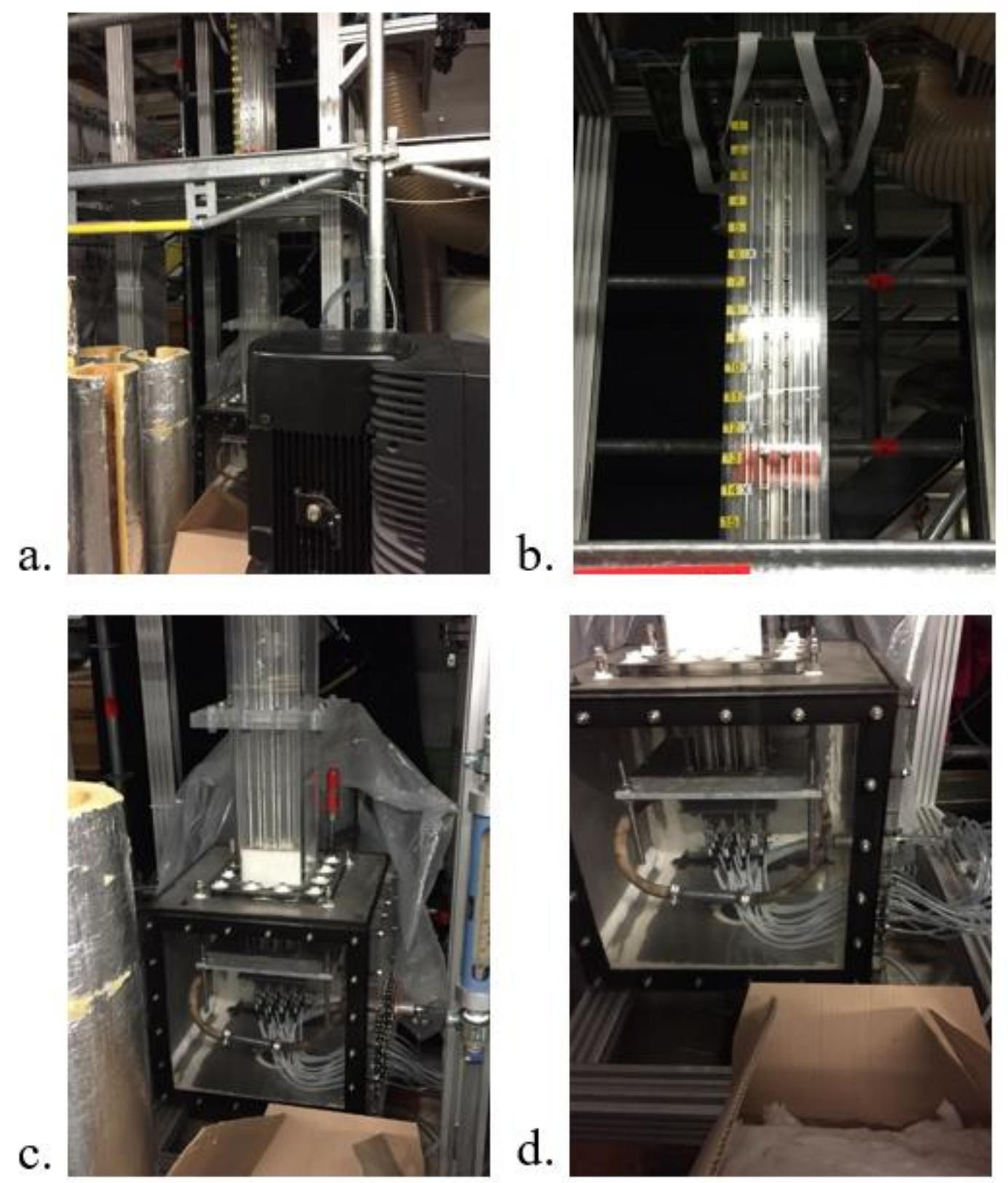

Figure 3.1. SUBFLOW Facility: (a) full facility, (b) spacer region, (c) inlet section d) air injector. 
The experiments with spacer grids used a moveable spacer that was held in place magnetically and could be moved in $50 \mathrm{~mm}$ increments. The data was recorded moving the spacer to four different locations. The four locations correspond to the distance from the top of the spacer to the WMS. The locations, as stated in Table 1.1, are $50 \mathrm{~mm}, 250 \mathrm{~mm}, 450 \mathrm{~mm}$, and $650 \mathrm{~mm}$. This allowed to maintain a distance of at least $25 \mathrm{~cm}$ between the simple support spacer and the inlet to the spacer grid investigated. If the assumption that the simple support spacer has little effect is valid, the $25 \mathrm{~cm}$ distance should be sufficiently long to assume fully developed flow entering the main spacer grid. This assumption allows the use of measurements without spacers as inlet conditions to the spacer grids when performing numerical simulations. The geometry of the standard/convective spacer grid used in the experiment is based on the work done by Navarro et al. [5], and is shown in 3.3. The vanes are bent $30^{\circ}$ from the axial flow direction to create swirl within the channels and cross-flow between the channels.
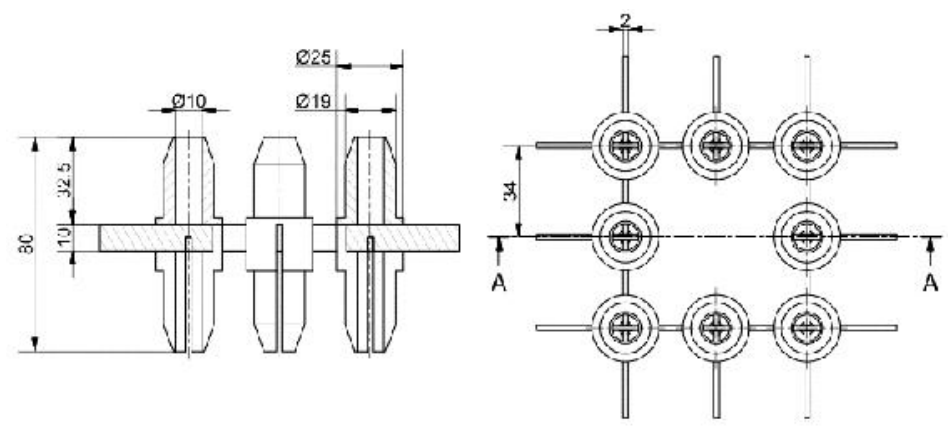

Figure 3.2. Simple support spacer located $912 \mathrm{~mm}$ upstream from WMS, reproduced from [2].
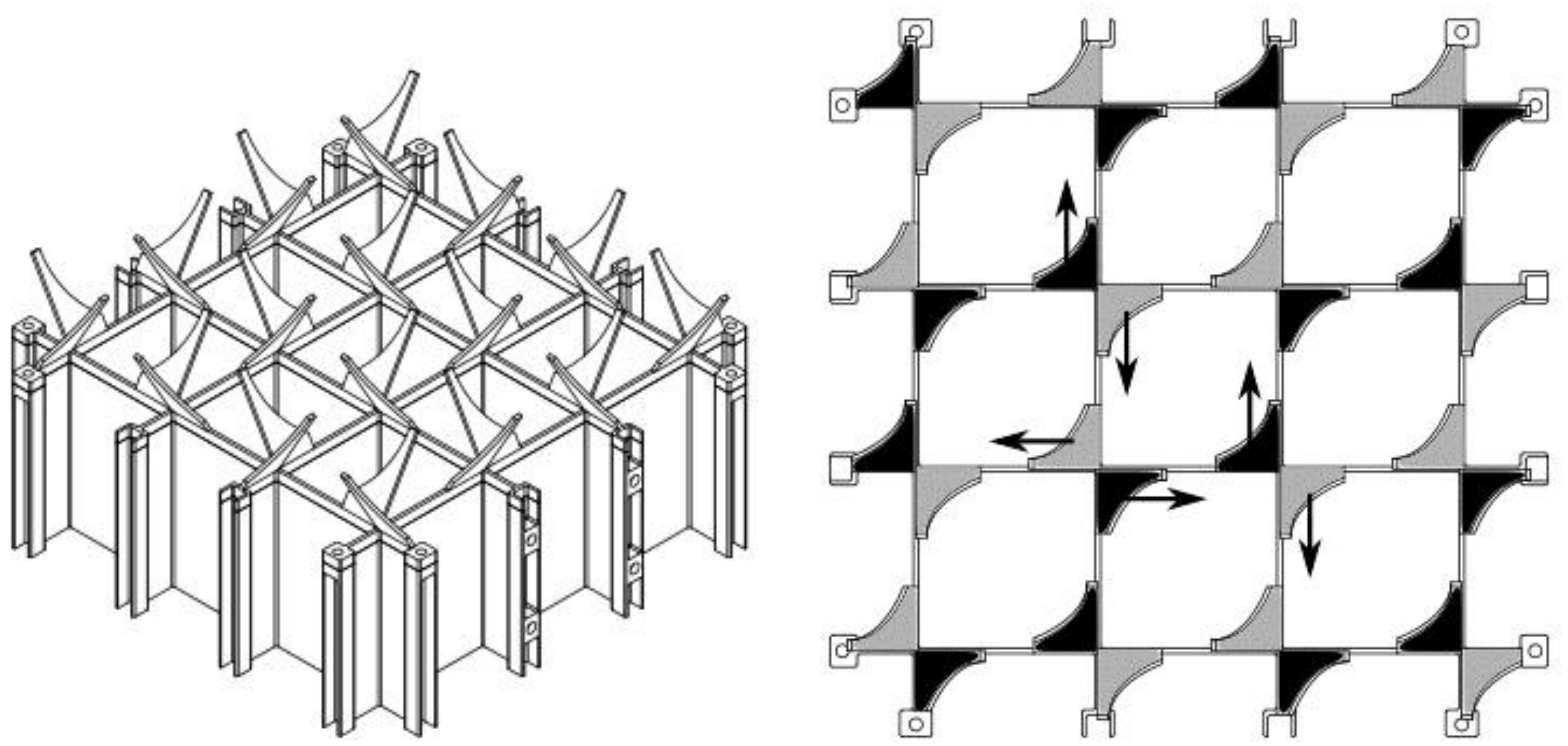

Figure 3.3. Standard/convective type spacer used in SUBFLOW two-phase flow experiments $\left(\measuredangle=30^{\circ}\right)$, reproduced from [2]. 


\subsection{Wire Mesh Sensor}

The wire mesh sensor is a two-layer sensor that allows for the evaluation of bubble velocity when the two signals are cross-correlated. The sensor operates at $2.5 \mathrm{kHz}$, which allows for high resolution time measurements. While it has been well documented that the first sensor may cause bubble breakup and other disturbances, the signal of the second sensor was normally consistent with the first sensor [6]. The spatial resolution of the WMS is not fine enough to pick up the differences caused by the first sensor, so the second sensor records similar signals. The WMS measures the conductivity at the crossing points of the wires to record time- and space-resolved data that void fraction information is derived from. More information on wire-mesh sensors can be found in the thesis of Ylönen [2], and other works by Prasser [6, 7]. The two WMSs here were placed $15 \mathrm{~mm}$ apart from one another in order to get a reasonable distance with minimal errors for the time-of-flight calculations used for velocity results. The wire mesh sensor was manufactured through the rods for easier access to all locations in the bundles. The measurement locations within the acyllic rods were then ignored during post processing.

\subsection{Air Injector}

The air injector used in the SUBFLOW facility was specifically designed for this experiment based upon previous works [8]. A schematic of the air injector is shown in Figure 3.4. The injector has 16 collocated air capillary outlets that allow the air to bubble into the flow. The secondary liquid flows in an annulus outside the air capillary. This liquid is taken from the primary liquid flow in order to keep the total liquid flow consistent. The rate of secondary liquid flow allows for controlling the conditions of the bubbles injected into the test section. It has been noticed that a simple capillary nozzle used originally limited the amount of conditions that could be used to obtain bubbly flow measurements [2], which led to the use of the current air injector design.

During the injection, the initial bubble size can be controlled by changing the secondary flow rate. For the measurements discussed here, this flow rate was kept constant at $1000 \mathrm{l} / \mathrm{hr}$. An increase in the secondary flow rate increases bubble departure frequency and decreases bubble size while keeping the airflow constant. As the airflow rate is increased and the secondary flow rate is kept constant, the bubble sizes are increased. Such technique was used in most SUBFLOW experiments. Therefore, only small airflow rates correspond to the cases that exhibit small bubbles near the walls of the subchannels. 


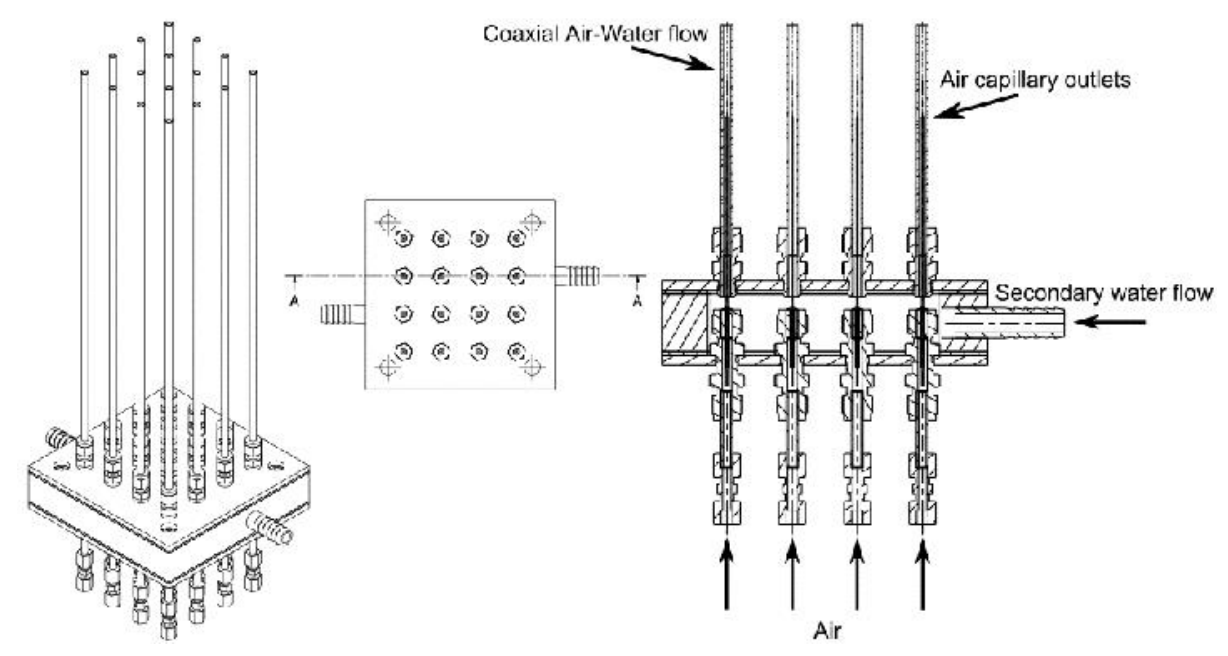

Figure 3.4. Air Injector of the SUBFLOW facility (16 Coaxial air-water flow) reproduced from [2].

Dällenbach [9] characterized the influence of the primary water flow, secondary water flow, and air flow, on bubble size and shape for the same type of air injector but using a single tube with a coaxial air-water injector. He concluded that with increasing airflow the size of the bubbles increased, also leading to a wider distribution of bubble sizes. This means that the high airflow cases have a large variety of bubble sizes. Such a trend was seen in the experiments of Ylönen [2], as the standard deviation of bubble size at higher air flow rates was larger. A future idea for investigating small bubble flows at higher volume fractions points to increasing the secondary liquid flow rate. However, Dällenbach studied a maximum volumetric flow rate of $60 \mathrm{l} / \mathrm{hr}$ and the SUBFLOW experiments outlined in Ylönen [2] used $62.5 \mathrm{l} / \mathrm{hr}$ per channel (1000 1/hr total). It is unclear if such values represent the upper limit for the secondary liquid flow rate, or if higher values could still be used in future experiments.

It is important to notice that there is no control of bubble size once the bubbles have left the air injector. In principle, larger bubbles may experience breakup and/or coalescence as they flow upstream, but such phenomena were apparently negligible in the SUBFLOW experiments since only low void fractions flows have been studied.

Finally, it should be mentioned that the SUBFLOW facility has not been in use since 2013, and its availability for future experiments is uncertain.

\section{Data Analysis}

\subsection{Average Volume Fraction Calculation}

The measured potential field around crossing points of the transmitter and receiver wires is reduced as a function of the local volume fraction. The pitch of the wires used in the experiment, i.e., $2.125 \mathrm{~mm}$, was a frame of reference for converting the crossing point indexes to $x$ and $y$ 
coordinates. The measurement frame index and the frequency of the system convert to the time of measurement according to

$$
x=i \cdot \Delta x \quad y=j \Delta y \quad t=k \cdot \Delta \mathrm{t}_{\text {meas }}=\frac{k}{f_{\text {meas }}}
$$

Here, the variable $k$ is the integer representing the frame of measurement. The measurement of the conductivity is converted into a local void fraction using a calibrated conductivity of plain water and the conductivity of gas, which is nearly zero in this case. The overall process can be described by the following relationship

$$
\alpha_{i, j, k}=1-\frac{I_{i, j, k}-I_{\text {gas }, i, j}}{I_{\text {water }, i, j}-I_{\text {gas }, i, j}}=1-\frac{I_{i, j, k}}{I_{\text {water }, i, j}} \cong \frac{1}{V} \int_{V} \delta\left(x, y_{\text {wmins }}, t\right) d V
$$

This is interpreted as the definition of void fraction, which is the average of the phase indicator function over a control volume. Eq.(2) shows the linear dependence between volume fraction and conductivity.

Ylönen [2] discarded deviations from the liquid conductivity lower than $10 \%$ as disturbances of that size could be attributed to electrical noise. This ensured that only the signals from bubbles were used to record the final signal, as given by

$$
\alpha_{i, j, k}=\left\{\begin{array}{l}
\alpha_{i, j, k} \text { if } \alpha_{i, j, k} \geq 0.1 \\
0 \text { if } \alpha_{i, j, k}<0.1
\end{array}\right.
$$

In reality this procedure could have resulted in neglecting some signals caused by the actual bubbles.

The time averaged void fraction is then found by a simple averaging over all measurement frames, $k$, in the 20 second run, according to the formula

$$
\bar{\alpha}_{i, j}=\frac{1}{n} \sum_{k=1}^{n} \alpha_{i, j, k}
$$

Ylönen [2] used a separate calibration run of pure demineralized water to determine the conductivity of water. This method could be inaccurate if the air/water mixture changed the baseline of conductivity throughout the course of the run. There has been changes in a new method of data reduction that have apparently improved the accuracy of experiments [10]. In this improved approach, a histogram is used of the local maximum of conductivity between measurements to determine the average conductivity of pure liquid for that specific situation. This improvement has been implemented in the "2017" data, which Professor Prasser has shared with CMR.

Prasser [10] has also determined that the "linear cut" method overpredicts void fraction in the channel. This inaccuracy arises from neglecting the overshoots in conductivity measurments where the measured conductivity is higher than that of pure water. Prasser has shown that there is a 
physical reason for these overshoots and should be accounted for in the analysis. He refers to this as a "no cut" method, which means that the void fraction is now determined by averaging over all of the measurements even if the measured values are negative due to a conductance higher than that of pure water. This reduces the void peaks and has been shown to be more accurate.

Prasser has also shown that the linear relationship is not the best approximation. For this reason, a "Maxwell no-cut" method has been selected to convert the conductivity readings into void fraction in the "2017" data analysis. The non-linear Maxwell distribution is given by

$$
\alpha_{i, j, k}=\frac{1-I_{i, j, k}}{1+\frac{I_{i, j, k}}{2}}
$$

The updated results are compared against the old results in Figure 4.5. The "2017" data analysis has lower channel void fractions than the "2013" analysis, which is evident by the lower peak value in each channel for the "2017" data. A full comparison of all the data for every case can be found in Appendix II: 2013 Void Fraction Analysis vs 2017 Void Fraction Methods. The two improvements in the "2017" analysis give the data more confidence. Appendix 1: Void and Velocity Distributions for All Cases, shows the void fraction for all cases from the 2017 data reduction. The void fraction data used is from the first WMS.
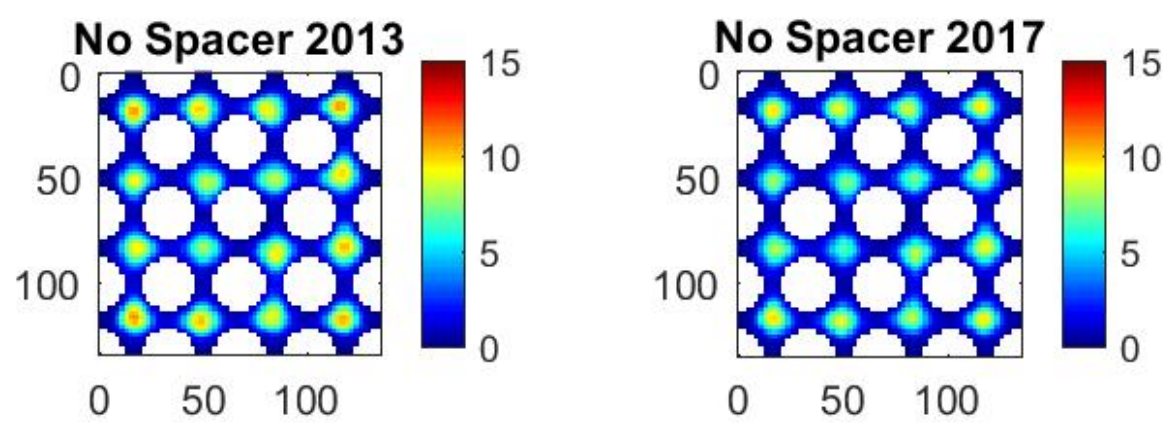

Figure 4.5. Case-2-3: Average void fraction results.

\subsection{Bubble Velocity}

The cross-correlation technique determines the bubble velocity. Even though the first sensor fragments the bubbles, the shape of the bubble at this sensor is correlated to the void at the second sensor. The cross correlation coefficient is maximized to determine how many frames it takes for a bubble to go from one sensor to the other. The fixed distance, $\mathrm{L}=15 \mathrm{~mm}$, is then used to determine the velocity once the frame rate is known. The standard deviation and void fraction of the two signals are used to find the cross-correlation coefficient, and the maximum is selected as the bestcorrelated location using the following relation 


$$
\max \left(\rho_{b u b, n}\right)=\frac{1}{N-1} \sum_{i, j, k \in b u b, n} \frac{\left(\alpha_{1, i, j, k}-\overline{\alpha_{1}}\right)\left(\alpha_{2, i, j, k+\Delta k}-\overline{\alpha_{2}}\right)}{s_{1} s_{2}}
$$

To minimize the search on $k$, limits are placed on $k_{\min }$ and $k_{\max }$ as the range of velocity from the flow rate is known. This method provides an estimation of the bubble velocity, $w_{b u b, n}$. This data is shown for all cases in Appendix I. Due to the intrusiveness of the measurement and inadequacies of the cross-correlation method, the velocity results are not very accurate, but can still be used for qualitative considerations. As can be seen in Figure 4.6, the velocity for Case 1-3 without spacers reaches a maximum in the center of the channels, as expected.

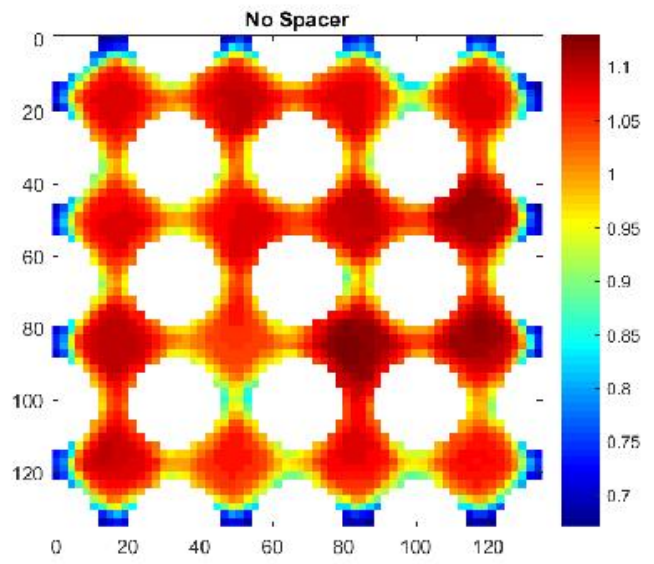

Figure 4.6. Case 1-3: Axial velocity without spacers.

For the experiments with spacers, the method discussed above is used to determine the maximum cross correlation coefficient in time and space at the second sensor. The spatial indexes in the neighborhood of the initial signal are examined to look for the time and location where the signal is most highly correlated to the initial signal. The lateral distance from the new location's coordinates to the initial signal's coordinates can then be used to get an estimation of the lateral bubble velocities. This result is again fairly inaccurate but gives a qualitative measure of how the bubbles are moving after the spacer grid. This velocity information can then be used to find the magnitude of the lateral velocity to see the areas of strong bubble movement. In Figure 4.7, the colors represent the magnitude of the lateral velocity and the arrows represent the velocity directions $50 \mathrm{~mm}$ downstream from the spacer in Case 1-3. The figure clearly shows that there is a swirling motion induced by the mixing vanes. The orientation of the vanes can also be clearly seen as some of the channels exhibit strong movement in the "top" and "bottom" and some exhibit movement on the "left" and "right". Appendix I. shows the data for all the cases. 


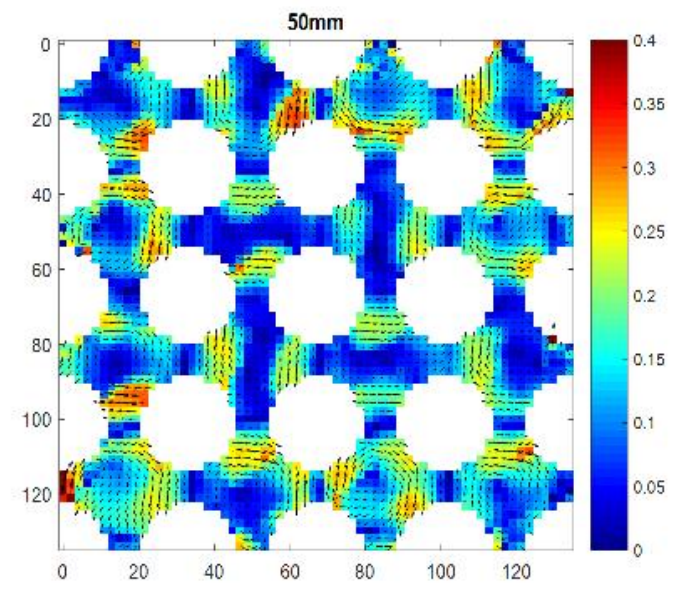

Figure 4.7. Case-1-3: Lateral bubble velocity distribution $50 \mathrm{~mm}$ downstream from the spacer.

\subsection{Bubble Size}

Bubble size can be determined from two different methods with the two-layer WMS. The bubble size is always an approximation based upon a spherical bubble assumption. One can determine the bubble size based on the volume of the bubble and/or the horizontal cross section of the bubble. The volume of the bubbles is calculated from

$$
V_{b u b} \cong w_{b u b, n} \Delta x \Delta y \Delta t \sum \alpha_{i, j, k} \forall(i, j, k) \in \text { bubble, } n
$$

where the axial velocity of the bubble is necessary to convert the $x, y, t$ information to a volume. It is important to note that bubble- $n$ must be identified first, as only the readings corresponding to the space occupied by the bubbles are used.

The diameter of the bubble is then calculated assuming a spherical particle

$$
D_{b u b, n}=\sqrt[3]{\frac{6 V_{b u b, n}}{\pi}}
$$

The cross sectional area of a bubble can be evaluated from

$$
A_{b u b} \cong \Delta x \Delta y \sum \alpha_{i, j, k} \forall(i, j, k) \in \text { bubble } n
$$

The horizontal bubble diameter is derived from

$$
D_{\text {horizontal }, b u b, n}=\sqrt{\frac{4 A_{b u b, c s}}{\pi}}
$$


Using this bubble diameter given by Eq.(10) to deduce to the volume of the bubble could lead to significant overestimates in the case of ellipsoidal bubble shapes.

Both definitions of bubble size can be used to separate void fraction distributions amongst bubble size classes. The results here have been separated for all cases based upon the Tomiyama "Critical Bubble Size" for atmospheric air water, equal to $5.8 \mathrm{~mm}$ [4]. The results for the experimental run without a spacer for Case 1-2 are shown in Figure 4.8. It is currently unclear which bubble diameter definition was used for the split in this case. It is interesting to note that Tomiyama originally used a horizontal bubble diameter in his proposed lift correlation for the modified Eötvos number. So, using the measured horizontal diameter would be consistent with the Tomiyama's formulation.
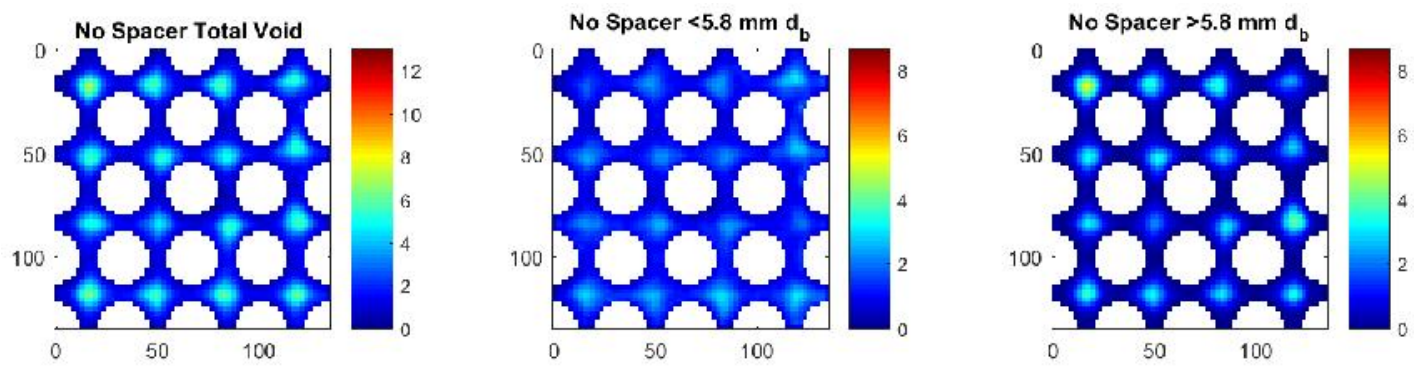

Figure 4.8. Case-1-2: Void fraction results split by bubble size.

\section{Brief Discussion of Results}

Some general conclusions about void fraction in subchannels before and after spacers can be made from the SUBFLOW data. First, it is important to notice that only the low gas flow cases (jv $=0.008 \mathrm{~m} / \mathrm{s}$ ) without spacers show stable wall-peaked void fraction corresponding to small bubbles near the wall. In the case of experiments with a spacer, such small bubbles are brought into the middle of the subchannels by the spacer and then return to the wall as the flow moves downstream. The higher liquid flow rates seem to cause flows to take longer to return to the conditions before spacer grids. This is best shown by examining Case $1-1(\mathrm{jl}=0.8 \mathrm{~m} / \mathrm{s}, \mathrm{jv}=0.008$ $\mathrm{m} / \mathrm{s})$ and Case $3-1(\mathrm{jl}=1.6 \mathrm{~m} / \mathrm{s}, \mathrm{jv}=0.008 \mathrm{~m} / \mathrm{s})$, which have different liquid flow rates but the same gas flow rate. Case 1-1 has bubbles all near the fuel surfaces by $650 \mathrm{~mm}$, whereas there are still peaks at the center in Case 3-1. This result is shown in Figure 5.9. 

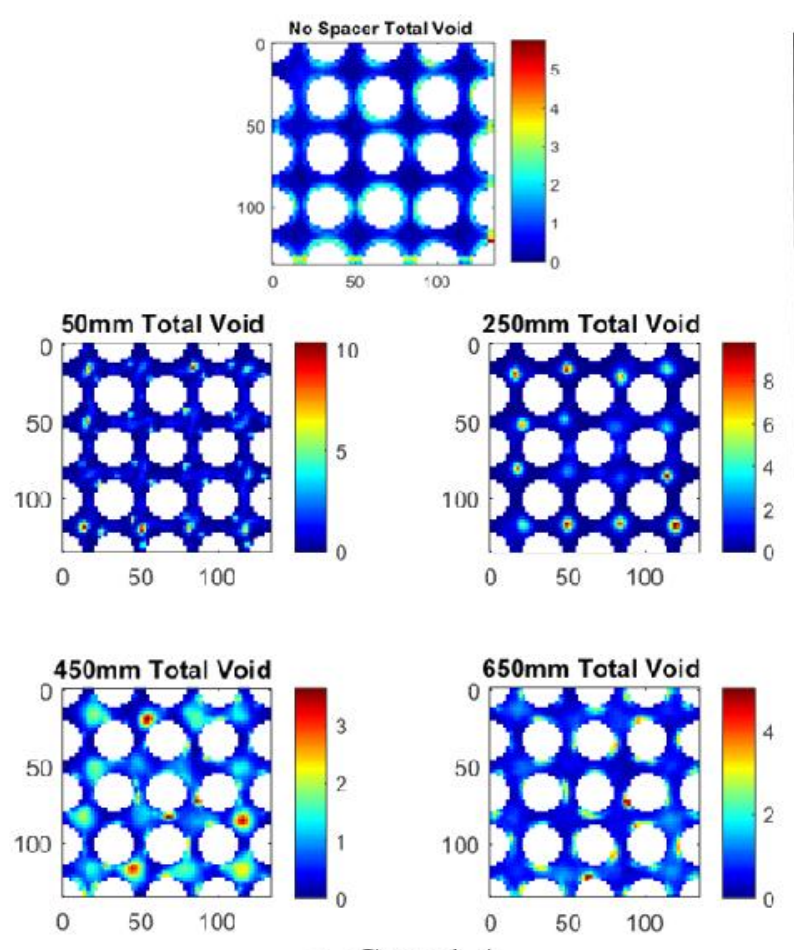

a. Case $1-1$
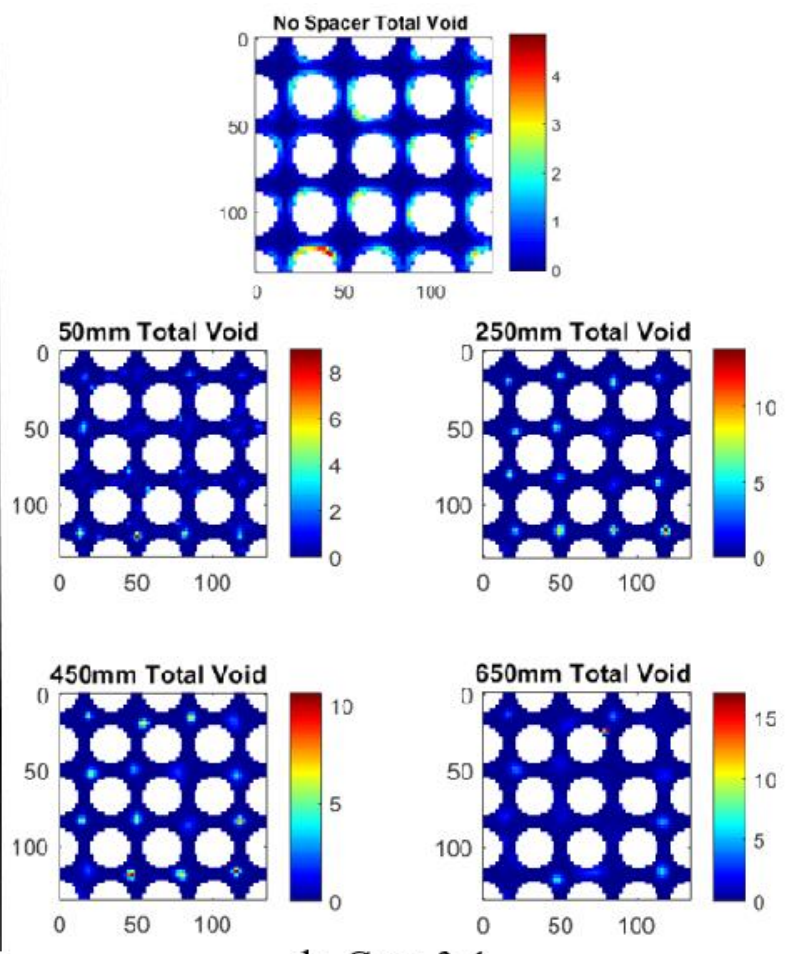

b. Case $3-1$

Figure 5.9. Case-1-3 and Case-3-1: Void comparison.

The cases with high gas flow rates $\left(j_{v}=0.039 \mathrm{~m} / \mathrm{s}\right)$ all exhibit center-peaked voids and have strong void fraction profiles corresponding to bubble diameters above $5.8 \mathrm{~mm}$ (large bubbles). Some cases show very limited evidence of breakup after the spacer grids as the void remains center-peaked after the mixing vanes. One notable case that does show breakup is Case-3-3 ( $j_{l}=1.6$ $\mathrm{m} / \mathrm{s}, j_{v}=0.039 \mathrm{~m} / \mathrm{s}$ ), which seems to show either evidence of breakup or strong effects of the spacer grids that are still felt $650 \mathrm{~mm}$ downstream from the spacer. This is shown in Fig. 5.2. An examination of the void fraction result without a spacer for this case indicates that the majority of bubbles are all large and the void is center-peaked. When the spacer perturbs the void, there are more small bubbles that appear in the channel not seen without spacers. The void distributions split by bubble size shows this clearly. The bubbles now have both wall- and center-peaks $650 \mathrm{~mm}$ downstream from the spacer. This would point to the evidence that there are either small bubbles or strong secondary flows remaining around the rods that cause the bubbles to be near the surfaces. 

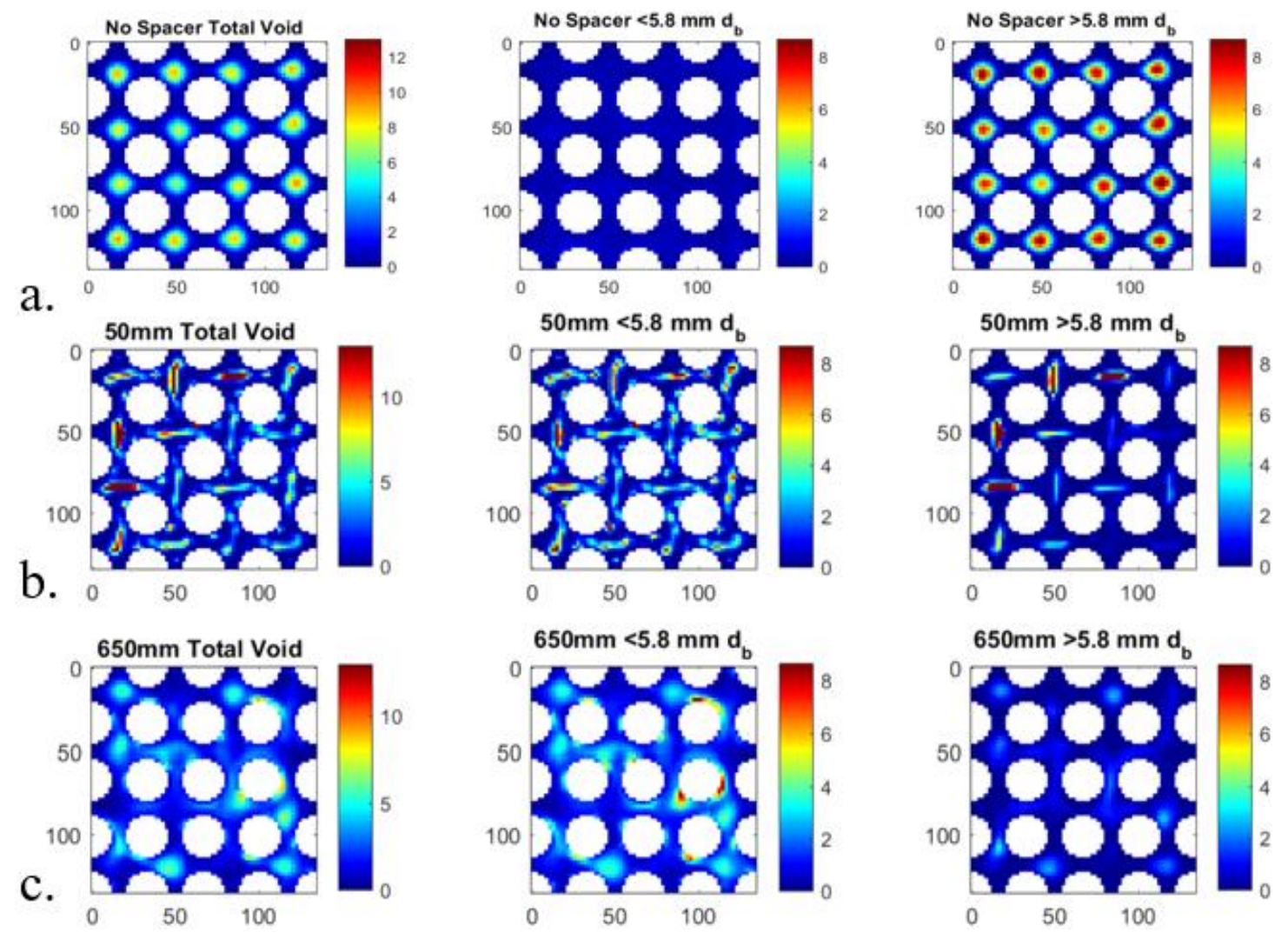

Figure 5.2. Case 3-3: Void results: (a) no spacer, (b) $50 \mathrm{~mm}$ downstream, (c) $650 \mathrm{~mm}$ downstream.

The velocity data provides information on vane orientation and swirling of channels. The lateral velocity data shows a decay of the velocity magnitude as the flow moves away from the spacer grids. Details in this regard are shown in Appendix A (e.g., see Fig. A-1.3). This is consistent with the observations that spacer grid effects decay moving downstream [11]. An examination of the axial velocity profiles shows that the cases before spacers or without spacers (see Fig. 5.3(a)) have relatively identical velocity profiles in all 16 channels, as expected because there is minimal mixing. At $650 \mathrm{~mm}$, the axial bubble velocity shown in Fig. 5.3(b) is very uneven between channels, which would point to evidence that the spacer grids have caused the air mass flow to be uneven between the 16 channels. This also points to the evidence that the results at 650 $\mathrm{mm}$ are not yet back to a fully developed condition. This extra information helps one to realize that the model should not be expected to predict a fully developed flow at $650 \mathrm{~mm}$ downstream from the spacer grid. This location is only 19.12 hydraulic diameters downstream, which is much shorter than the accepted developing length in two-phase flows. 
a.

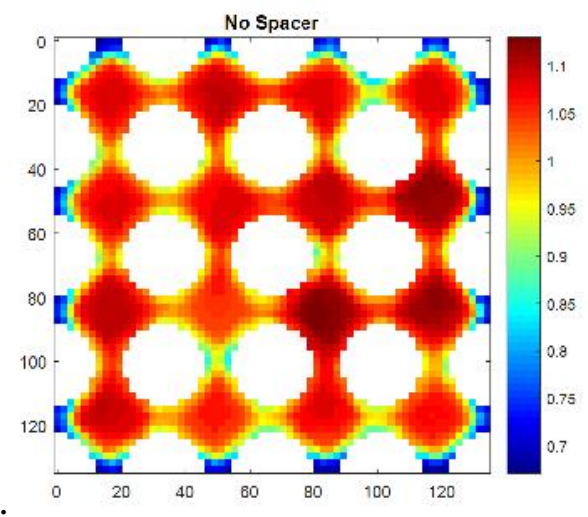

b.

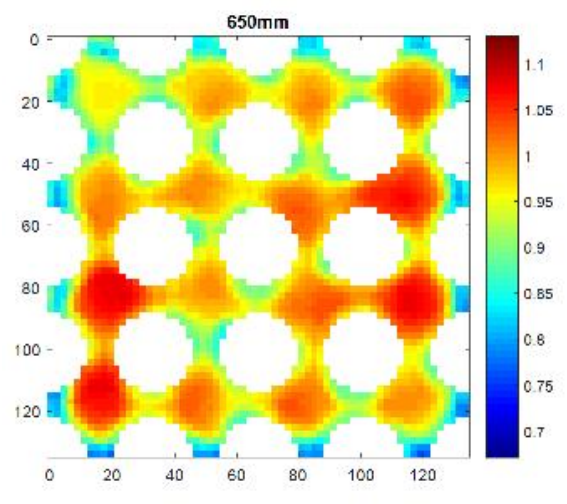

Figure 5.3. Case 1-3: Axial bubble velocity: (a) with no effect of spacer, (b) $650 \mathrm{~mm}$ downstream of the spacer.

\section{Recommendations for Use of Data for Model Verification}

The data that has been collected at the SUBFLOW facility to date can be used to validate adiabatic two-fluid models for multiple bubbly flow conditions. The expanded data set obtained during the trip allows for extending the range of quantitative void comparisons with the results of CMFD simulations. This, in turn, will help to perform a more informed and consistent model validation. The increased number of flow conditions will allow to perform additional parametric testing to ensure that the models are not just tuned to specific conditions. Needless to say, mechanistic modeling should capture the physics and trends, rather than be tuned to specific experimental data. Qualitative checks with velocity information will also be used to ensure similar behavior between reality and simulations.

\section{Other Activities during Trip}

During the trip, Brian Waite also had the opportunity to visit other experimental facilities at ETH-Zurich as well as at PSI. The two-phase flow experimental facilities at ETH-Zurich are smaller scale and seem focused on separate effect studies, whereas the resources at PSI allow for larger scale integral testing. At ETH Zurich, he visited a lab that uses a sensor embedded in the fuel rod surface to investigate liquid film thickness in a subchannel during annular flow. The concept is similar to the wire mesh sensor as it uses the conductivity of the fluid to determine the thickness of the film on top of the spacer. A similar sensor has been described by Tiwari et al. [12]. This sensor is of interest to boiling water reactor spacers. The same experimental setup is also used in conjunction with a salt tracer in the liquid film in order to determine mixing between two subchannels in the annular flow regime. A different facility is currently using cold neutron imaging to investigate the dryout mode. The facility uses Chloroform as a working fluid, so that dryout can be induced at low heat fluxes and low pressures. A unique and clever feature of the facility is the method in which the heat flux is applied. The flowing fluid is heated using heavy water channels, which allows for applying a consistent heat flux and does not impede the neutron imaging. The 
heating with heavy water channels eliminates the possibility of burning out panels, as is the issue with electrically heated channels. This allows for performing testing and measurement of sustained dryout conditions.

At PSI, there are many thermal-hydraulic facilities which target a variety of issues. As stated before, the use of the SUBFLOW facility is at PSI, but its use since 2013 has been limited. A similar wire mesh sensor is currently used in another facility, to understand the flow downstream from a xenon scrubber used if the containment has to vent to the atmosphere. Tours of the LINX and PANDA facilities showed the large-scale experimental capabilities at PSI. LINX provides a prototypical pressure environment to study containment safety. The facility is equipped with infrared cameras in order to study heat flux variations in a liquid film during the periods of evaporation and condensation. PANDA is a large-scale facility originally designed to investigate passive cooling capabilities of advanced light water reactor designs. The reactor is simulated as an electrically heated system with a maximum power supply of $1.5 \mathrm{MW}$, and it is coupled with the drywell, pressure suppression champers and gravity driven coolant systems. The purpose of the experiments is to test passive decay heat removal capabilities for station blackout scenarios. This facility has been used in the development and testing of passive cooling systems for the ESBWR.

The visit also coincided with a tour of SwissFel, a brand new facility designed to deliver extremely short and intense flashes of X-ray radiation at laser quality. This very expensive largescale facility currently consists of an electron source, a linear accelerator, undulators and experimental setups in a kilometer long tunnel. This facility is unique as it is extremely short flashes should allow snapshots of individual intermediate steps of chemical reactions at the molecular level. This would be the first time scientists should be able to follow the smallest reaction components in a systematic manner. 


\section{References}

[1] "Laboratory for Thermal-Hydraulics," 2017. https://www.psi.ch/lth/laboratory-for-thermalhydraulics.

[2] A. Ylönen, "High-resolution flow structure measurements in a rod bundle," ETH ZURICH, 2013.

[3] A. Ylönen, W.-M. Bissels, and H.-M. Prasser, "Single-phase cross-mixing measurements in a $4 \times 4$ rod bundle," Nucl. Eng. Des., vol. 241, no. 7, pp. 2484-2493, 2011.

[4] A. Tomiyama, H. Tamai, I. Zun, and S. Hosokawa, "Transverse migration of single bubble in simple shear flows," Chem. Eng. Sci., vol. 57, pp. 1849-1858, 2002.

[5] M. Navarro and a. a. C. Santos, "Numerical Evaluation of Flow Through a 5X5 Pwr Rod Bundle: Effect of the Vane Arrangement in a Spacer Grid," Library.Sinap.Ac.Cn, 2009.

[6] H.-M. Prasser, D. Scholz, and C. Zippe, "Bubble size measurement using wire-mesh sensors," Flow Meas. Instrum., vol. 12, no. 4, pp. 299-312, 2001.

[7] H.-M. Prasser, M. Misawa, and I. Tiseanu, "Comparison between wire-mesh sensor and ultra-fast X-ray tomograph for an air-water flow in a vertical pipe," Flow Meas. Instrum., vol. 16, no. 2, pp. 73-83, 2005.

[8] R. Milenković, "Experimental Investigation of Bubbly Jets," ETH-Zurich, 2005.

[9] M. Dällenbach, "High-Speed Camera Observation of Bubble Generation," ETH Zurich, 2014.

[10] H. Prasser and R. Häfeli, "Signal Response Of Wire-Mesh Sensors to an Idealized Bubbly Flow," in Specialist Workshop on Advanced Instrumentation and Measurement Techniques for Nuclear Reactor Thermal Hydraulcis, 2016.

[11] H. L. McClusky, M. V. Holloway, T. a. Conover, D. E. Beasley, M. E. Conner, and L. D. Smith, "Mapping of the Lateral Flow Field in Typical Subchannels of a Support Grid With Vanes," J. Fluids Eng., vol. 125, no. 6, p. 987, 2003.

[12] R. Tiwari, M. Damsohn, H.-M. Prasser, D. Wymann, and C. Gossweiler, "Multi-range sensors for the measurement of liquid film thickness distributions based on electrical conductance," Flow Meas. Instrum., vol. 40, pp. 124-132, 2014. 


\section{Appendix 1: Void and Velocity Distributions for All Cases}

\subsection{Case 1-1}
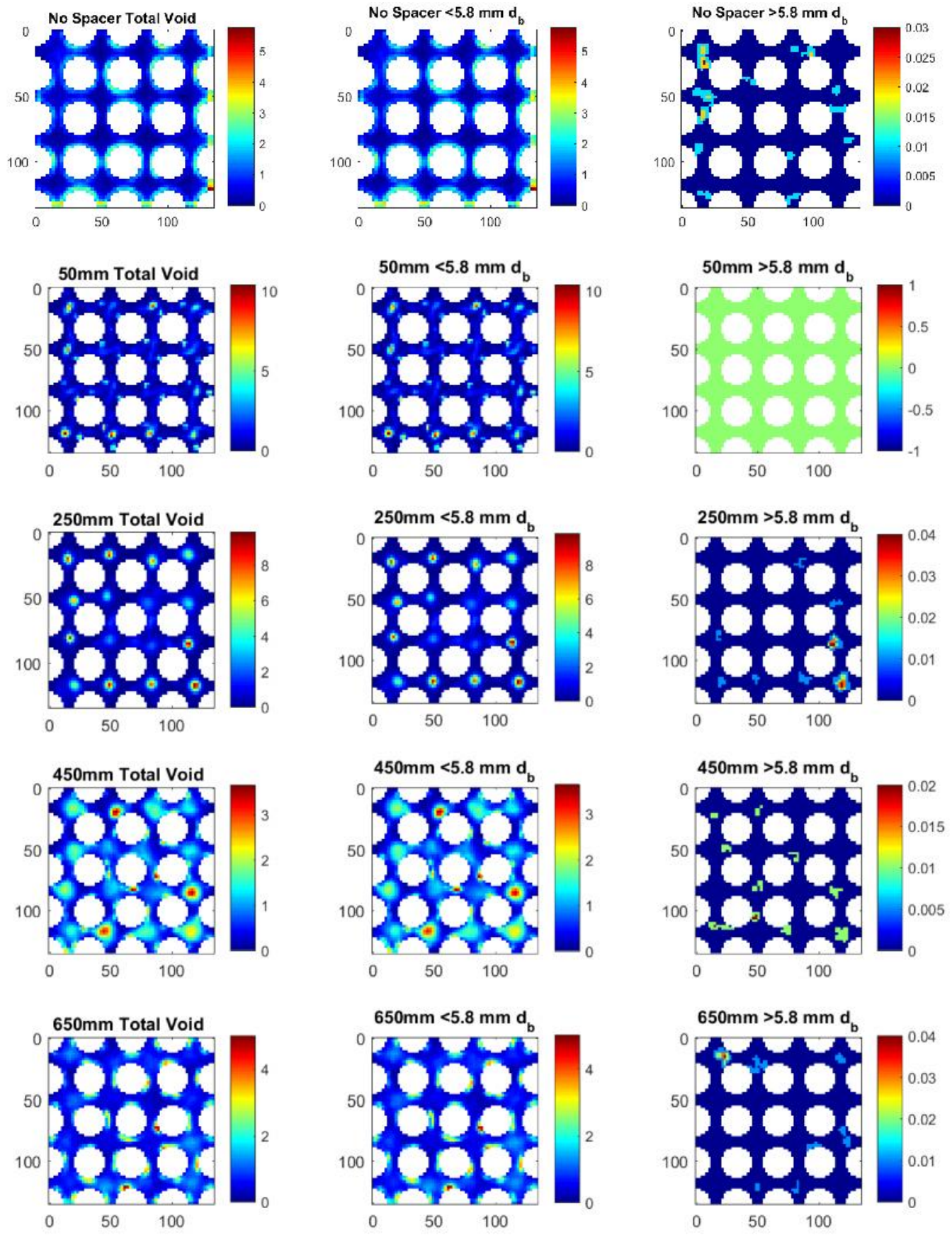

Figure A-1.1. Case 1-1: Average void fraction results. 

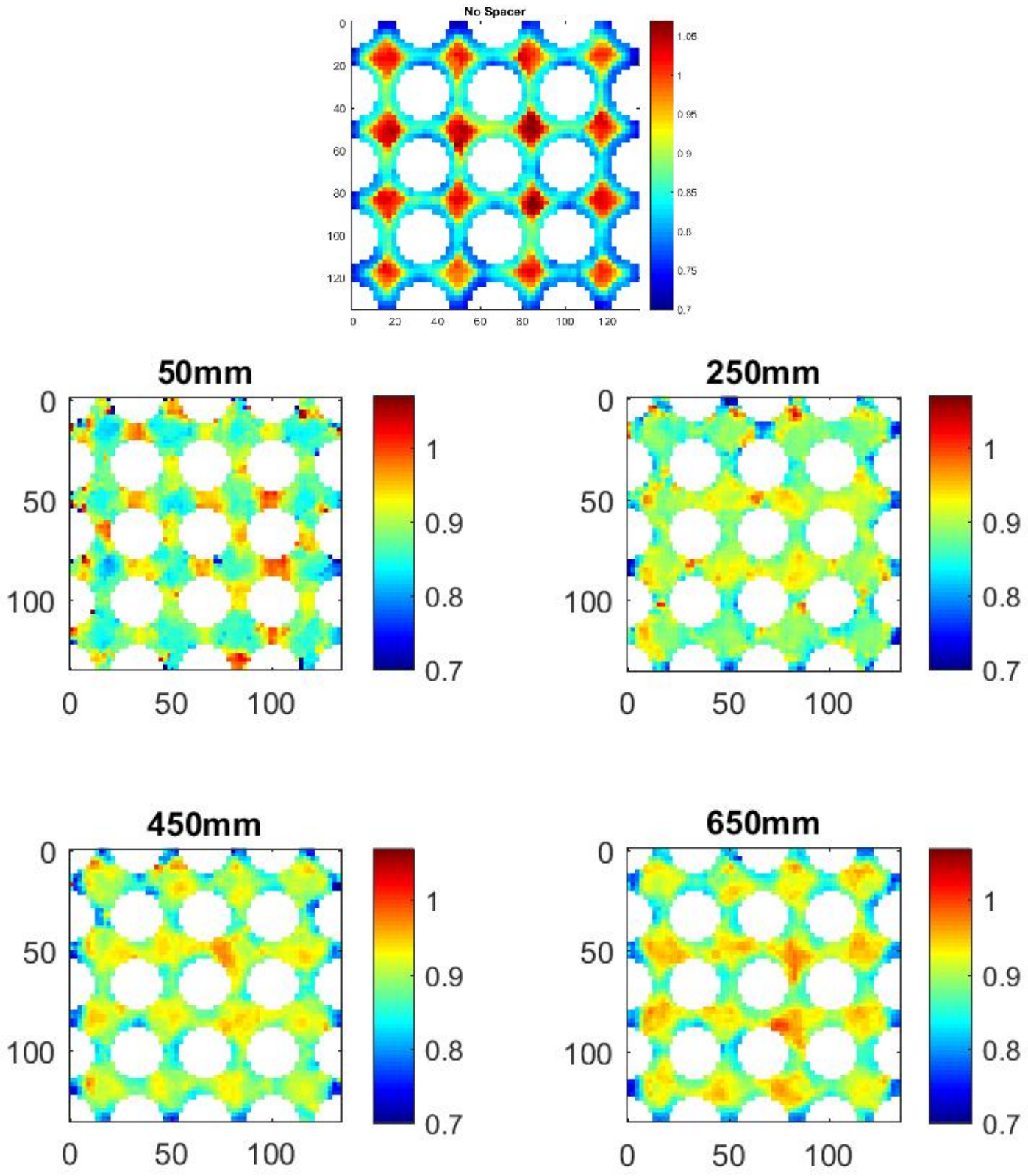

Figure A-1.2. Case 1-1: axial velocity results. 

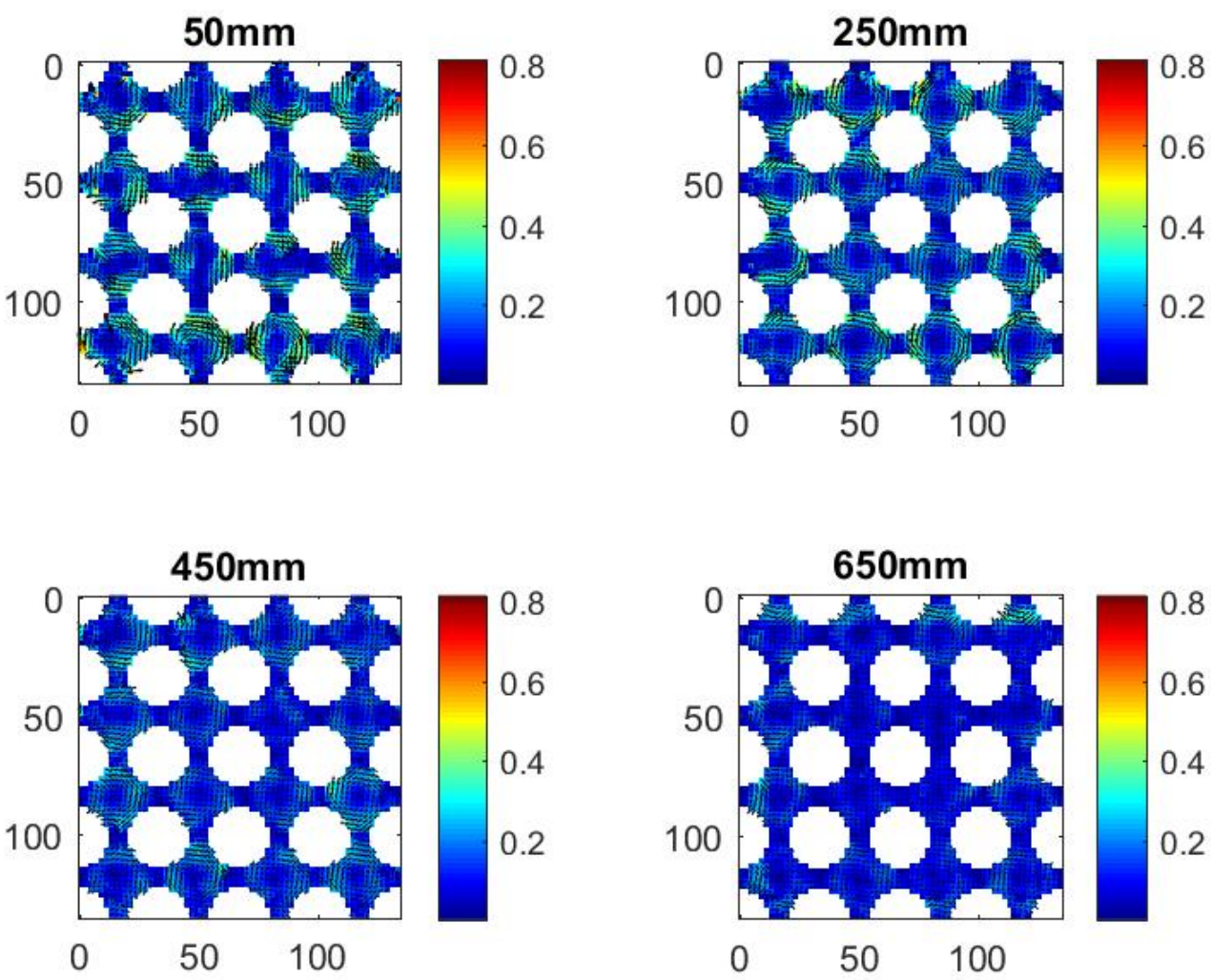

Figure A-1.3. Case 1-1: lateral velocity results. 


\subsection{Case 1-2}
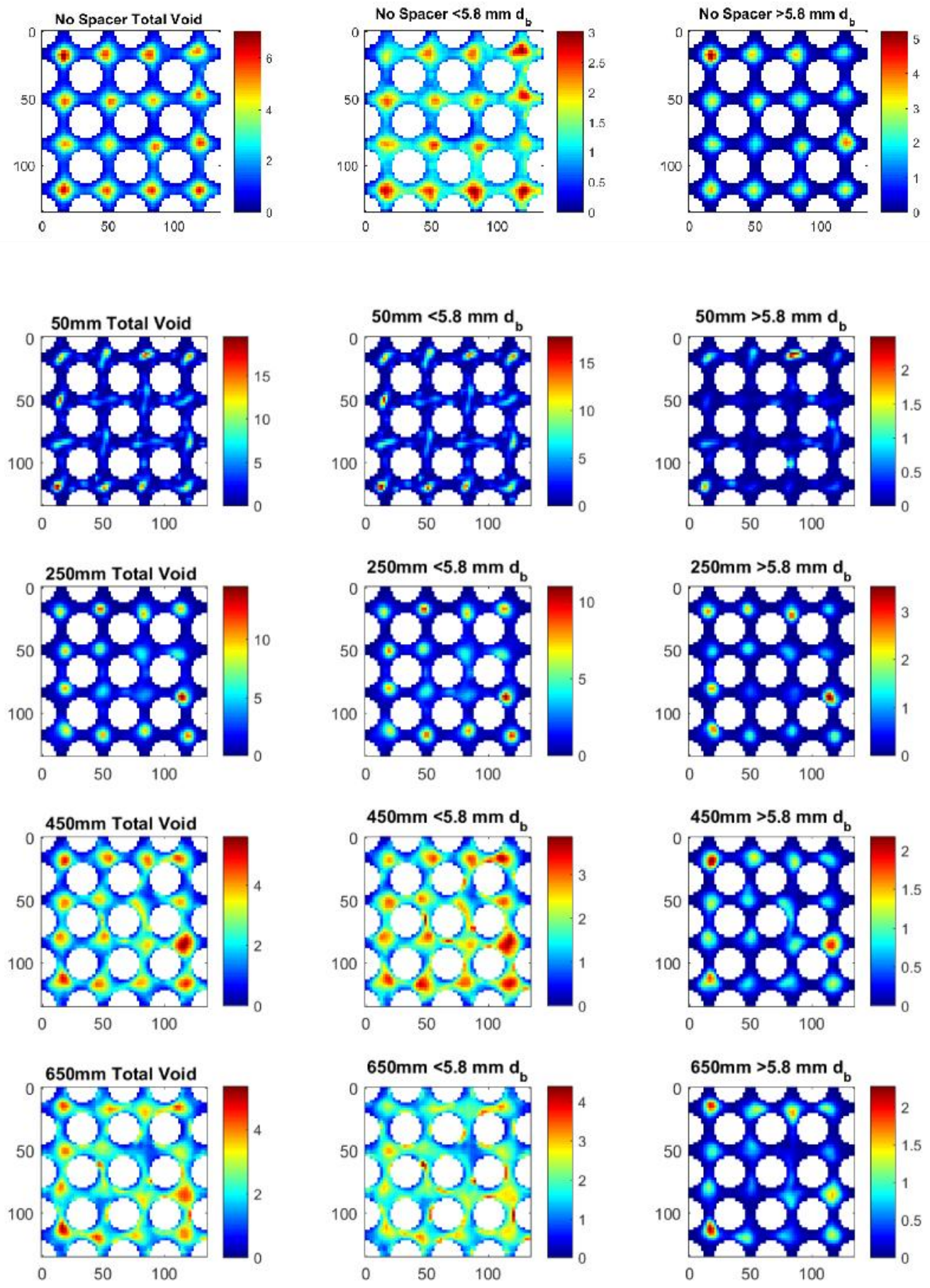

Figure A-1.4. Case 1-2: Average void fraction results. 

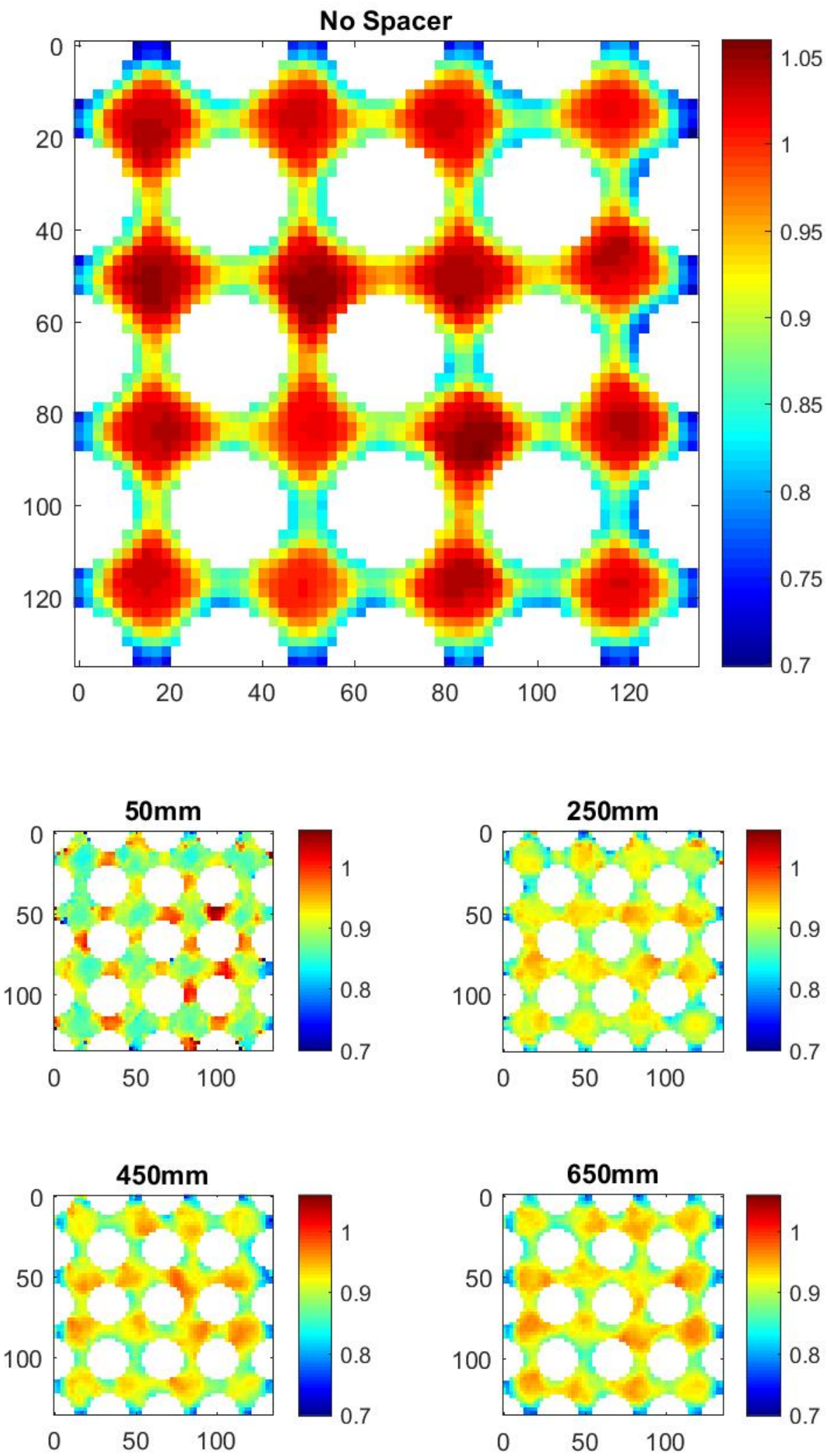

Figure A-1.5. Case 1-2: Axial velocity results. 

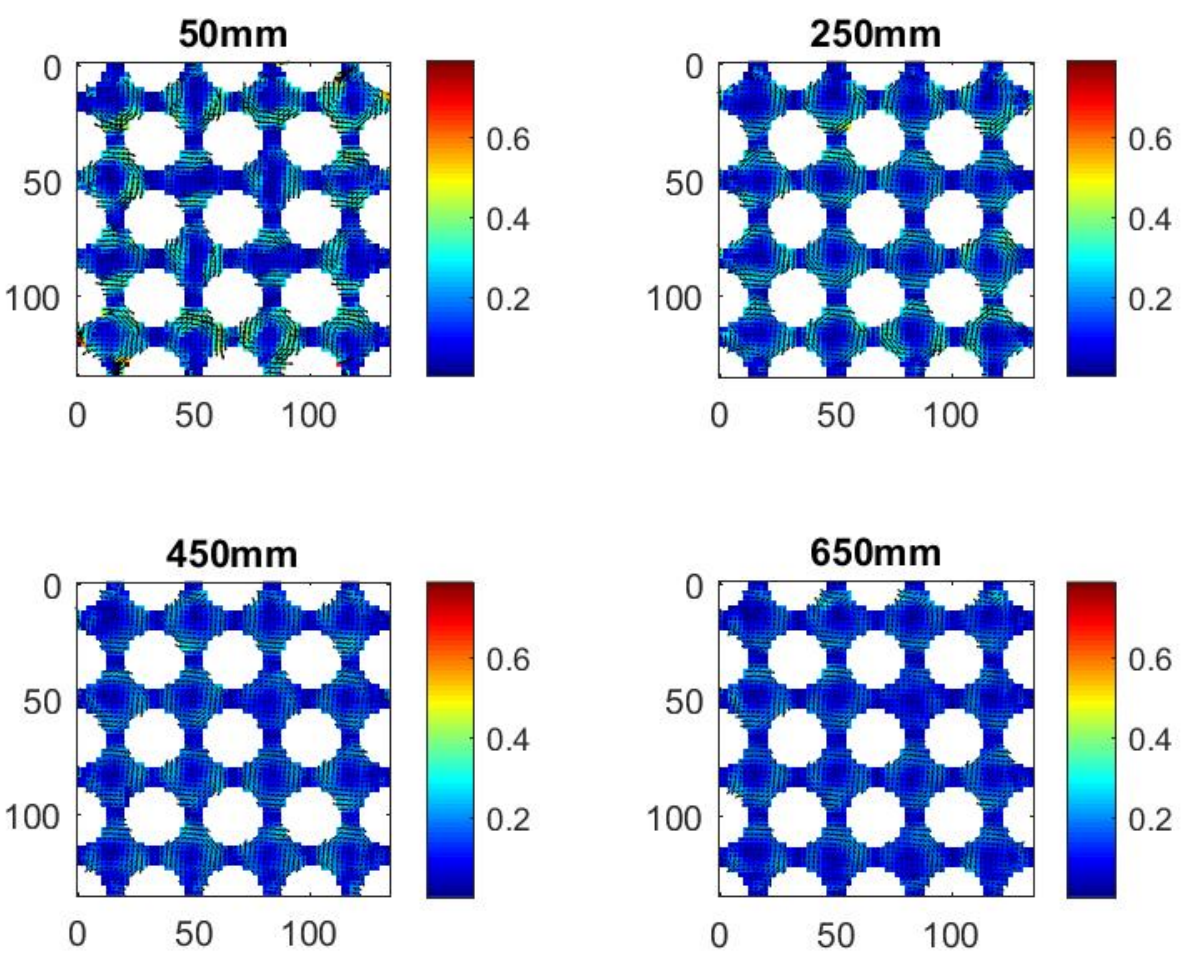

Figure A-1.6. Case-1-2: Lateral velocity results. 


\subsection{Case 1-3}
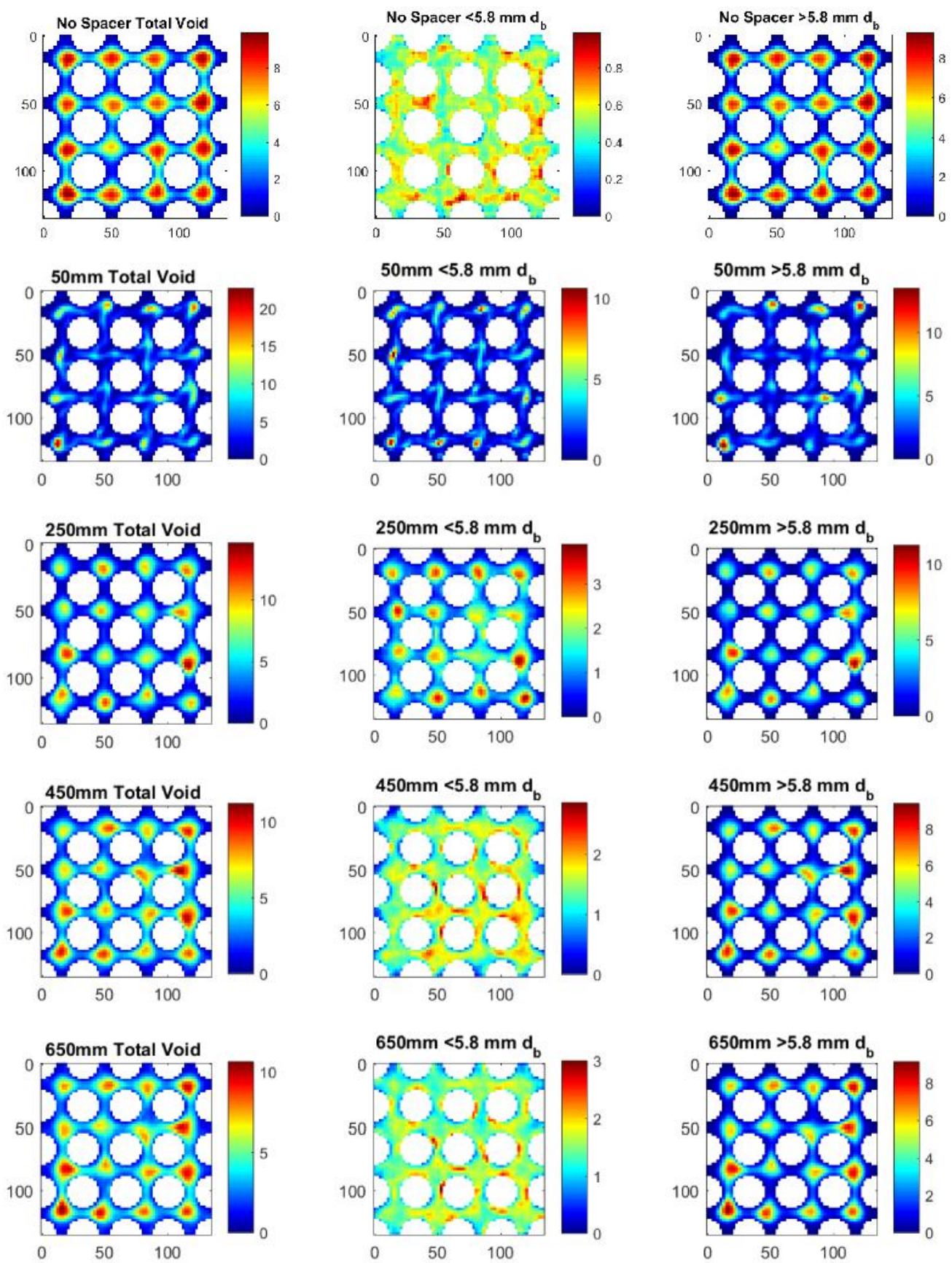

Figure A-1.7. Case-1-3: Average void fraction results. 

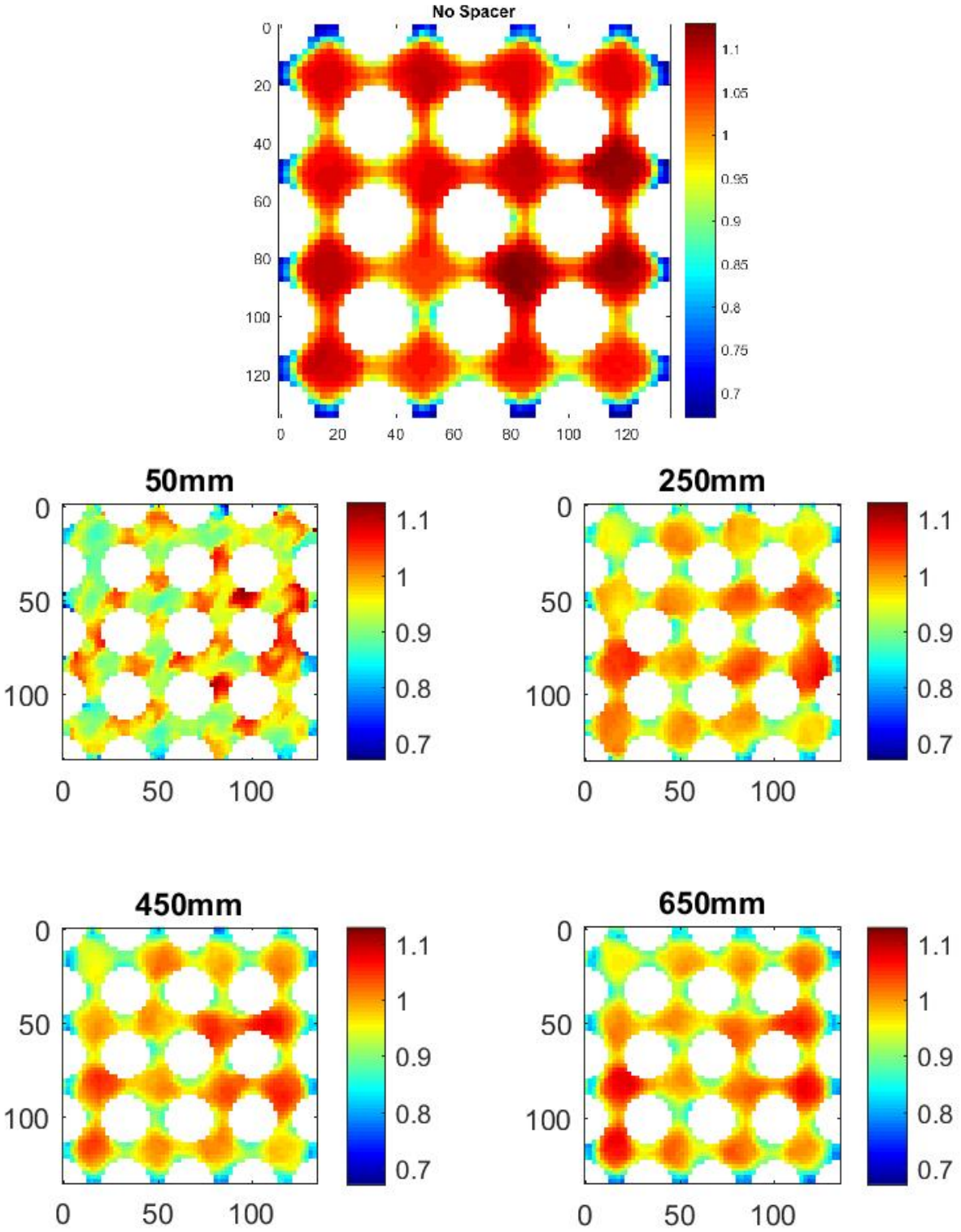

Figure A-1.8. Case-1-3: Axial velocity results. 

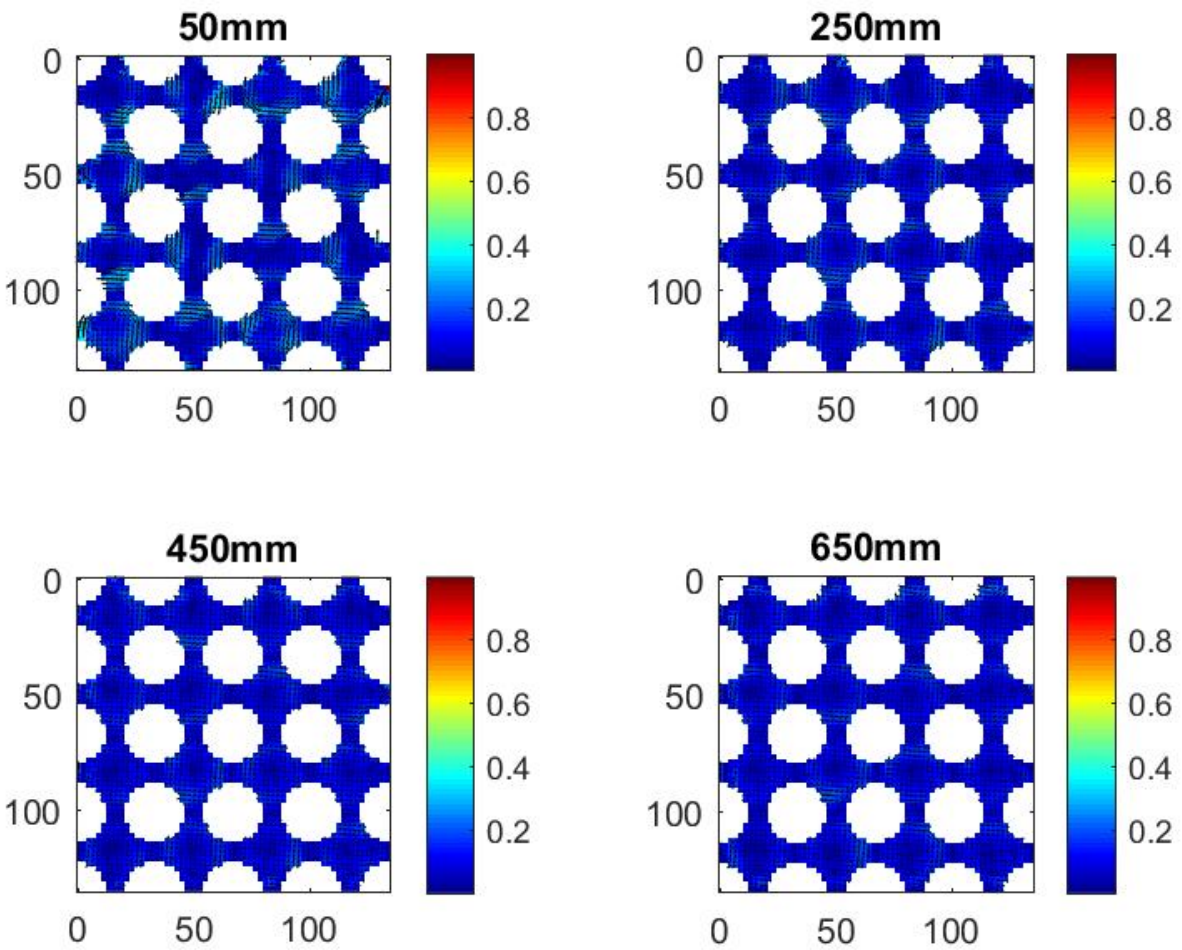

Figure A-1.9. Case-1-3: Lateral velocity results. 


\subsection{Case 1-4}
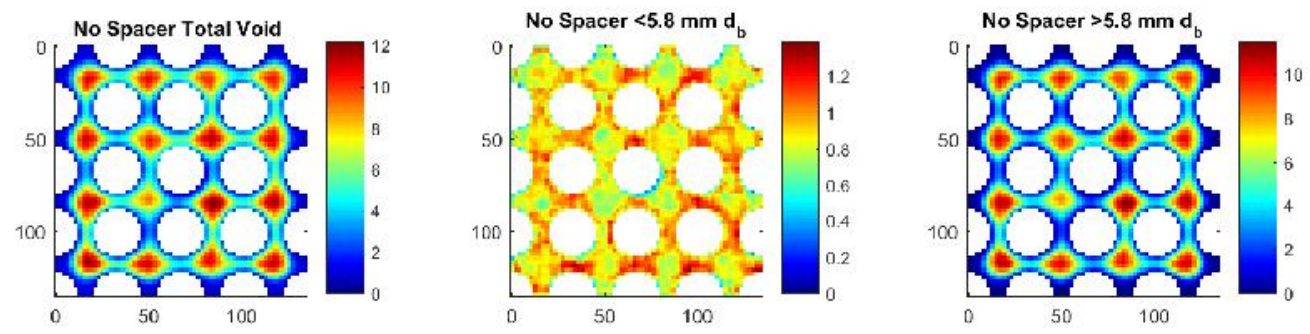

Figure A-1.10. Case-1-4: Average void fraction results.

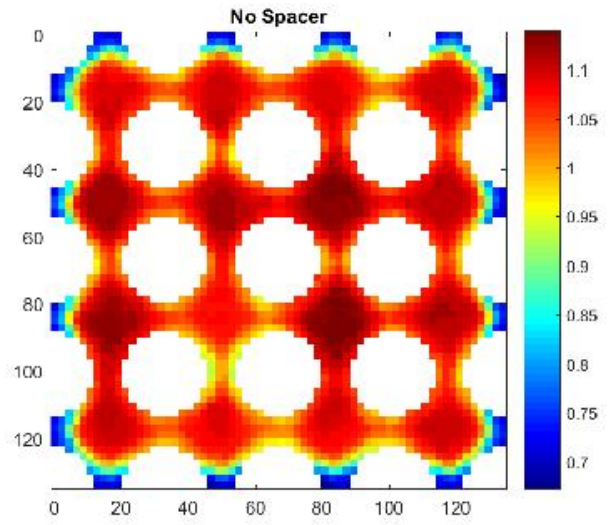

Figure A-1.11. Case-1-4: Axial velocity results. 


\subsection{Case 2-1}
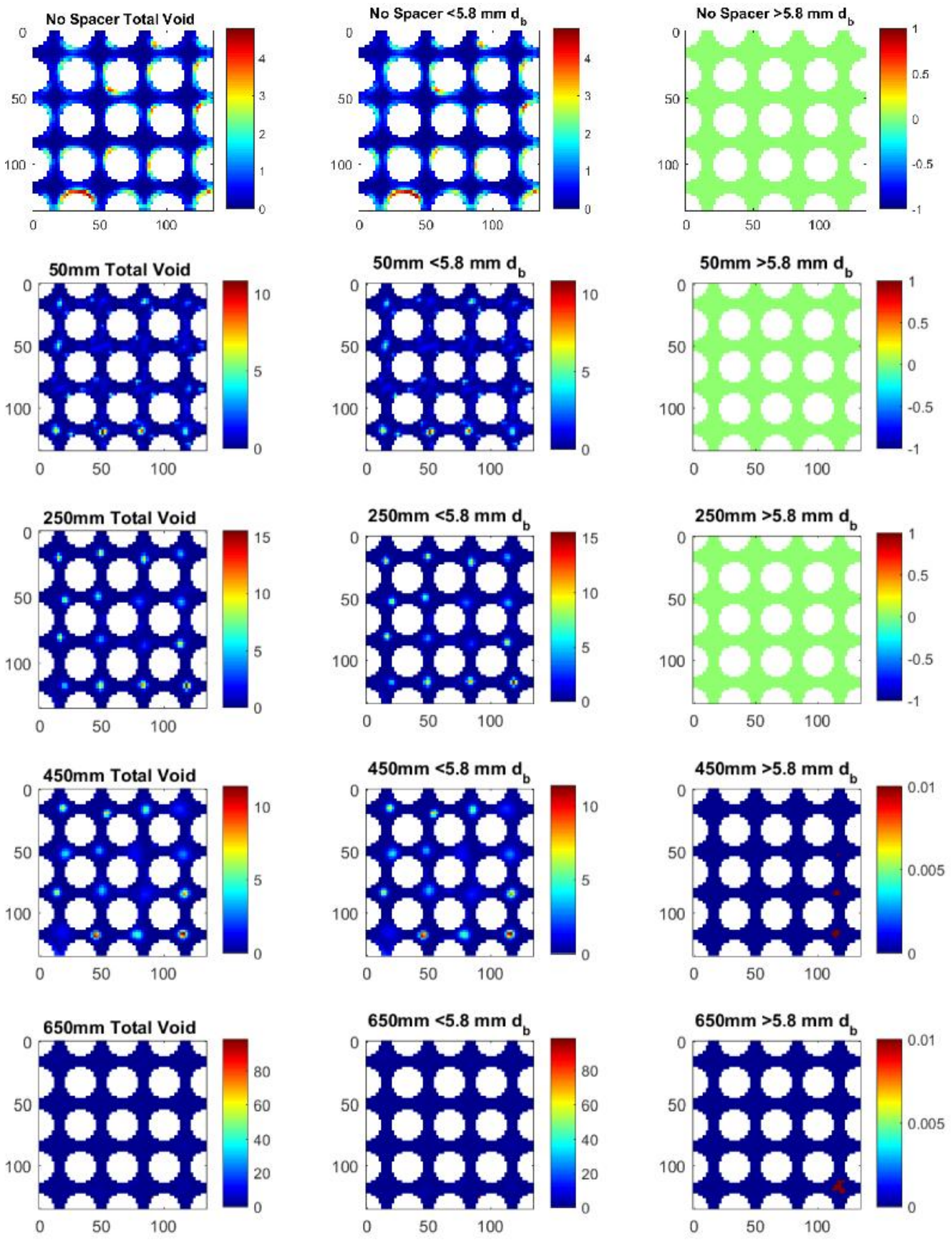

Figure A-1.12. Case-2-1: Average Void fraction results. 

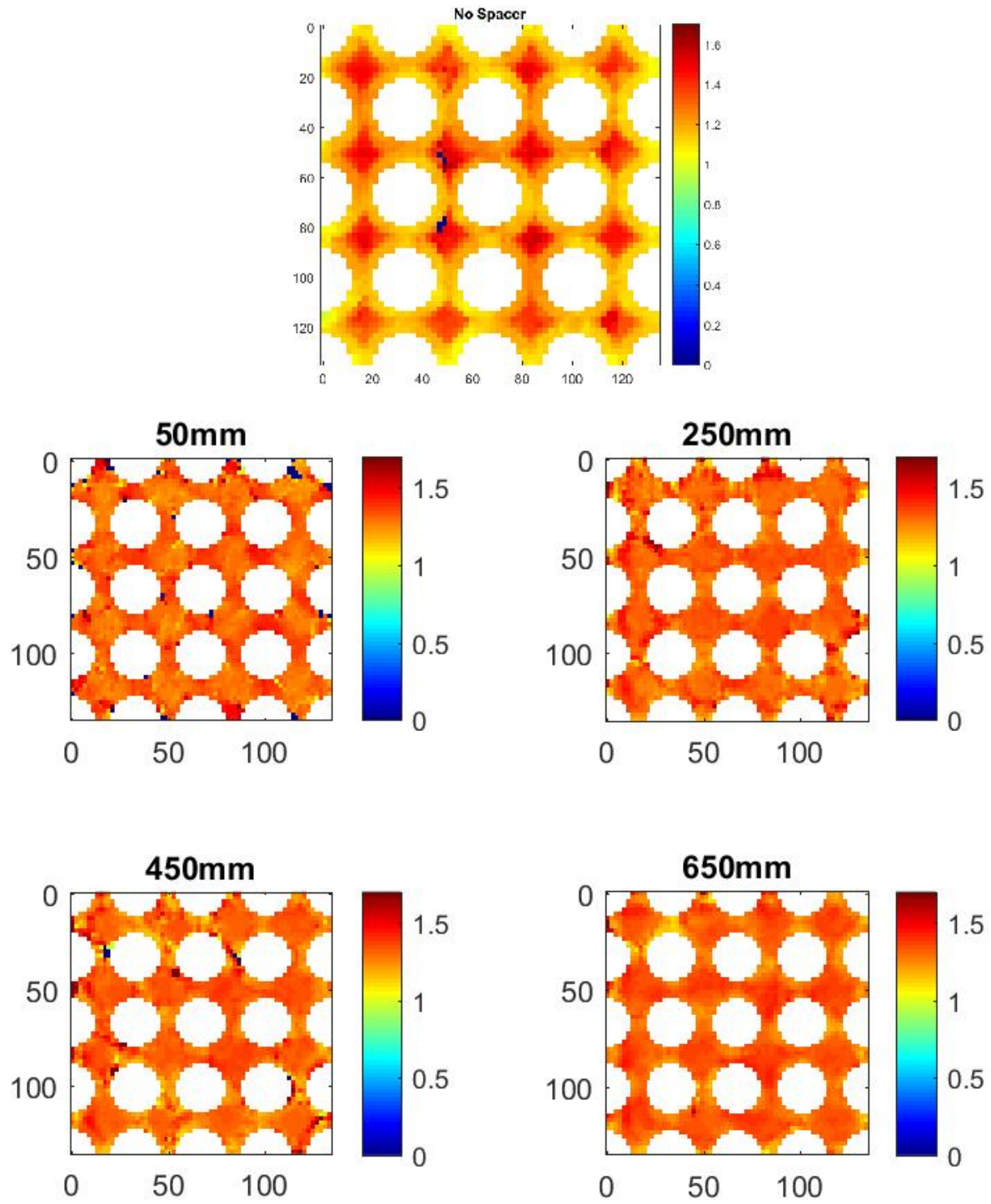

Figure A-1.13. Case-2-1: Axial velocity results. 

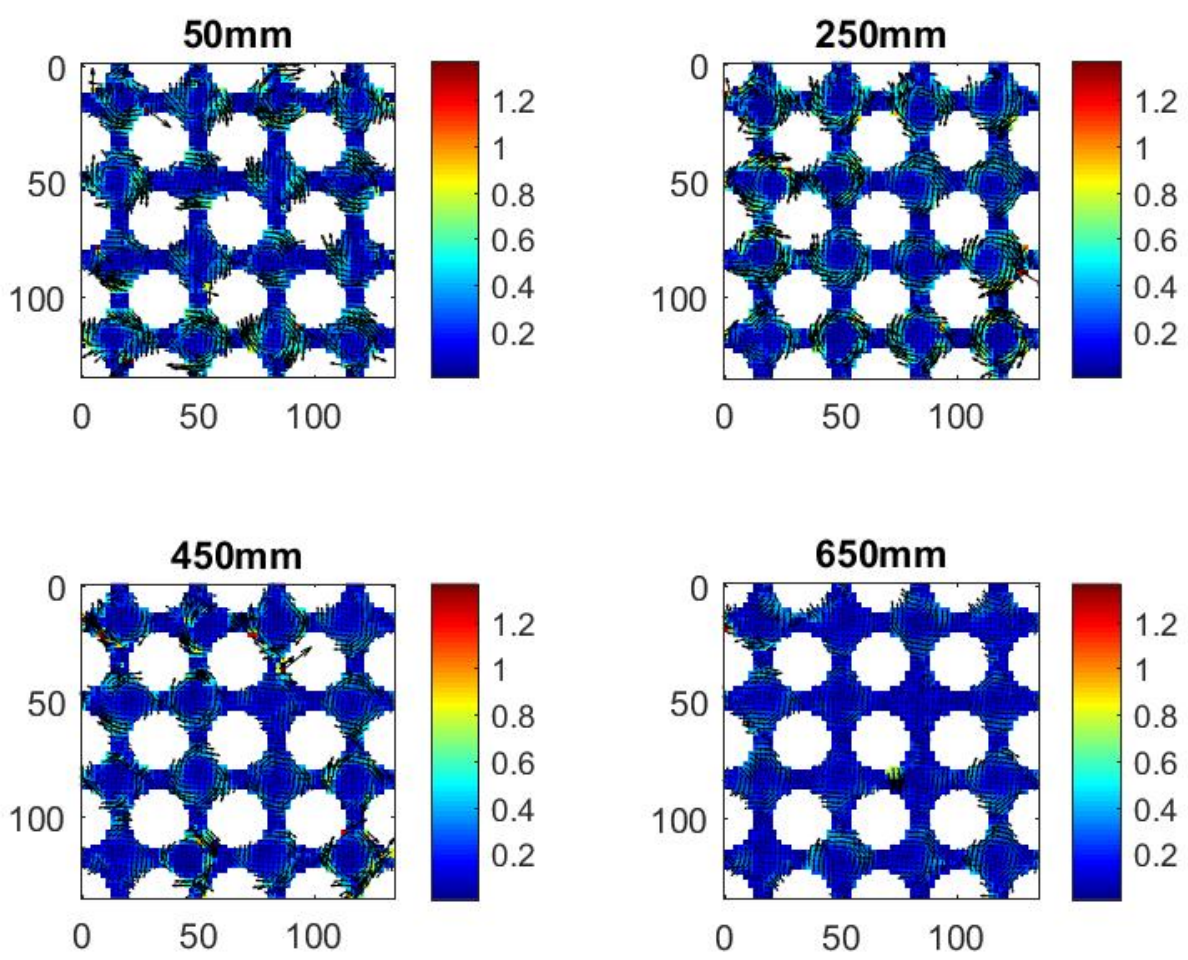

Figure A-1.14. Case-2-1: Lateral velocity results. 


\subsection{Case 2-2}
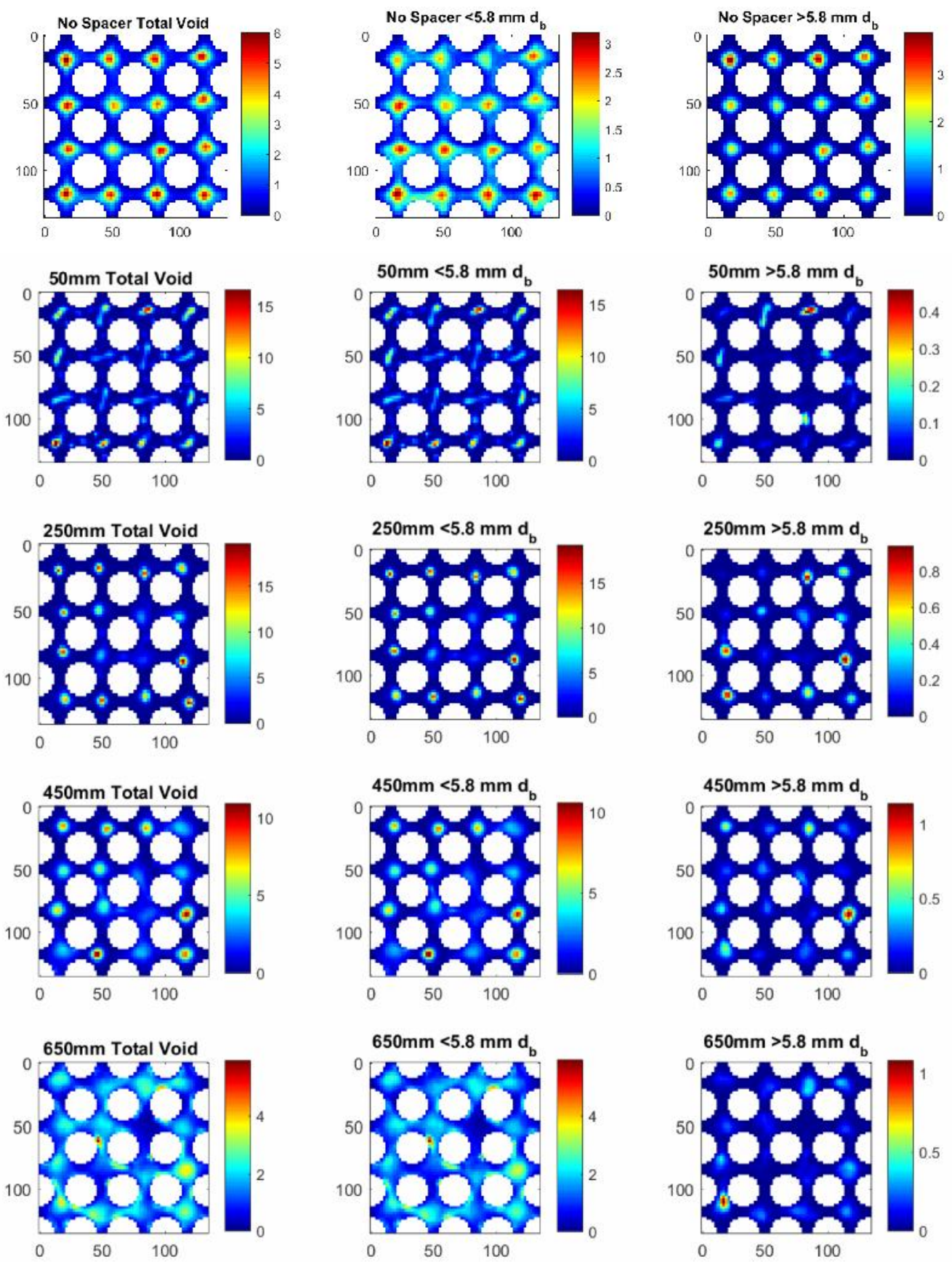

Figure A-1.15. Case-2-2: Average void fraction results. 

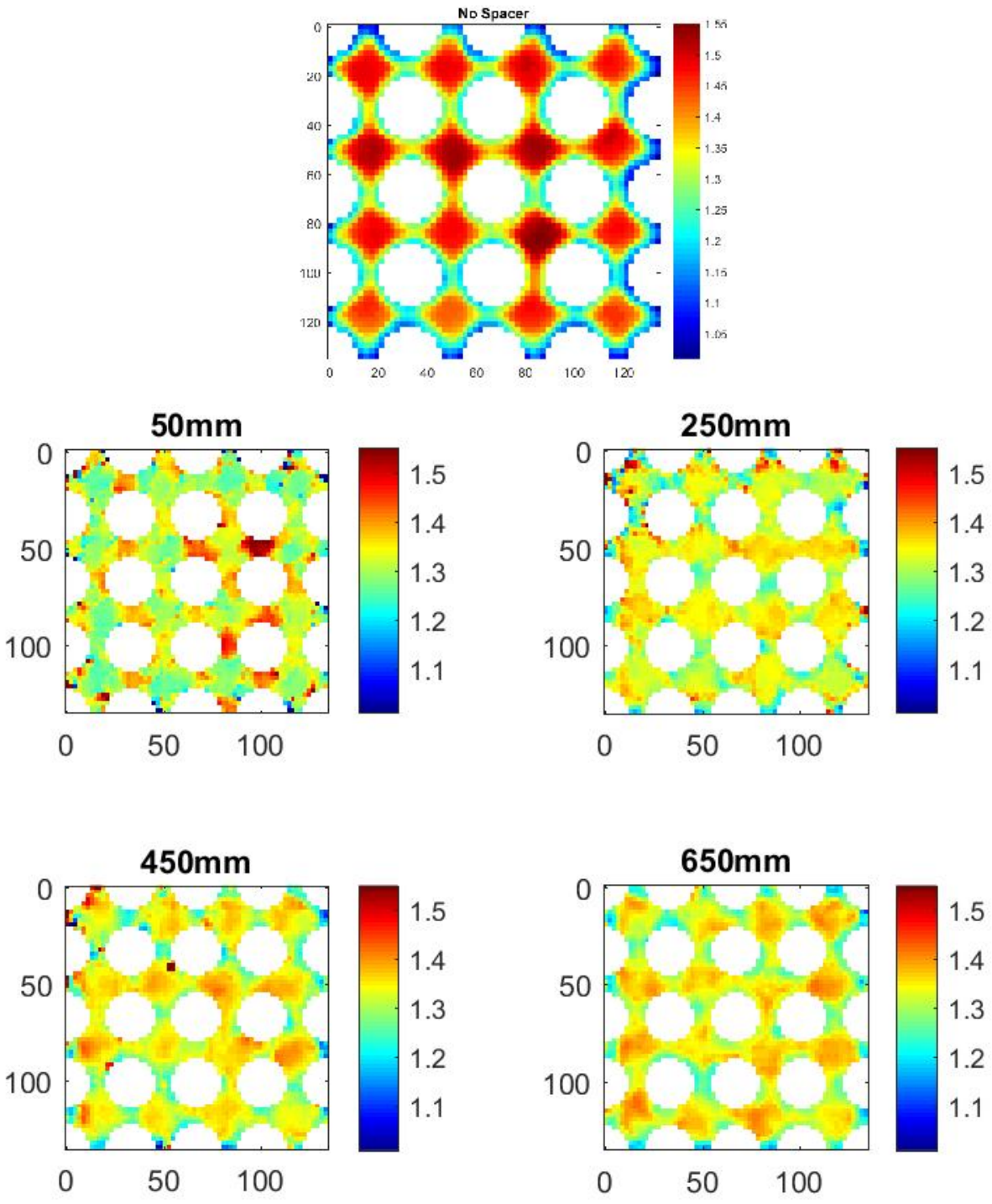

Figure A-1.16. Case-2-2: Axial velocity results. 

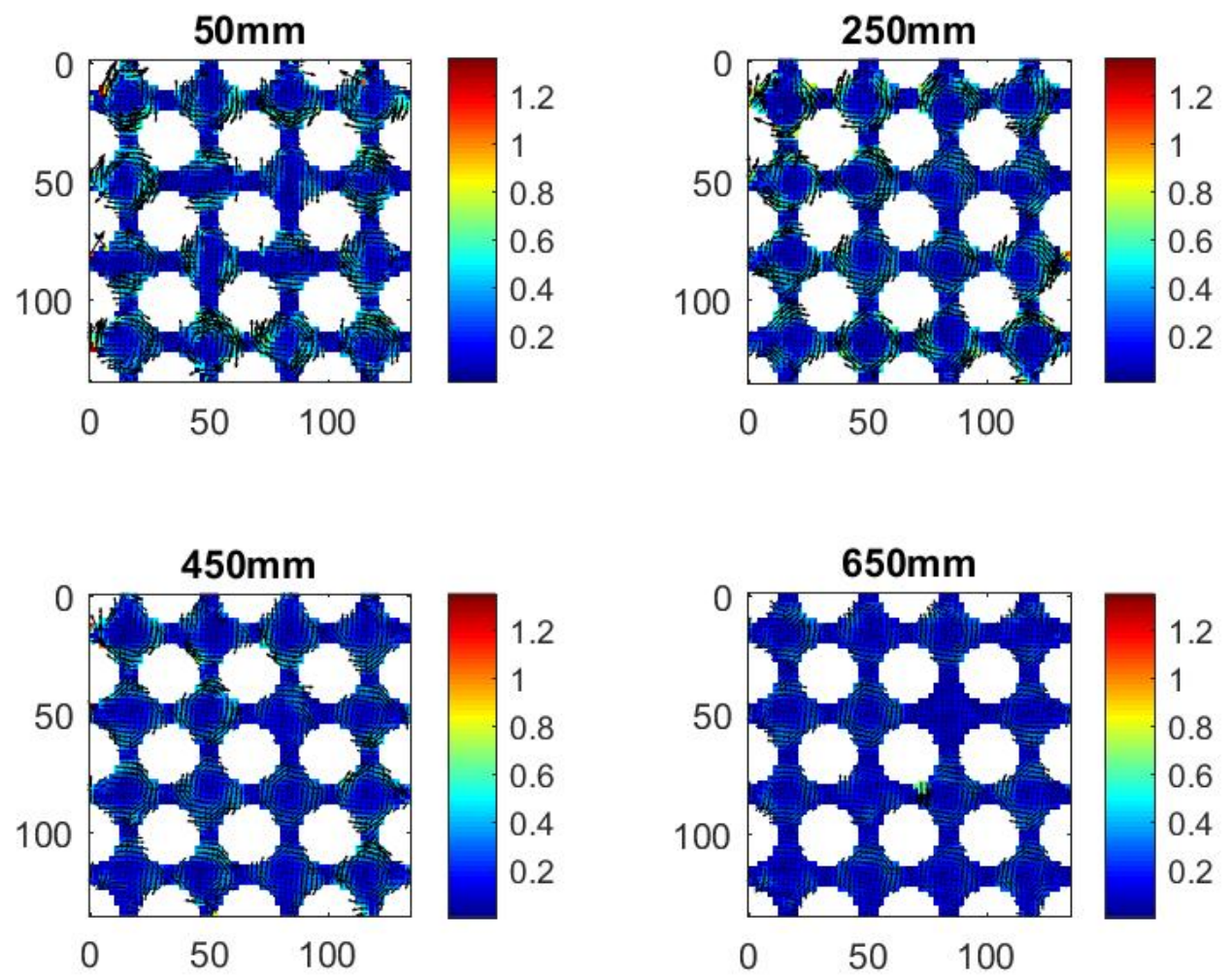

Figure A-1.17. Case-2-2: Lateral velocity results. 


\subsection{Case 2-3}
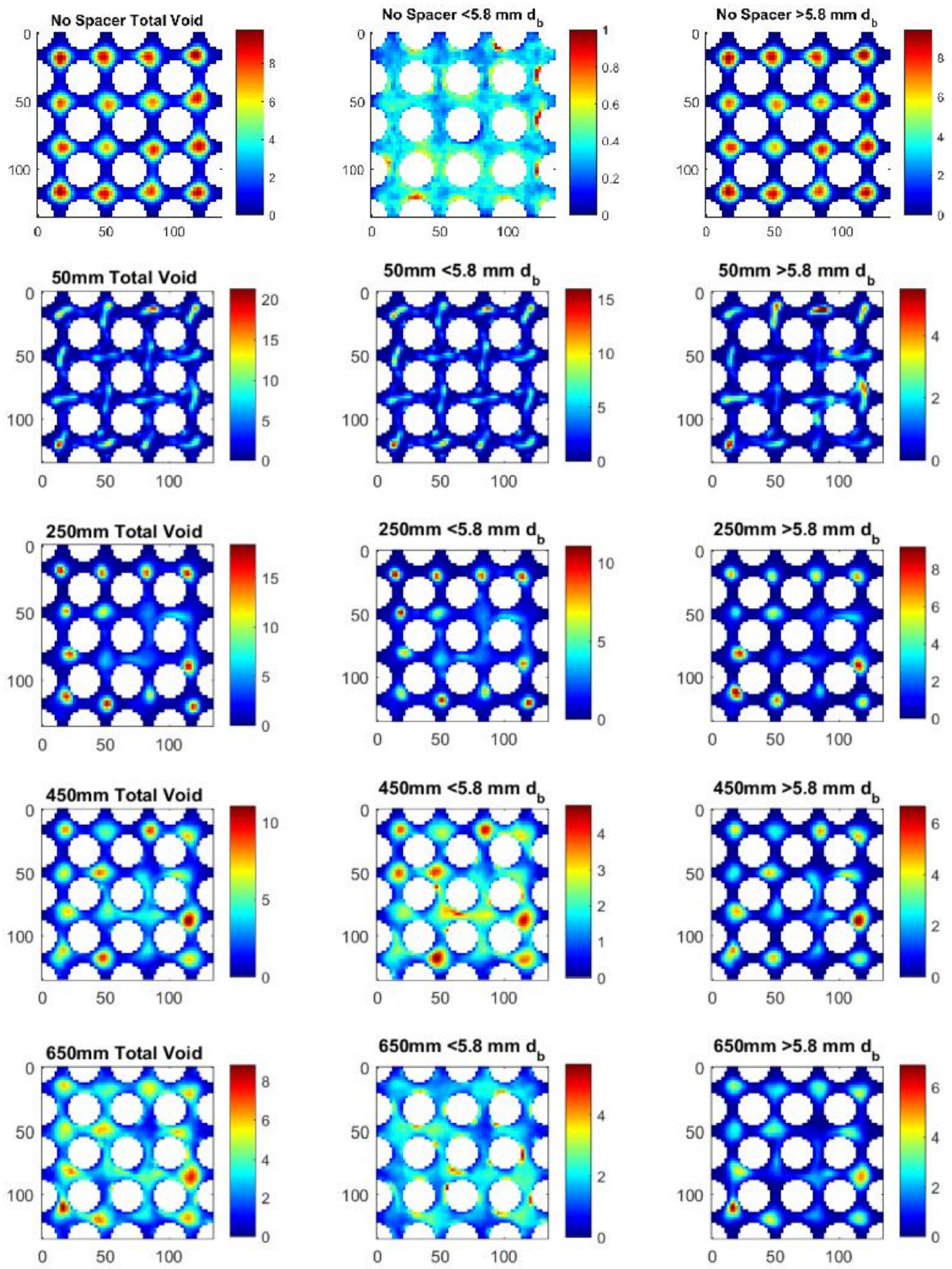

Figure A-1.18. Case-2-3: Average void fraction results. 

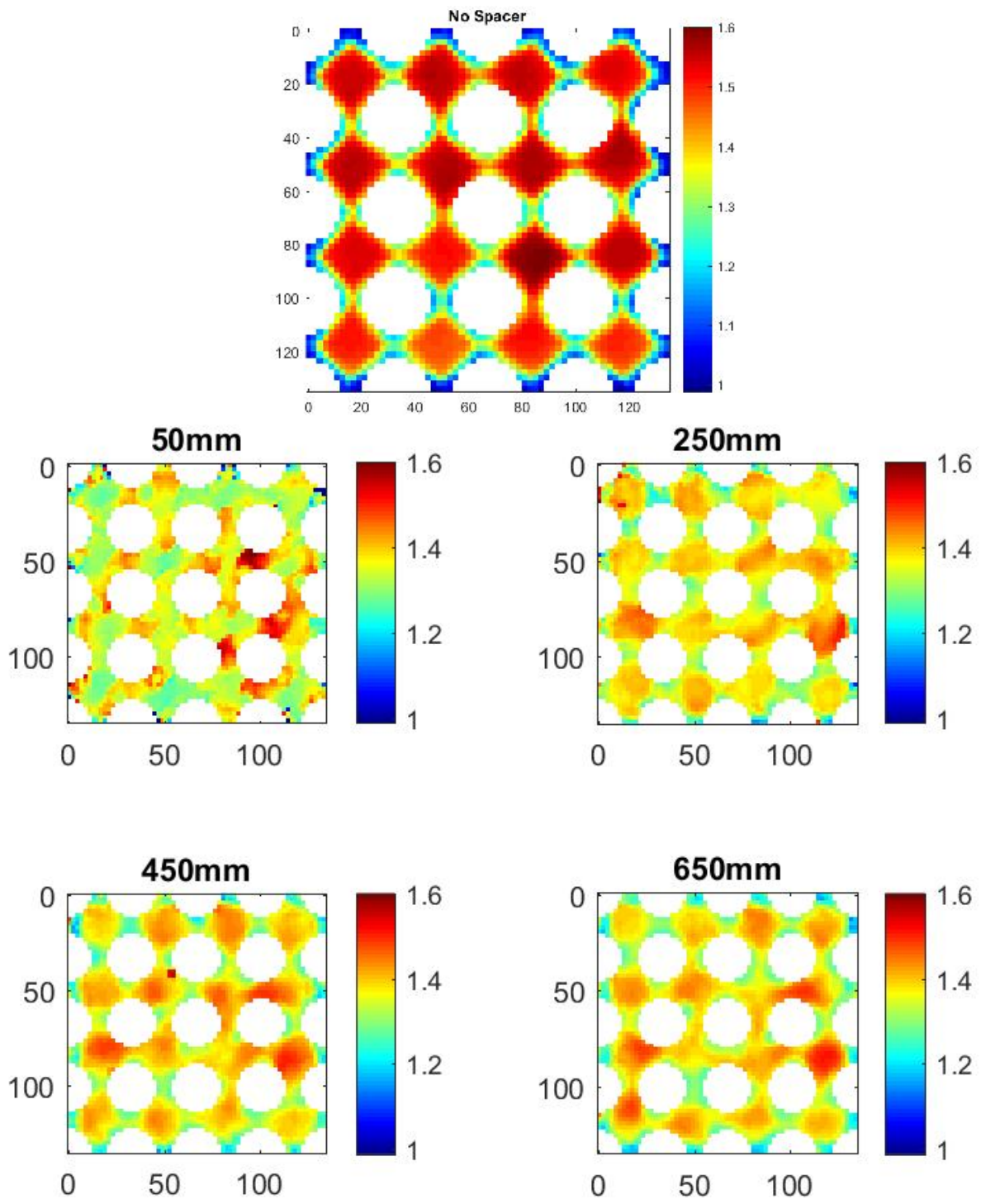

Figure A-1.19. Case-2-3: Axial velocity results. 

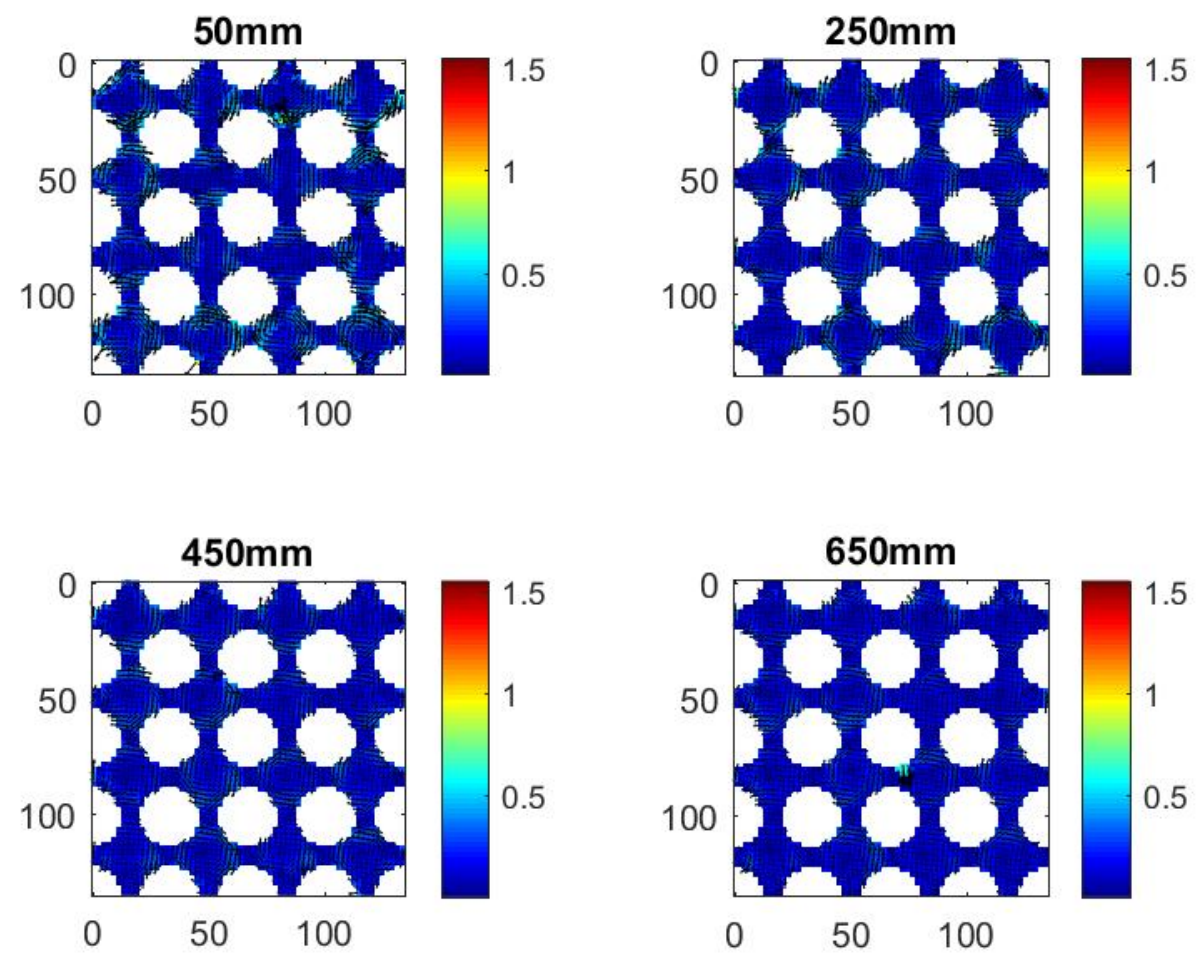

Figure A-1.20. Case-2-3: Lateral velocity results. 


\subsection{Case 2-4}
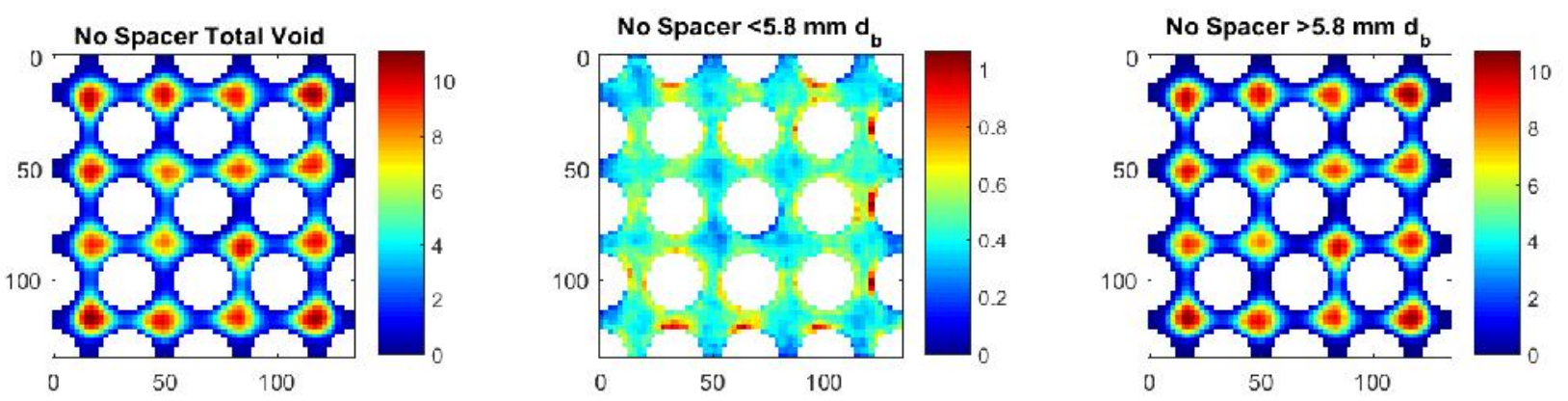

Figure A-1.21. Case-2-4: Average void fraction results.

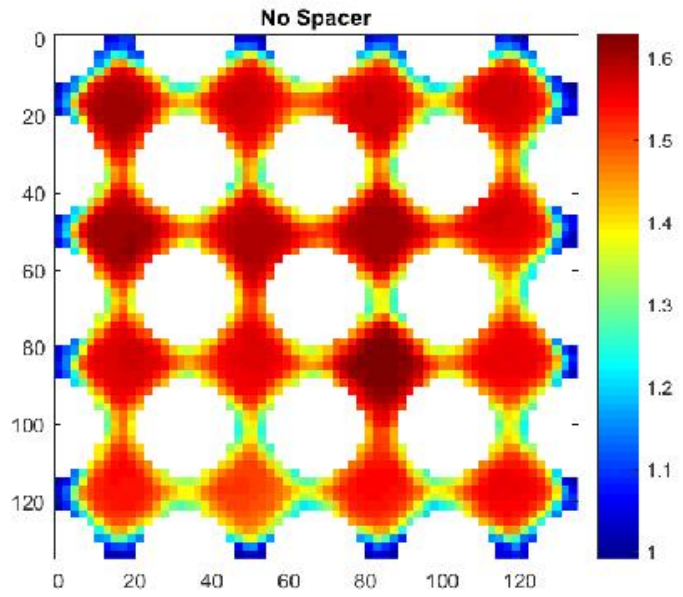

Figure A-1.22. Case-2-4: Axial velocity results. 


\subsection{Case 3-1}
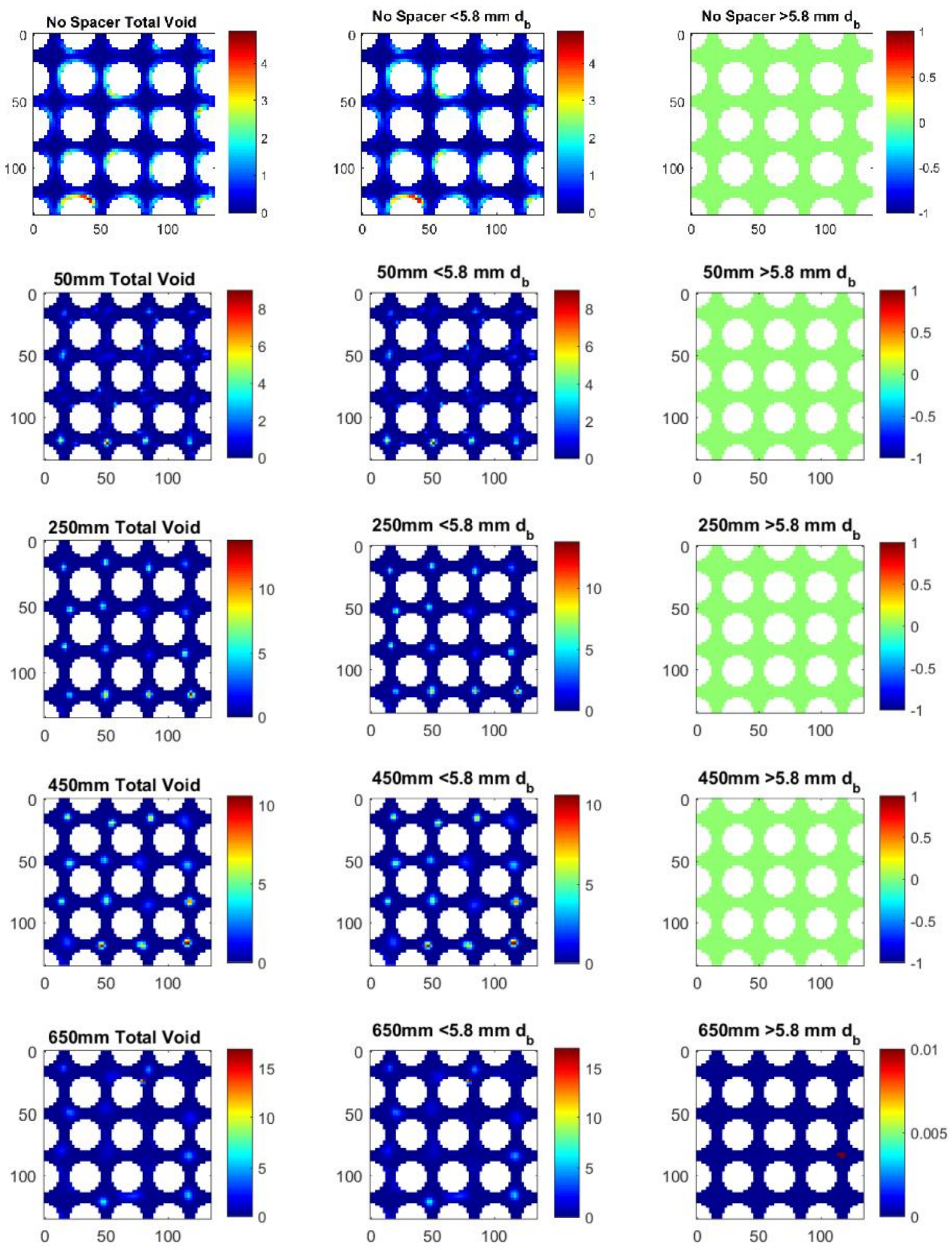

Figure A-1.23. Case-3-1: Average void fraction results. 

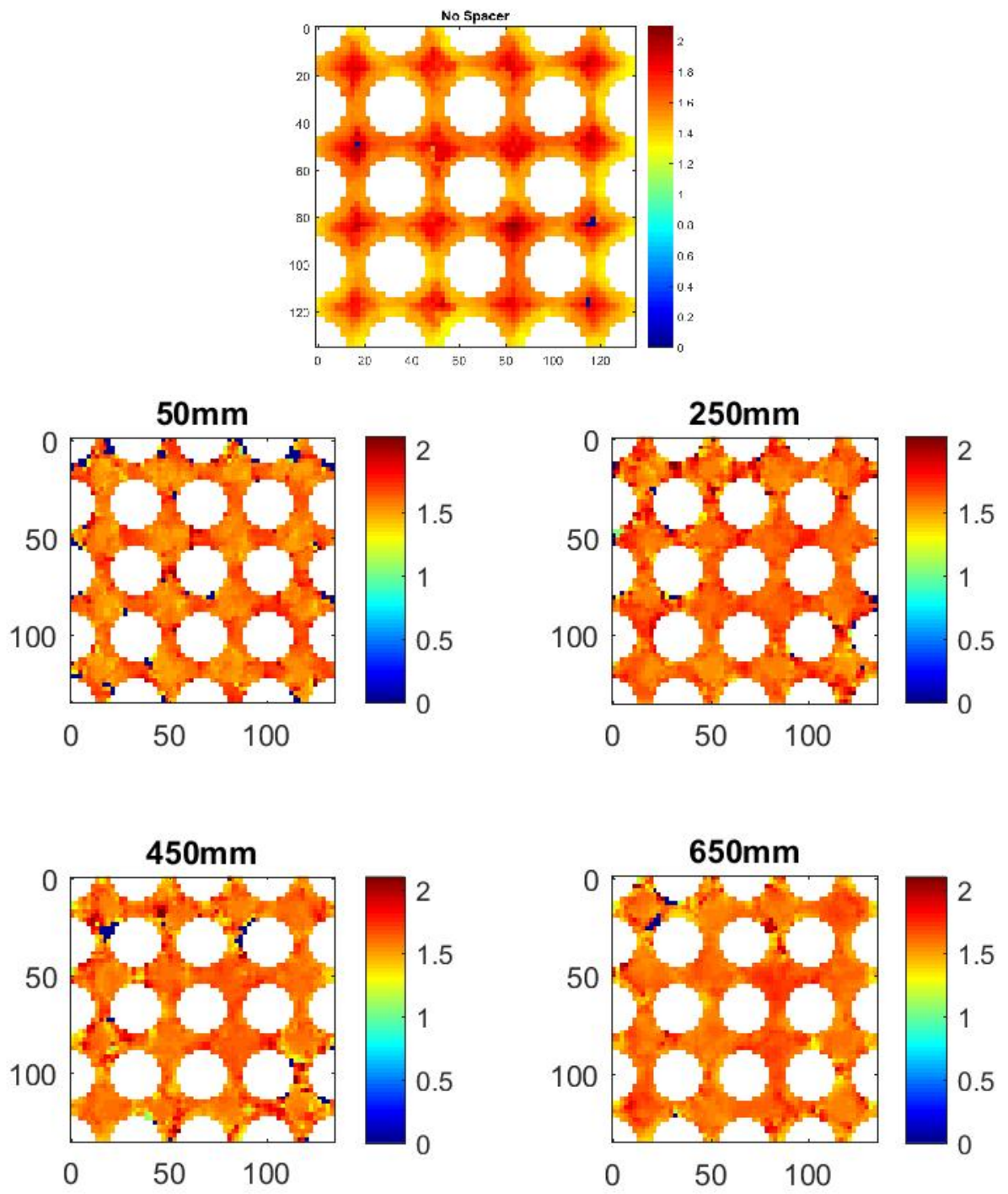

Figure A-1.24. Case-3-1: Axial velocity results. 

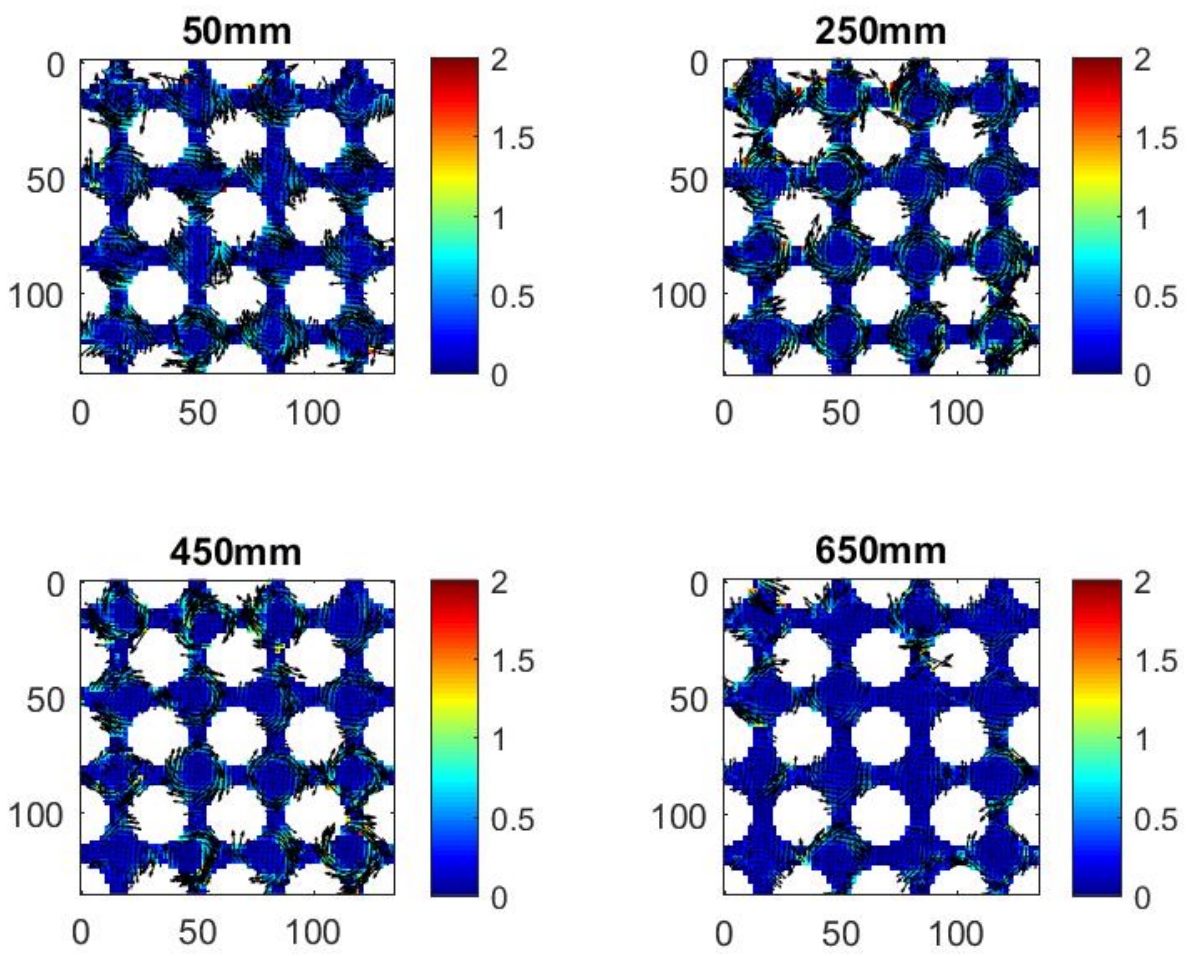

Figure A-1.25. Case-3-1: Lateral velocity results. 


\subsection{Case 3-2}
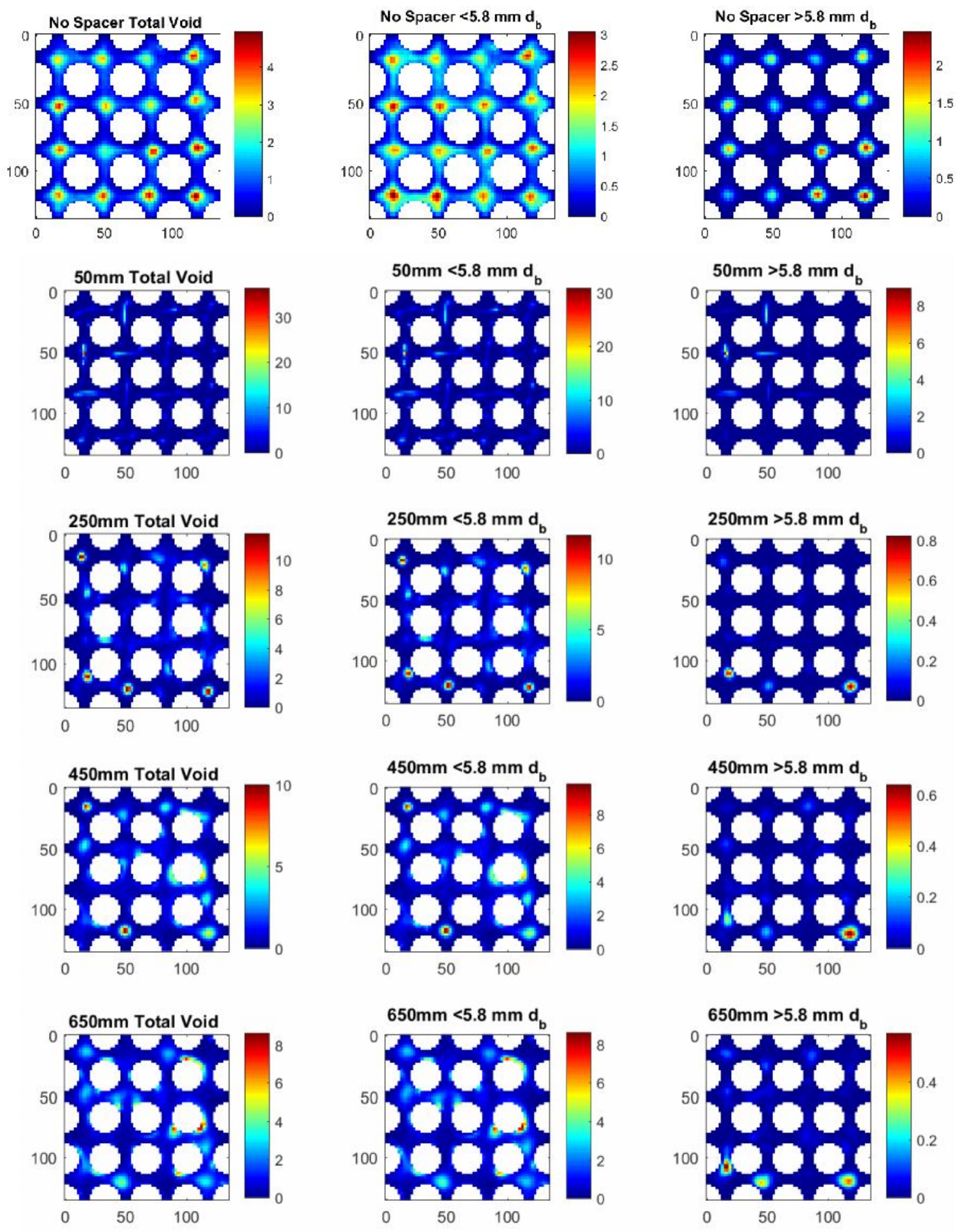

Figure A-1.26. Case-3-2: Average void fraction results. 

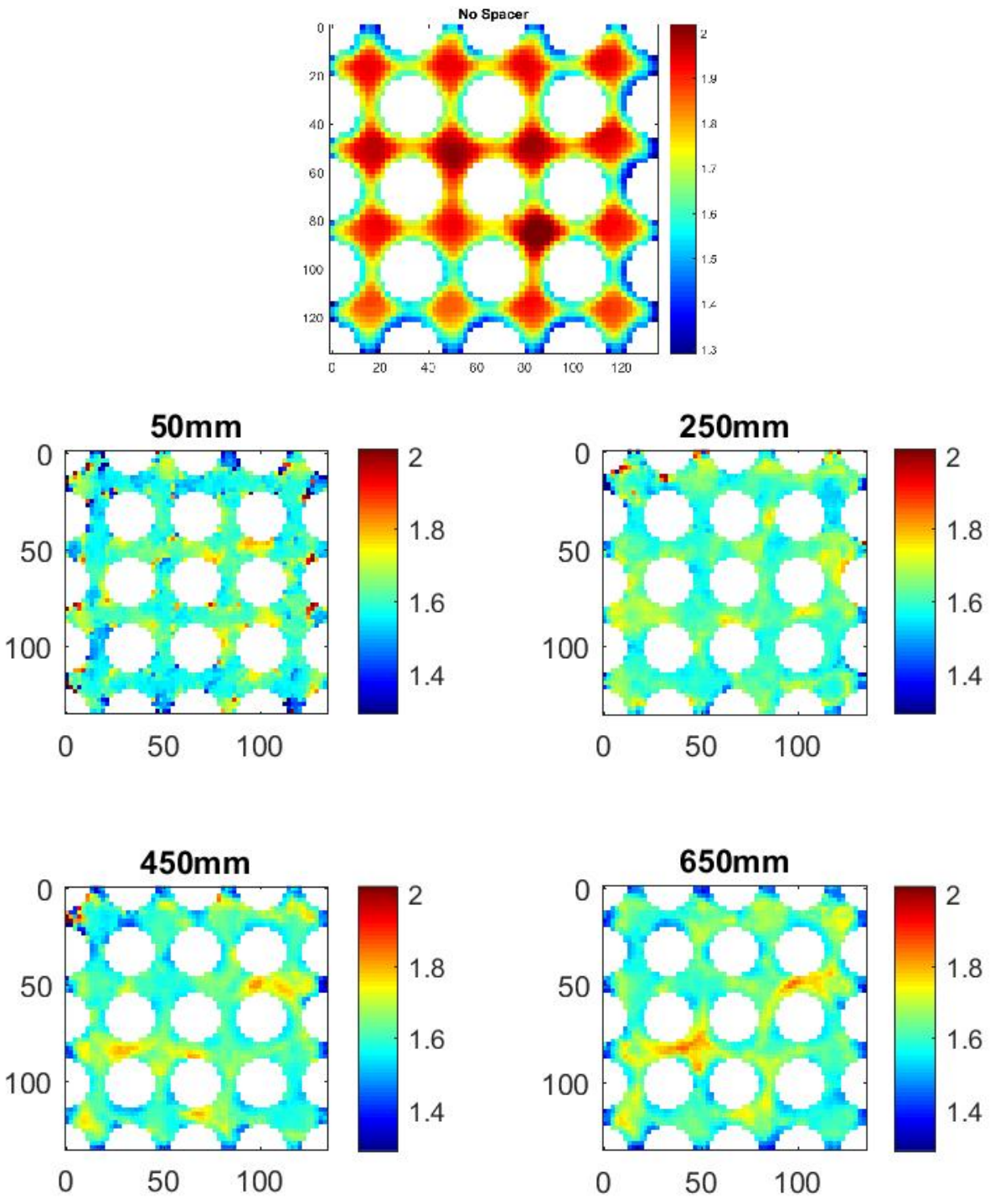

Figure A-1.27. Case-3-2: Axial velocity results. 

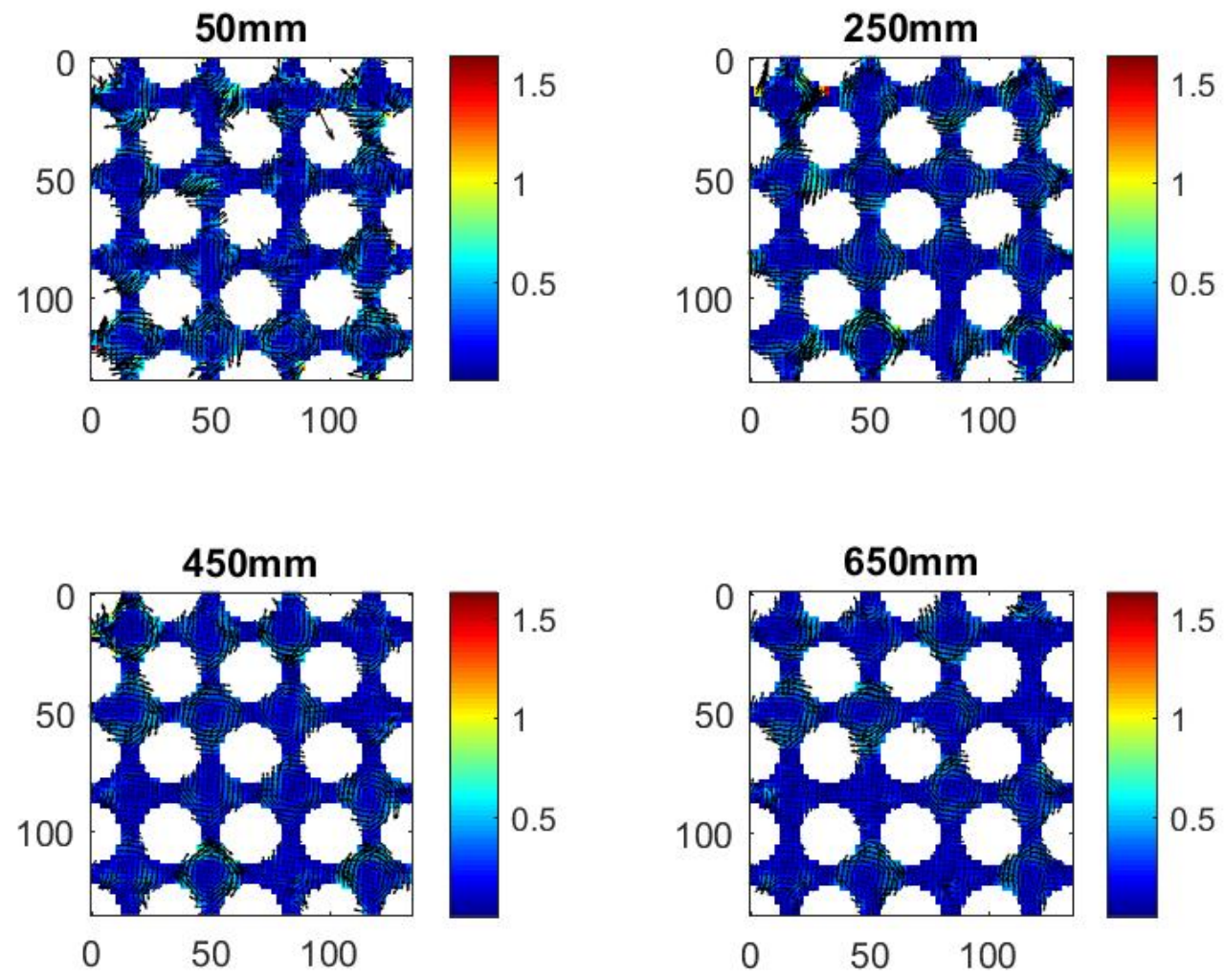

Figure A-1.28. Case-3-2: Lateral velocity results. 


\subsection{Case 3-3}
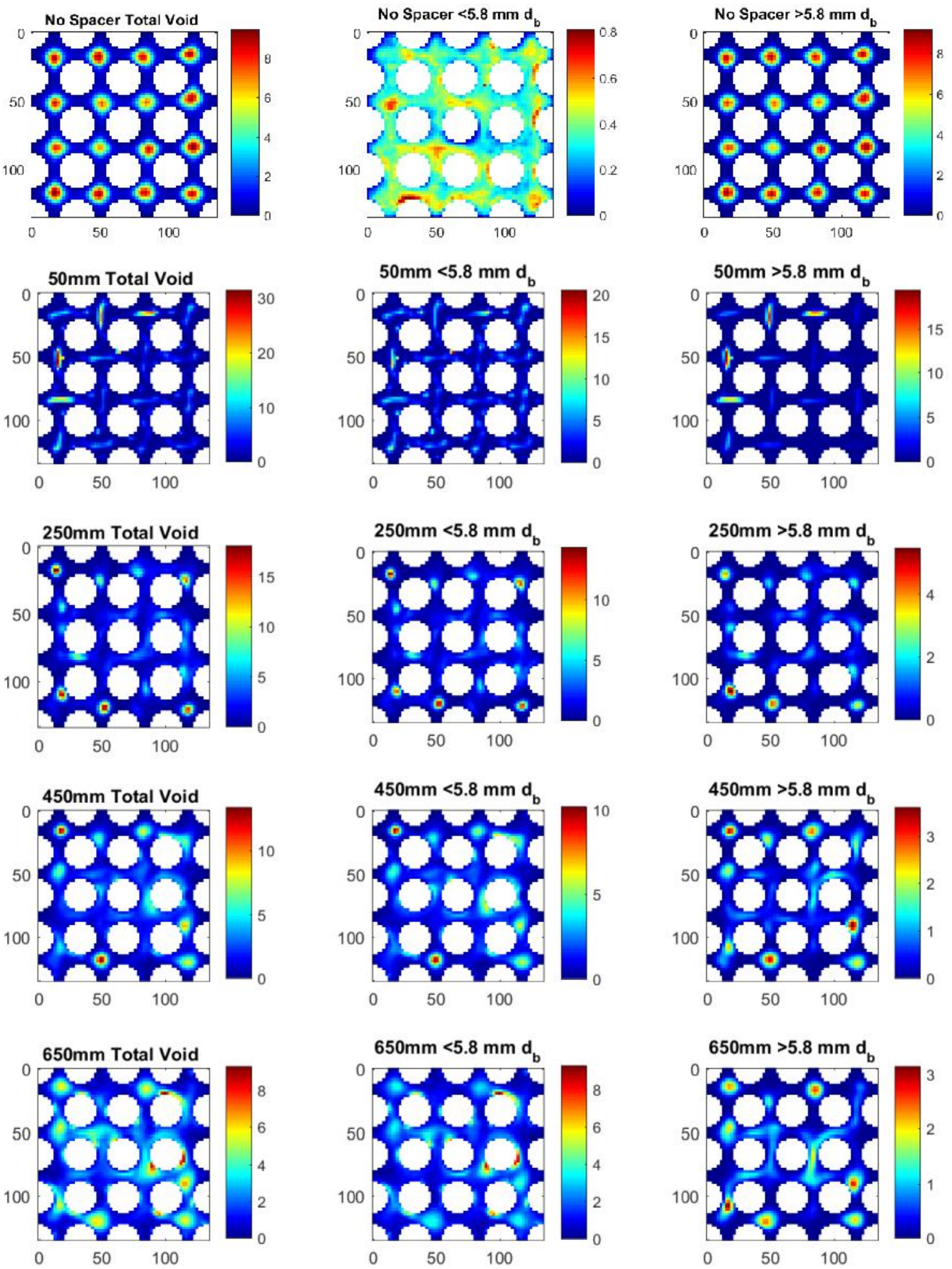

Figure A-1.29. Case-3-3: Average void fraction results. 

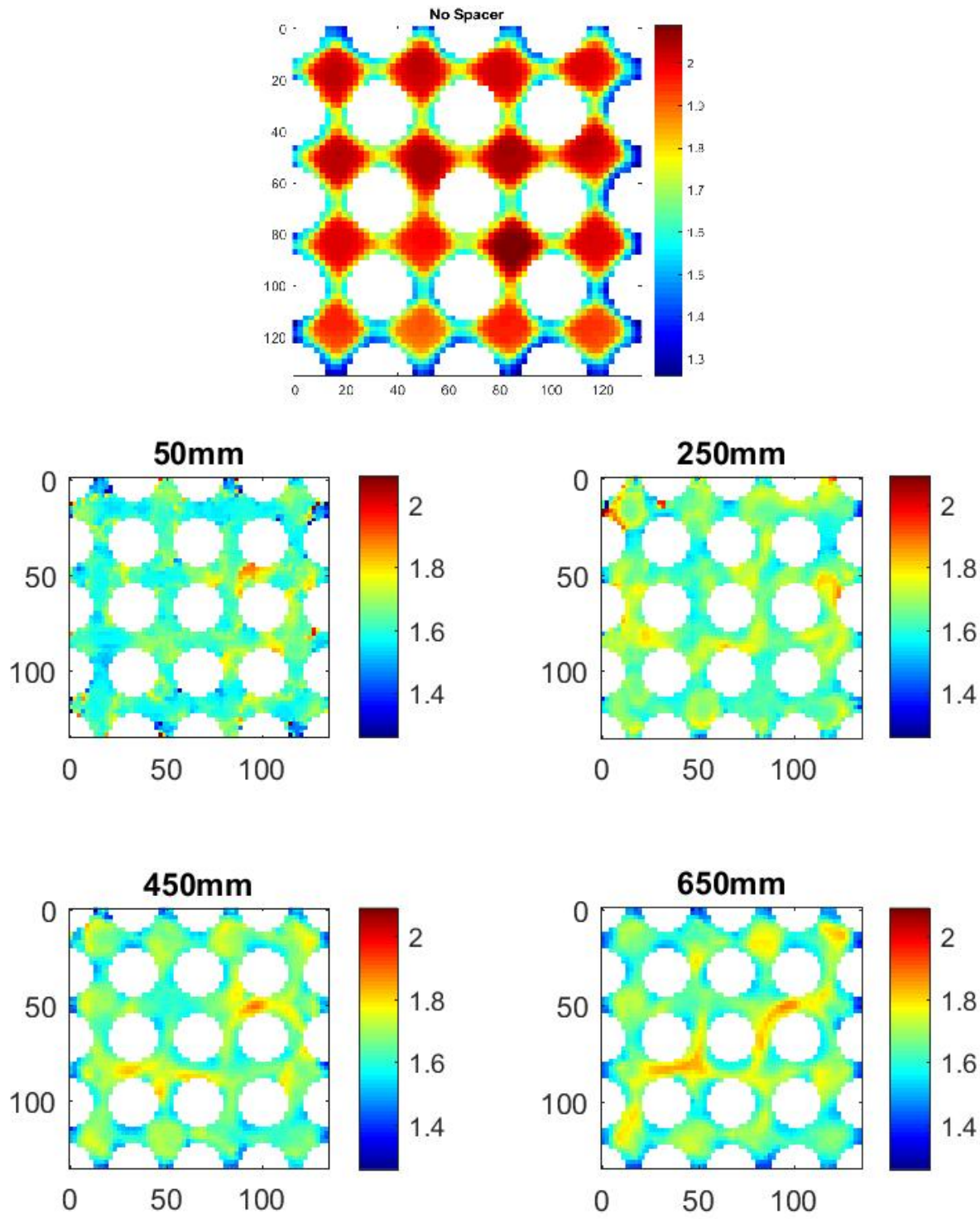

Figure A-1.30. Case-3-3: Axial velocity results. 

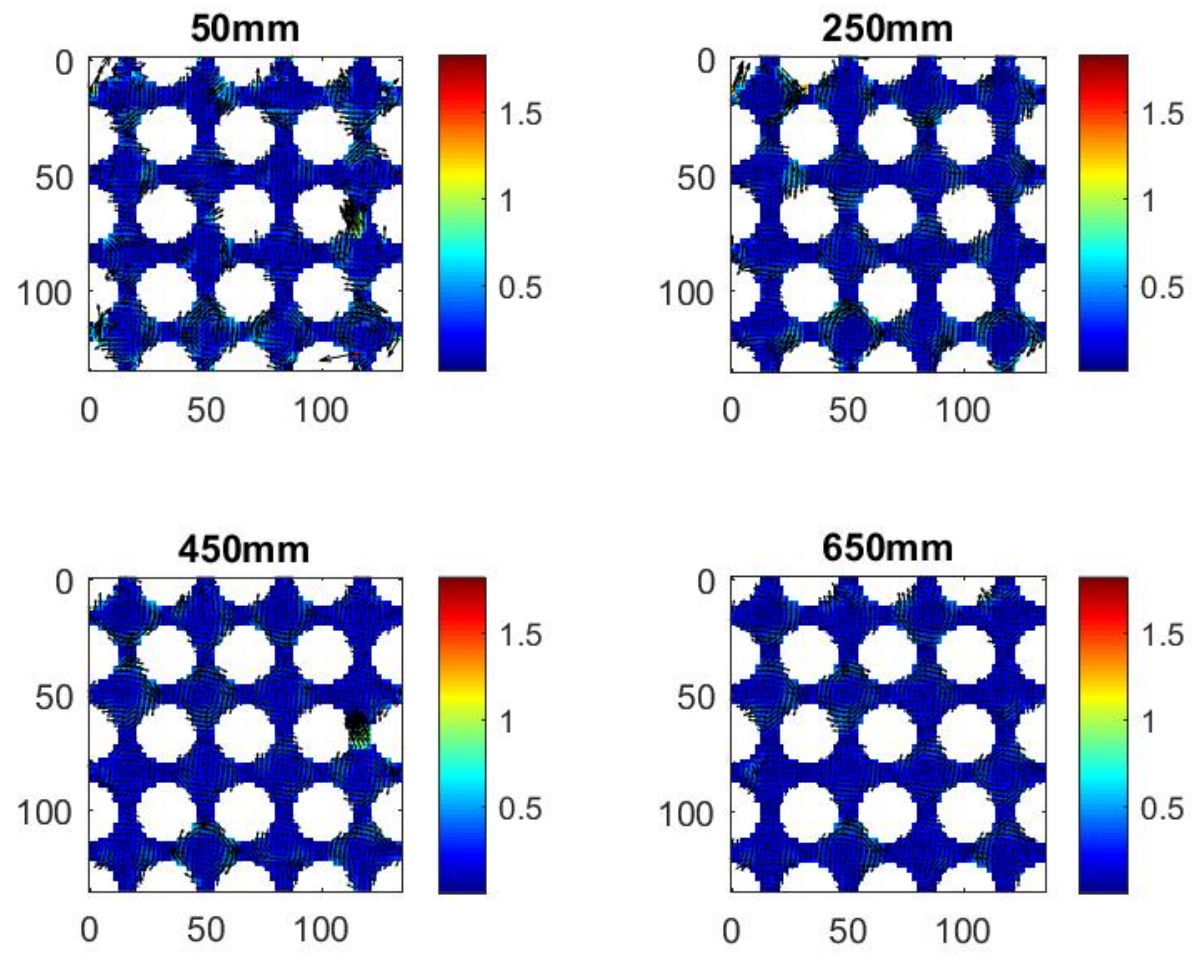

Figure A-1.31. Case-3-3: Lateral velocity results. 


\subsection{Case 3-4}
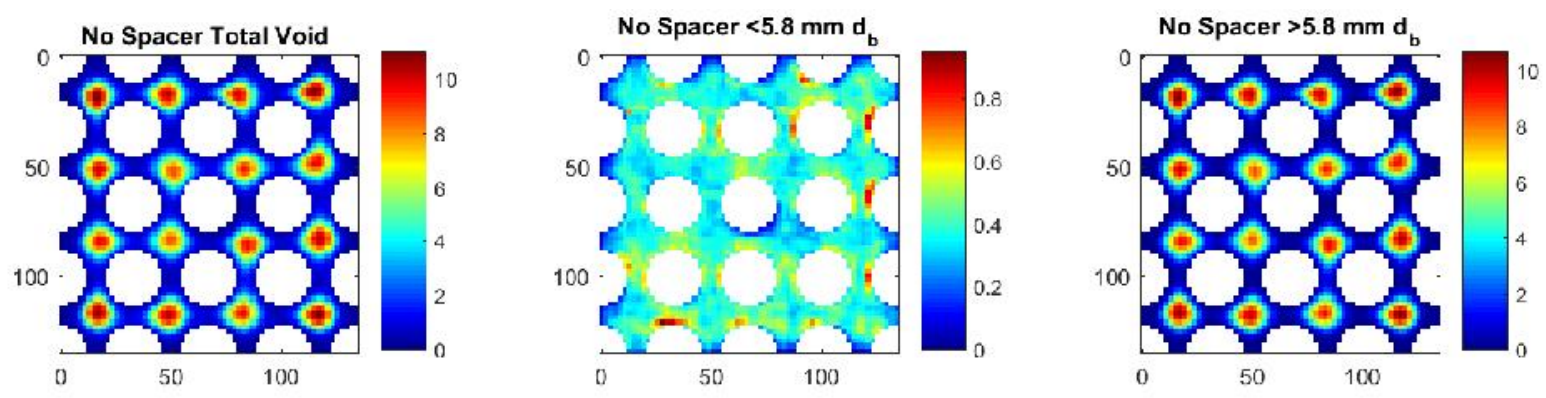

Figure A-1.32. Case-3-4: Average void fraction results.

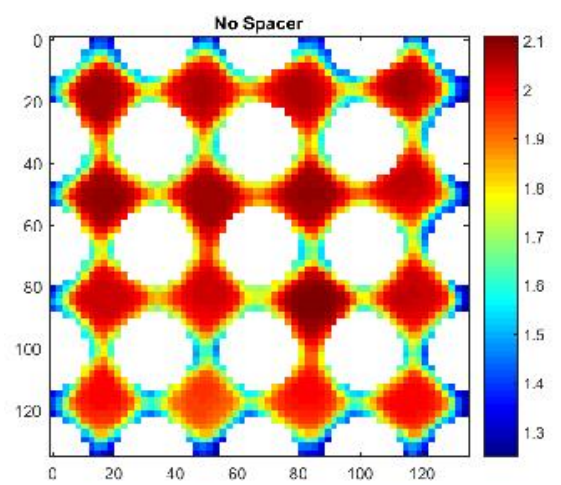

Figure A-1.33. Case-3-4: Axial velocity results. 
Appendix 2: 2013 Void Fraction Analysis vs 2017 Void Fraction Methods

\subsection{Case 1-1}
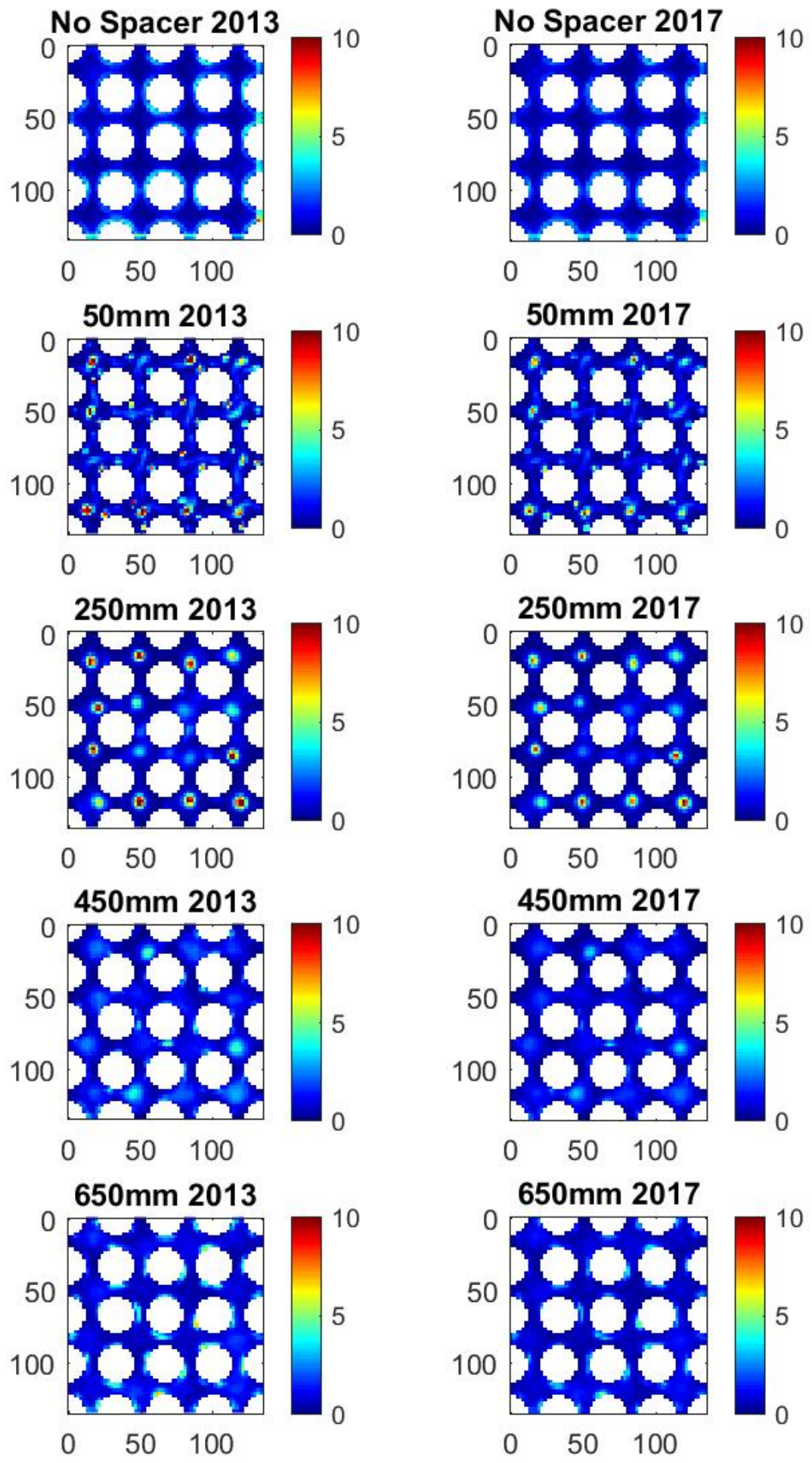

Figure A-2.1. Case-1-1: Average void fraction results. 


\subsection{Case 1-2}
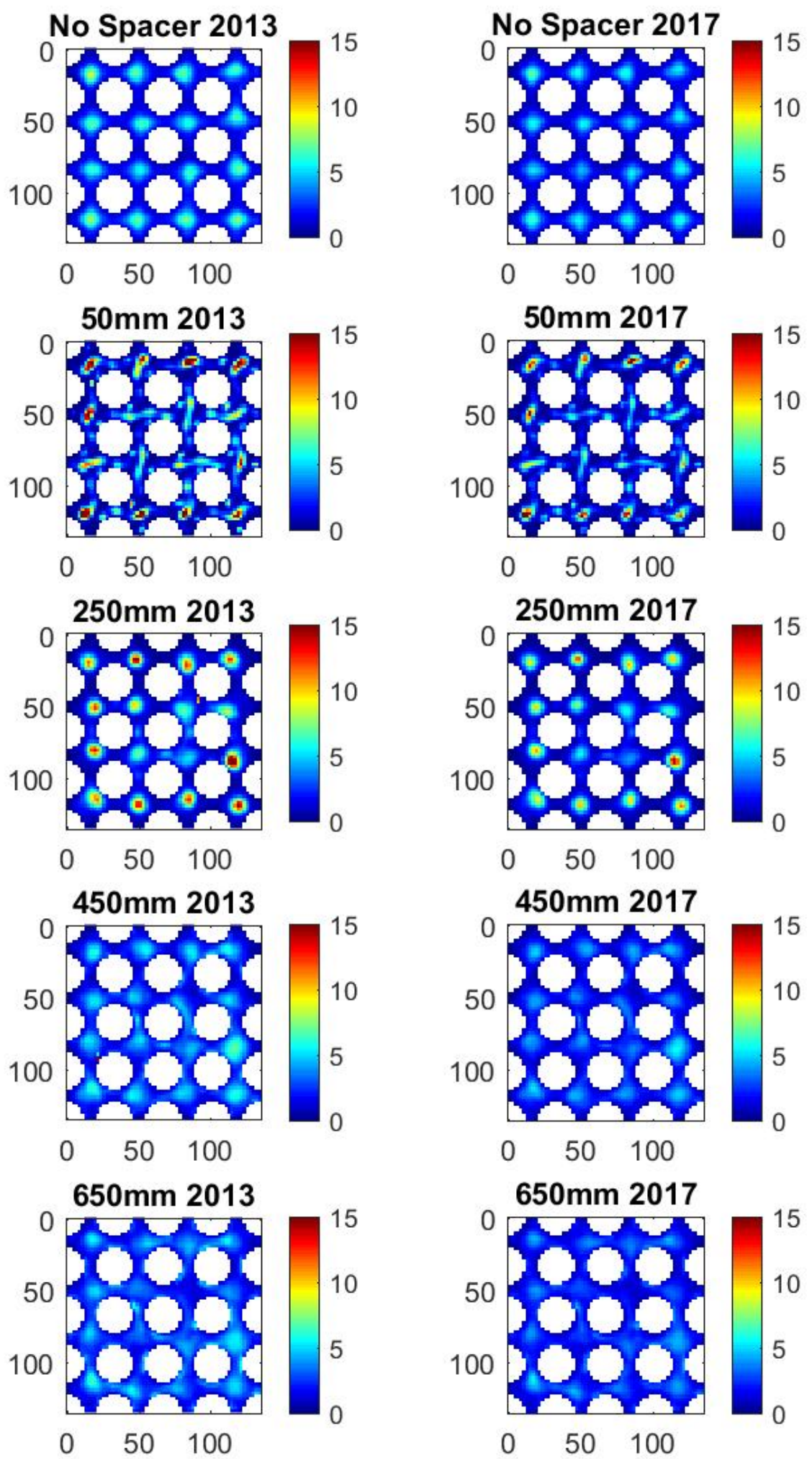

Figure A-2.2. Case-1-2: Average void fraction results. 


\subsection{Case 1-3}
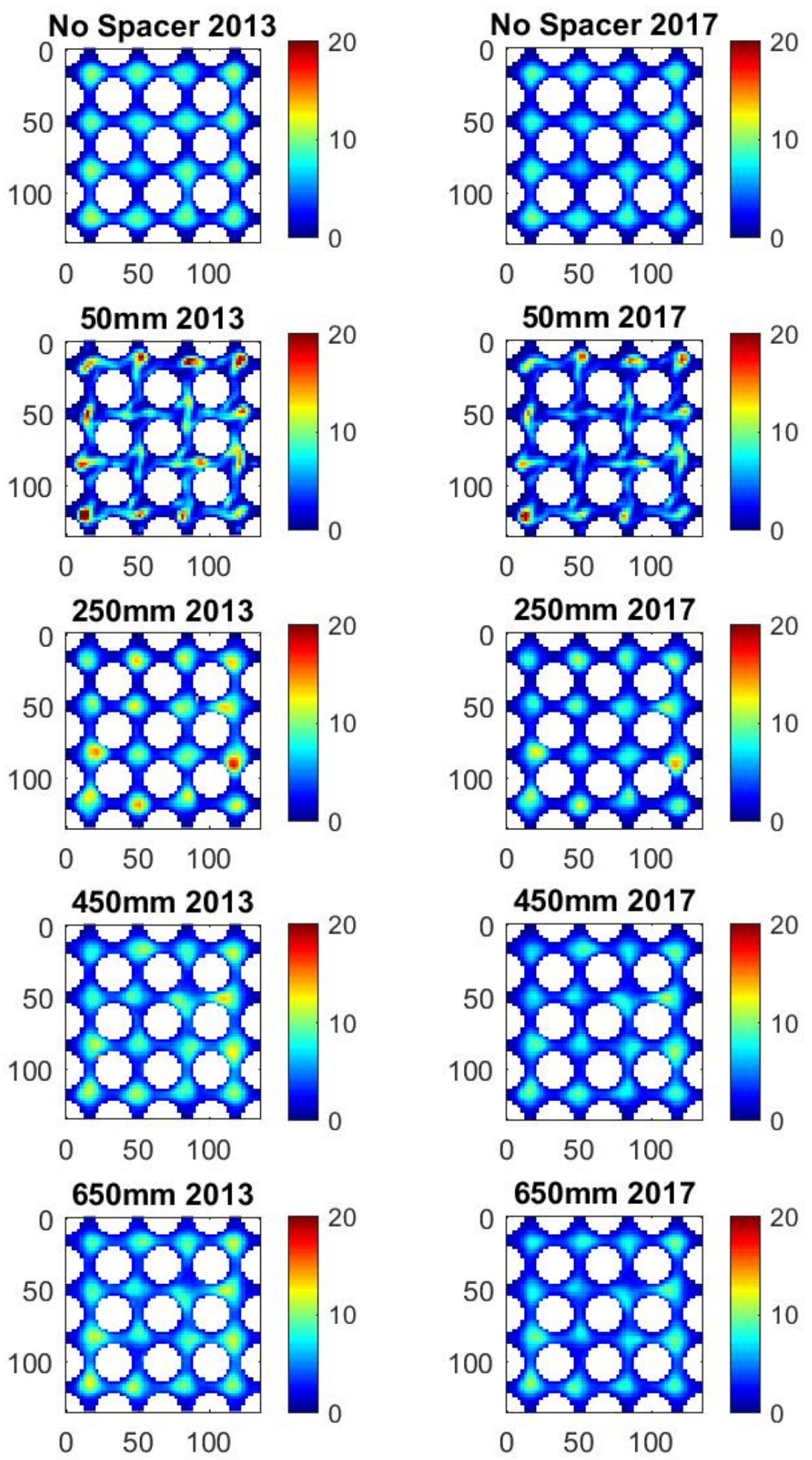

Figure A-2.3. Case-1-3: Average void fraction results. 


\subsection{Case 1-4}
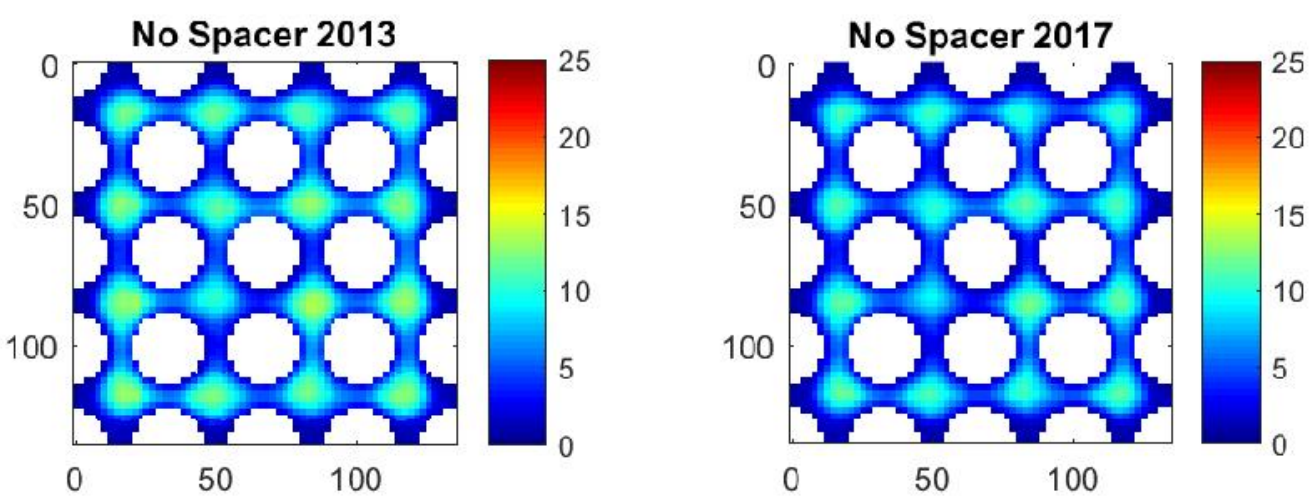

Figure A-2.4. Case-1-4: Average void fraction results. 

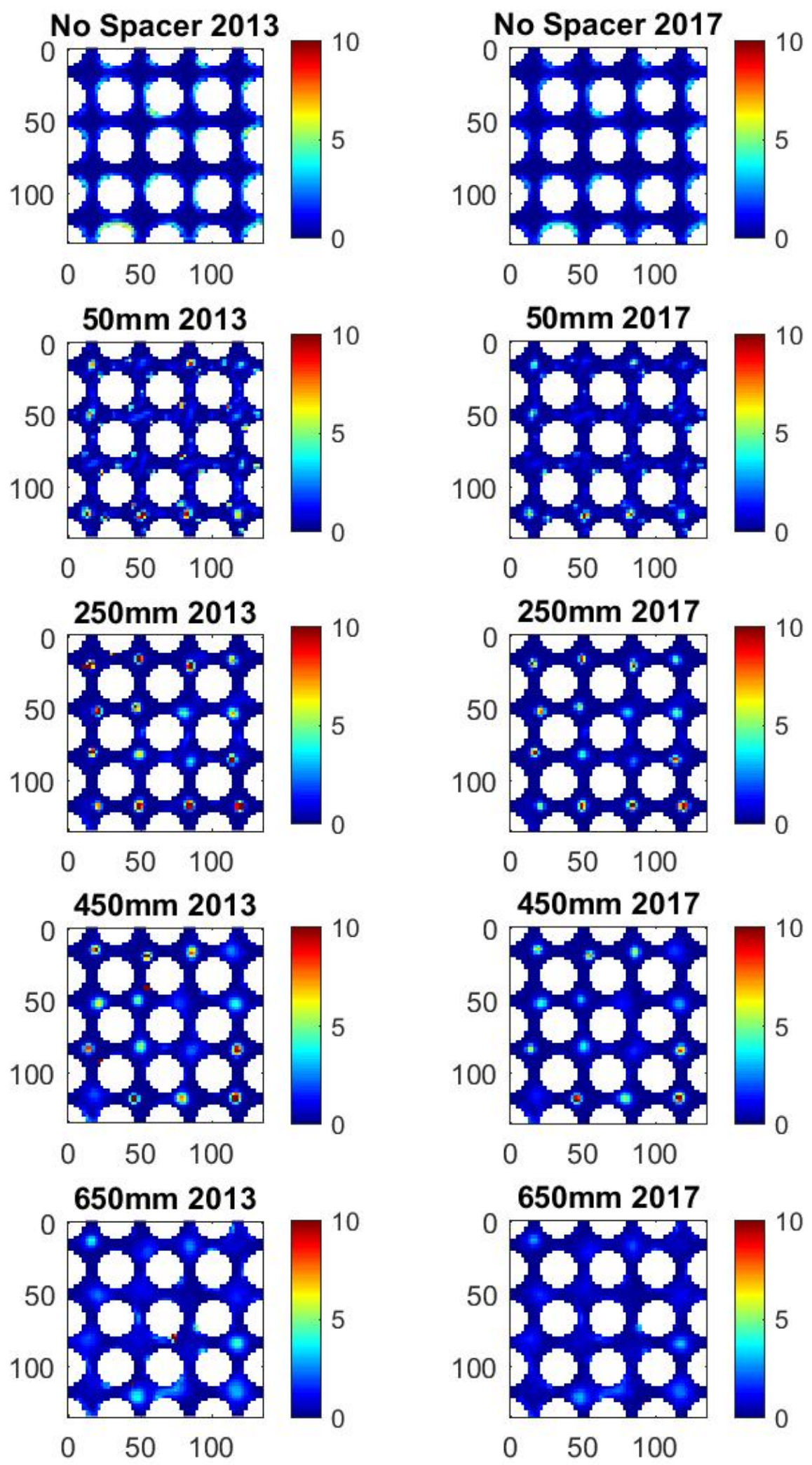

Figure A-2.5. Case-2-1: Average void fraction results. 


\subsection{Case 2-2}

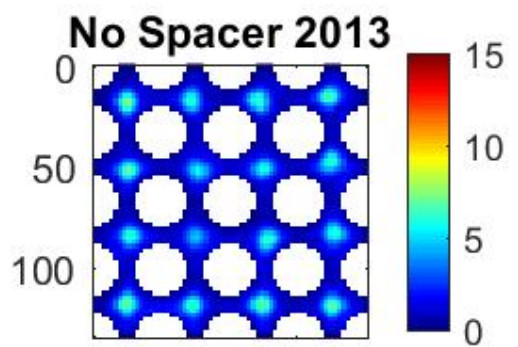

$0 \quad 50 \quad 100$

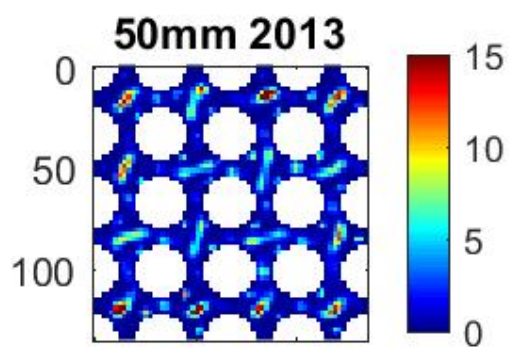

$\begin{array}{lll}0 & 50 & 100\end{array}$

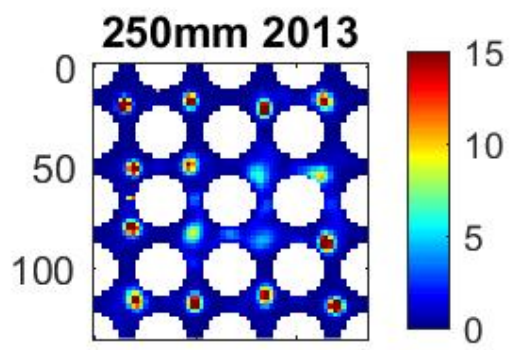

$0 \quad 50 \quad 100$
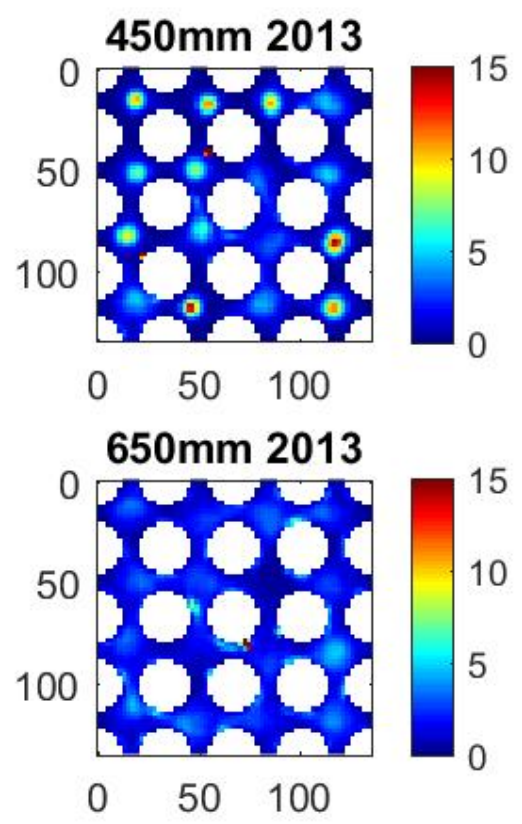

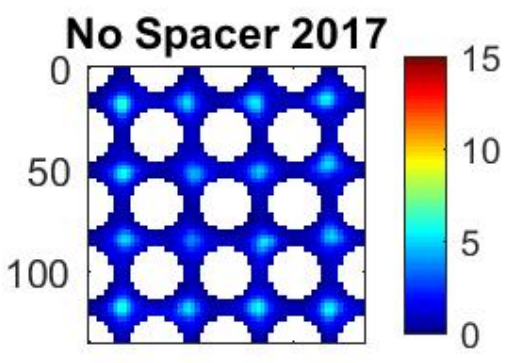

$\begin{array}{lll}0 & 50 & 100\end{array}$
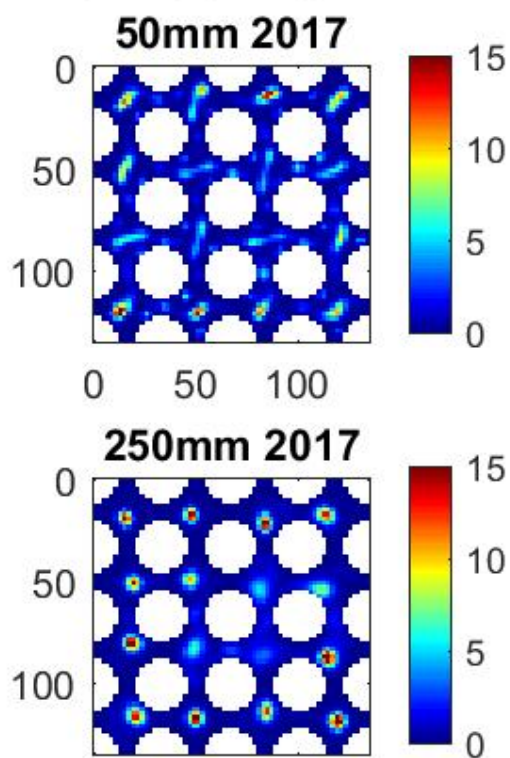

$0 \quad 50 \quad 100$
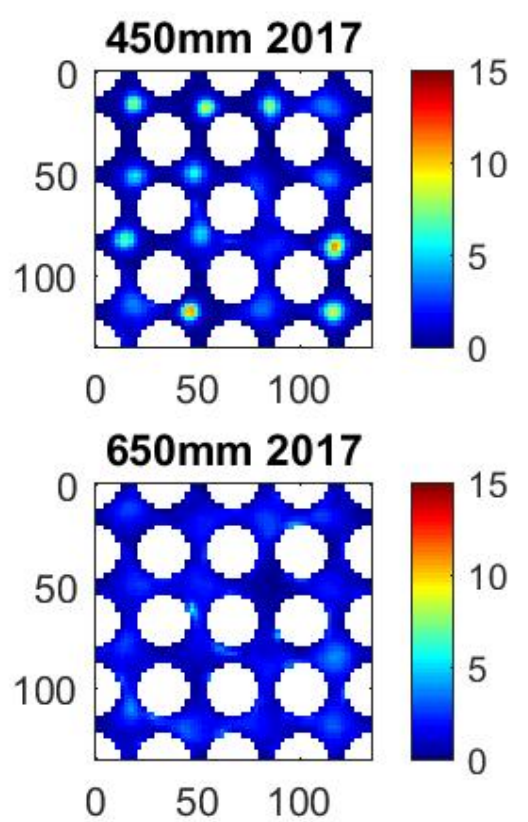

Figure A-2.6. Case-2-2: Average void fraction results. 
2.7 Case 2-3
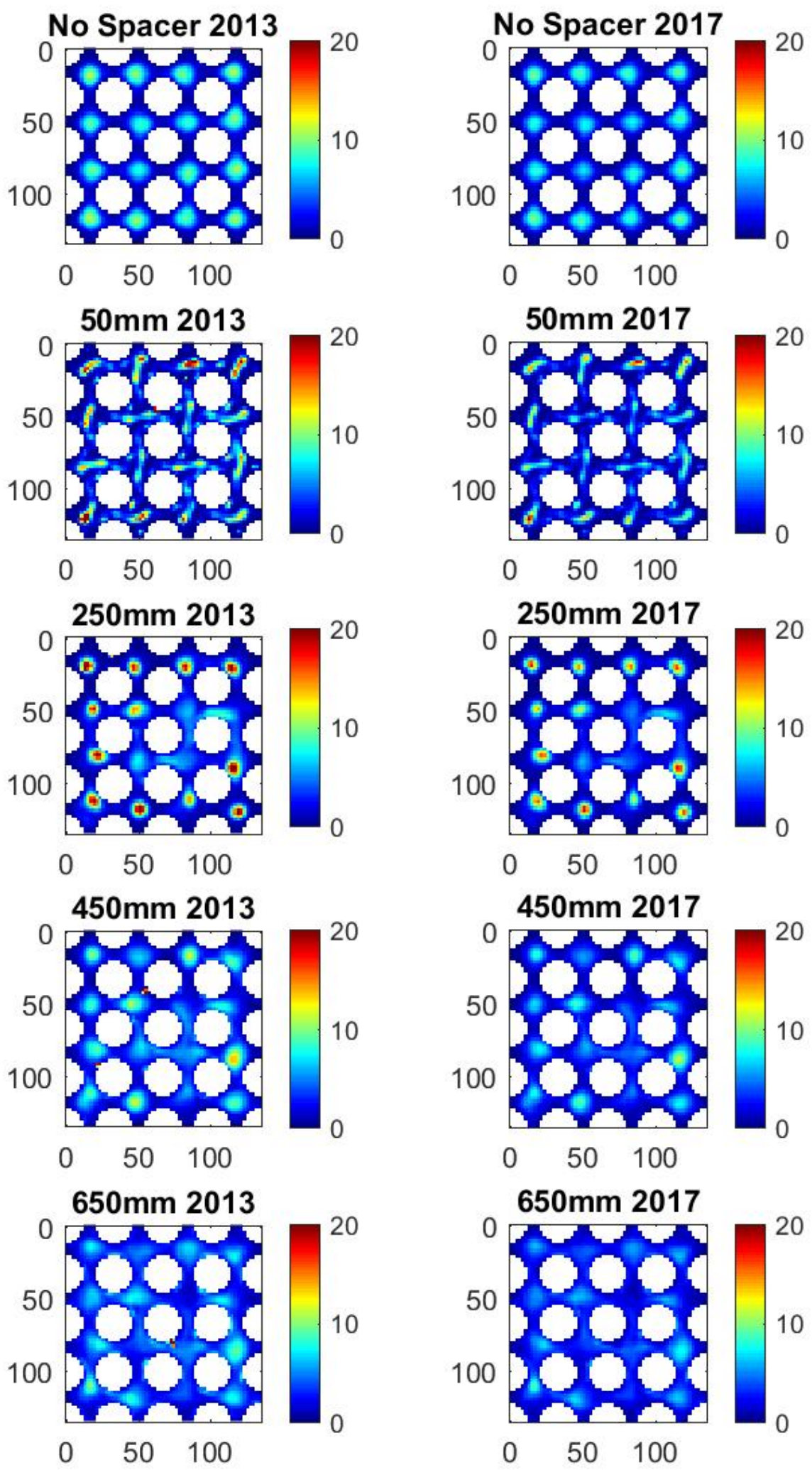

Figure A-2.7. Case-2-3: Average void fraction results. 


\subsection{Case 2-4}
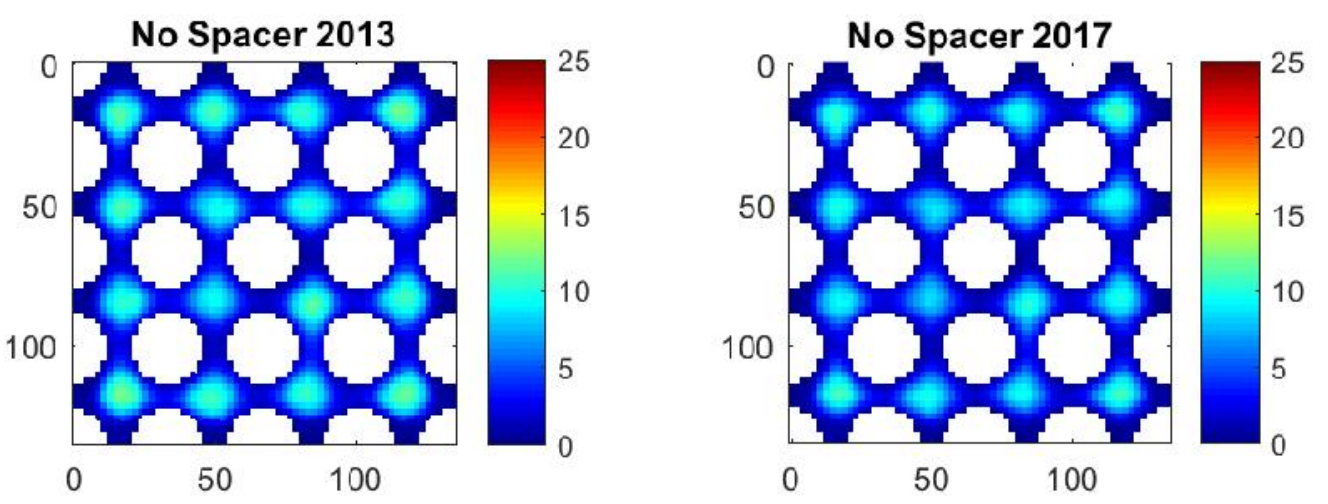

Figure A-2.8. Case-2-4: Average void fraction results. 
2.9 Case 3-1
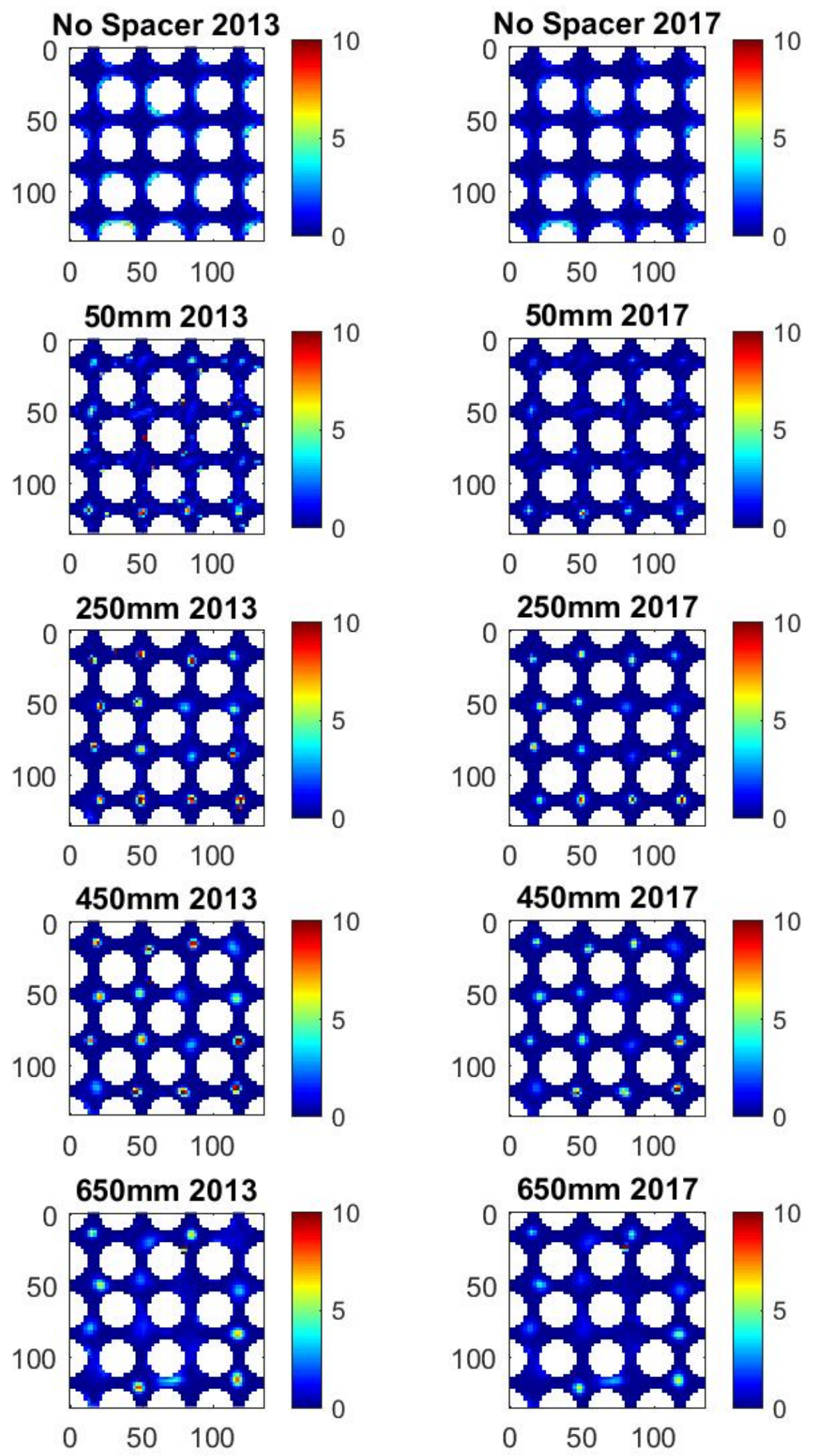

Figure A-2.9. Case-3-1: Average void fraction results. 
2.10 Case 3-2
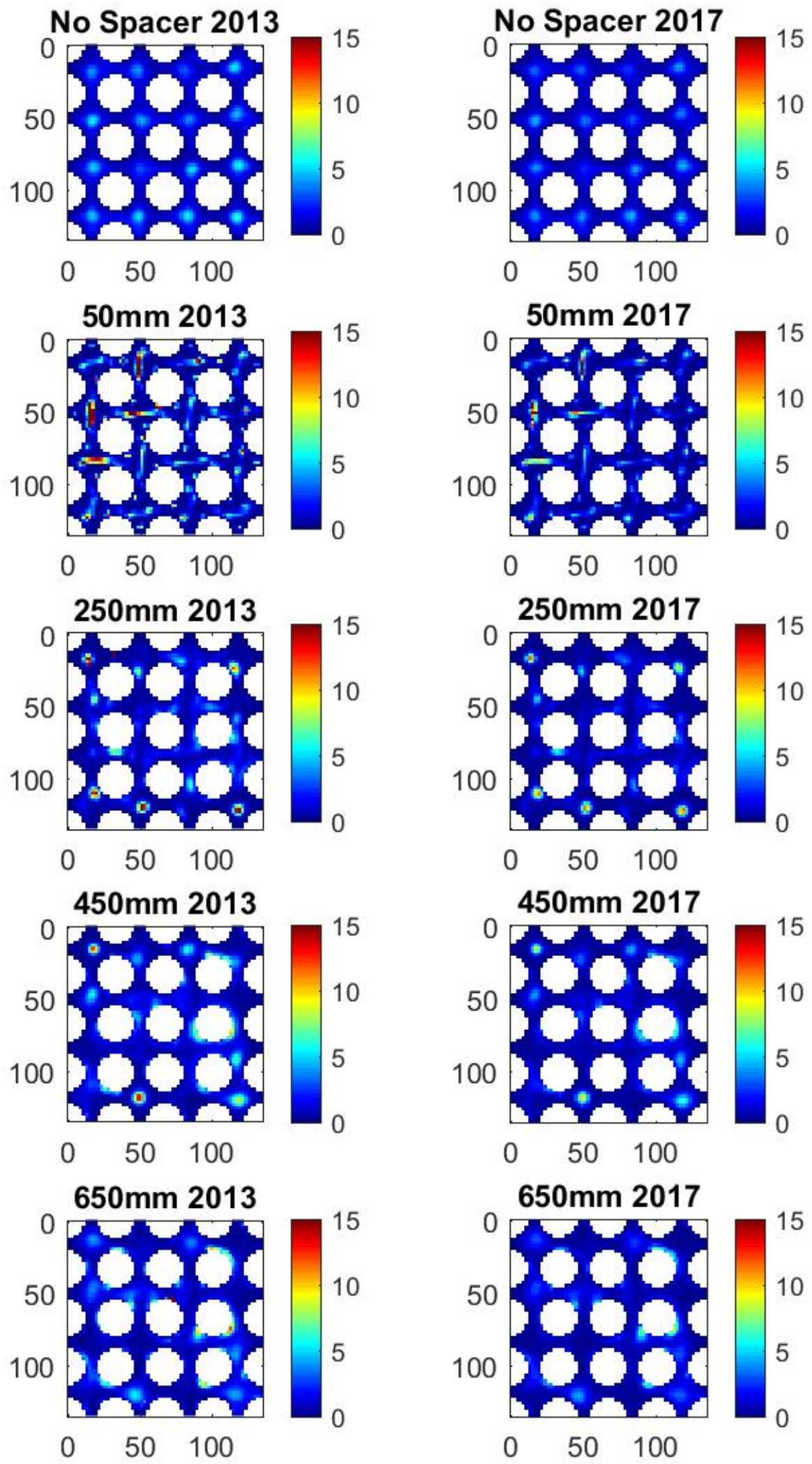

Figure A-2.10. Case-3-2: Average void fraction results. 
2.11 Case 3-3
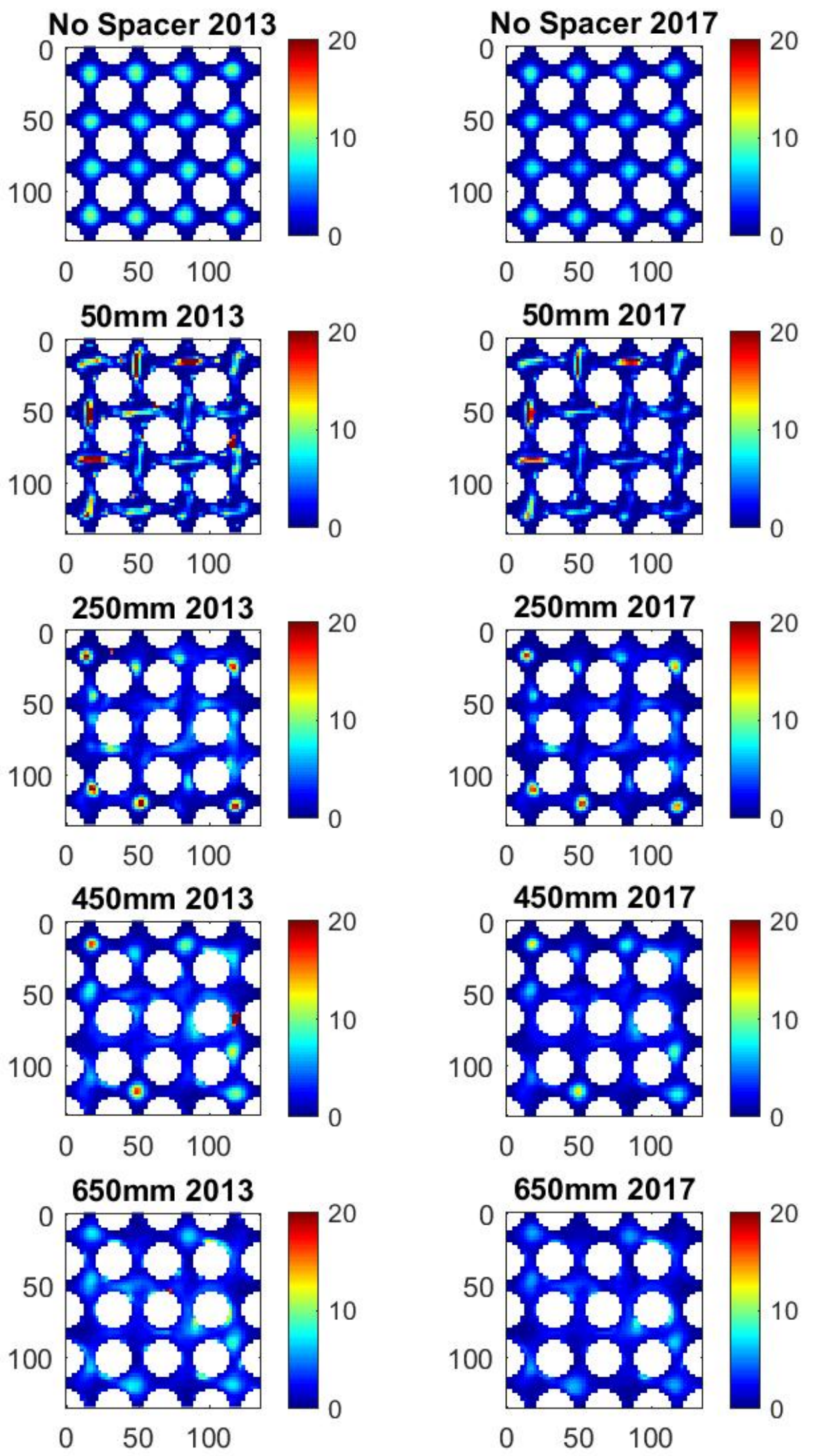

Figure A-2.11. Case-3-3: Average void fraction results. 


\subsection{Case 3-4}
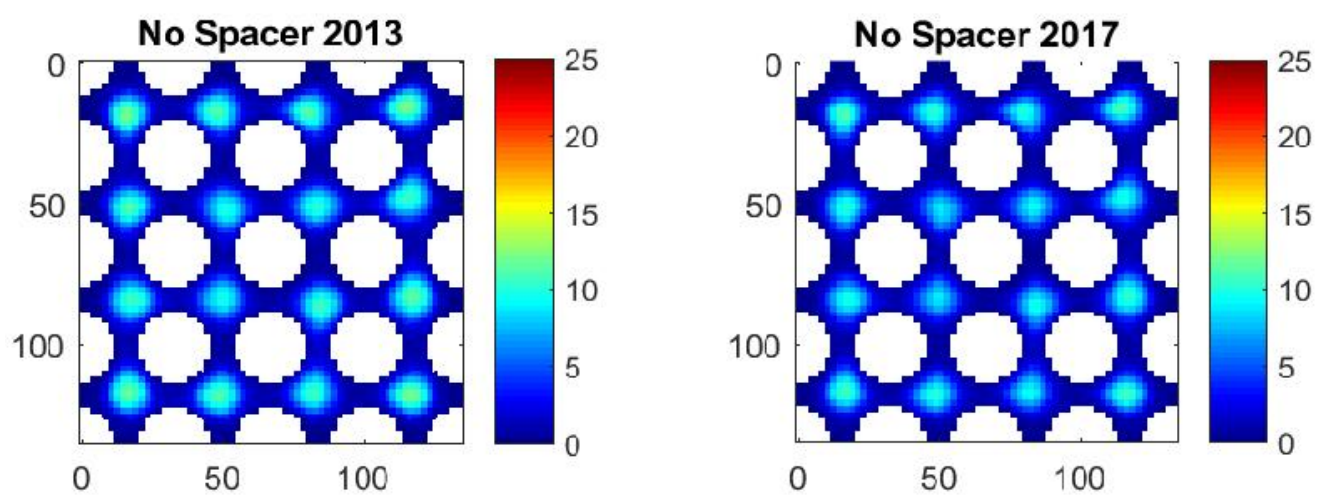

Figure A-2.12. Case-3-4: Average void fraction results. 


\section{Part B. Bibliography on Forced Convection Boiling and CHF}

C. Bang, S.H. Chang and W.P. Baek. Visualization of the subcooled flow boiling of R-134a in a vertical rectangular channel with an electrically heated wall. Int. J. Heat \& MassTransfer, 47(1920), pp.4349-4363, 2004.

N. Basu, G.R. Warrier and V.K. Dhir. Wall Heat Flux Partitioning During Subcooled Flow Boiling: Part1, Model Development. J. Heat Transfer, 127(2) p.131, 2005.

S. Bertoletti, G.P. Gaspari, C. Lombardi, G. Peterlongo, M. Silvestri and F.A. Tacconi. Heat transfer crisis with steam-water mixtures. Energia Nucl. 12, 1965.

G.P. Celata, M. Cumo, A. Mariani, M. Simoncini and G. Zummo. Rationalization of existing mechanistic models for the prediction of water subcooled flow boiling critical heat flux. Int. J. Heat \& Mass Transfer, 37, pp.347-360, 1994.

V.H. DelValle and D.B.R. Kenning. Subcooled flow boiling at high heat flux. Int. J. Heat \& Mass Transfer, 28(10), pp.1907-1920, 1985.

M.P. Fiori and A.E. Bergles. Model of critical heat flux. Technical Report DSR 70281-56, MIT, 1970.

J.E. Galloway and I. Mudawar. CHF mechanism in flow boiling from a short heated wall; Examination of near-wall conditions with the aid of photomicrography and high-speed video imaging. Int. J. Heat \& Mass Transfer, 36(10), pp.2511-2526, 1993.

F.C. Gunther. Photographic study of surface-boiling heat transfer to water with forced convection. Trans. ASME, 73(2), pp.115-123 1951.

R. Hino and T. Ueda. Studies on heat transfer and flow characteristics in subcooled flow boiling, Part2: Flow characteristics. Int. J. Multiphase Flow, 11(3), pp.283-297, 1985.

S.G. Kandlikar. A theoretical model to predict pool boiling CHF incorporating effects of contact angle and orientation. J. HeatTransfer, 123(6), pp.1071-1079, 2001.

H. Kinoshita, T. Yoshida, H. Nariai and F. Inasaka. Effect of heated length on the critical heat flux of subcooled flow boiling; Part1: Observation of bubbles and slug length at atmospheric pressure. Heat Transfer Asian Research, 29(2), pp.132-143, 2000.

W.Liu, H.Nariai and F. Inasaka. Prediction of critical heat flux for subcooled flow boiling. Int. J. Heat \& Mass Transfer 43, pp.3371-3390, 2000,

W.Liu, and H. Nariai. Ultrahigh CHF prediction for subcooled flow boiling based on homogeneous nucleation mechanism. J. Heat Transfer, 127, pp.149-158, 2005. 
W. Liu, M. Kureta, H. Yoshida, A. Ohnuki and H. Akimoto. An Improved Critical Power Correlation for Tight-Lattice Rod Bundles. J. Nucl. Sci. \& Techn., 44(4), pp.558-571, 2007.

W.Liu, M. Kureta, H.Tamai, A. Ohnuki and H. Akimoto. Critical power characteristics in 37-rod tight lattice bundles under transient conditions. J. Nucl. Sci. \& Techn., 44(9), p.1172-1181, 2007.

J.W. Park, W.P. Baek and S.H. Chang. Critical heat flux and flow pattern for water flow in annular geometry. Nucl. Eng. Des. 172(1-2), pp.137-155, 1997.

H. Sakashita and A. Ono. Boiling behaviors and critical heat flux on a horizontal plate in saturated pool boiling of water at high pressures. Int. J. Heat \& Mass Transfer, 52(3), pp.744-750, 2009. 


\title{
Part C. Development of Improved Mechanistic Closure Laws for Boiling Heat Transfer
}

Proceedings of ICAPP 2017

April 24-28, 2017 - Fukui and Kyoto (Japan)

\author{
Mechanistic Modeling of Bubble Ebullition Cycle
}

\author{
Zeyong Wang ${ }^{1}$ and Michael Z. Podowski ${ }^{2}$ \\ Center for Multiphase Research, Rensselaer Polytechnic Institute: 110 Eighth St., Troy, NY 12180, USA
}

(1)wangz18@rpi.edu, (2)podowm@rpi.edu

\begin{abstract}
The significance of mechanistic modeling of bubble ebullition cycle for the accuracy of boiling heat transfer predictions has already been demonstrated before. The objective of this paper is to present a new analytical model of transient heat transfer between solid walls and the surrounding coolant during wall quenching. The proposed model covers a large spectrum of the geometries pertaining to both experimental boiling test sections and nuclear reactor fuel assemblies. The new model has been parametrically tested and validated against experimental data. A good agreement between the model predictions and experimental data has been obtained.
\end{abstract}

\section{Introduction}

Accurate predictions of subcooled boiling heat transfer and the resultant vapor generation are of special interest in nuclear engineering, as they affect the reactor operating conditions and safety characteristics. As it has already been shown before ${ }^{1-2}$, both our understanding of the underlying physics and the accuracy of predictions based on computer simulations can be considerably improved by replacing heuristic correlations with mechanistic models.

Most mechanistic approaches ${ }^{3-7}$ proposed in the past to subcooled boiling were based on using the average (constant) temperature of the heated wall as a common reference to evaluate the heat flux components of the overall wall heat flux. However, in time- and spaceresolved boiling experiments ${ }^{8-12}$, the wall surface temperature was observed to fluctuate during the bubble ebullition cycle.

Shai and Rohsenow ${ }^{13}$ observed that the time for bubble growth and departure was a very small fraction of the total bubble ebullition cycle. They also solved the transient conduction heat transfer for a periodic quenching process. Podowski et al. (Ref. 1) proposed a mechanistic model for determining the bubble ebullition process in forced convection subcooled boiling, which combines transient heat transfer solutions for the heated wall (externally heated flat plate) and the liquid filling the space vacated by departing bubbles. The authors assumed the heater can be treated as a semi-infinite wall and their models apply only to flat plates.

The objective of this paper is to present a mathematically rigorous and physically consistent new model of the bubble ebullition cycle. Since the average wall superheat is mainly controlled by the temperature history during the waiting period, the emphasis has been on the formulation of consistent analytical models of transient heat transfer between solid walls and the surrounding coolant during wall quenching period. Several versions of the model have been rigorously derived for the following conditions and geometries: flat and cylindrical solid walls heated by an external heater, and flat and cylindrical internally heated walls. In particular, two limiting cases have been considered: thick heaters and thin heaters, of which the definitions will be discussed in the following sections. Needless to say, the situations mentioned above encompass a large spectrum of geometries pertaining to both experimental boiling test sections and nuclear reactor fuel assemblies.

The new models have been parametrically tested and validated against experimental data. The modeling consistency has been illustrated by showing that the internally heated flat wall model with appropriate boundary conditions approaches the solution in Ref. 1. It has also been shown that as the radius of the cylindrical wall increases, the solution approaches the corresponding expression for a solid plate of the same thickness. The predictions by the proposed models have been compared against selected experimental results and good agreement has been observed.

\section{Model Description}

\section{II.A. Definition of Thick Heater}

Consider a 1-D transient heat conduction equation

$$
\frac{1}{\alpha} \frac{\partial T}{\partial t}=\frac{\partial^{2} T}{\partial x^{2}}, x>0, t>0
$$

with the following boundary conditions

and

$$
T(0, t)=C e^{i \omega t}
$$




$$
T(\infty, t)=0
$$

A general periodic solution of Eq. (1) can be written as

$$
T=C e^{\alpha A^{2} t-A x}
$$

Applying the above boundary conditions, the solution given by Eq.(4) becomes

$$
T(x, t)=C e^{-\sqrt{\frac{\omega}{2 \alpha}} x} e^{-i \sqrt{\frac{\omega}{2 \alpha}}(x-\sqrt{2 \alpha \omega} t)}
$$

The penetration depth of the oscillatory solution can be defined as as the location where the magnitude of oscillations decreases to $1 \%$ of the original value, i.e., where $T(x, t)$ decays to $0.01 C$. The corresponding expression for this depth is

$$
x_{0}=4.6 \sqrt{\frac{t_{0} \alpha}{\pi}}
$$

where $t_{0}=\frac{2 \pi}{\omega}$ is the period of the surface temperature oscillations.

\section{II.B. Internally Heated Thick Flat Plate}

\section{II.B.1. Problem Formulation}

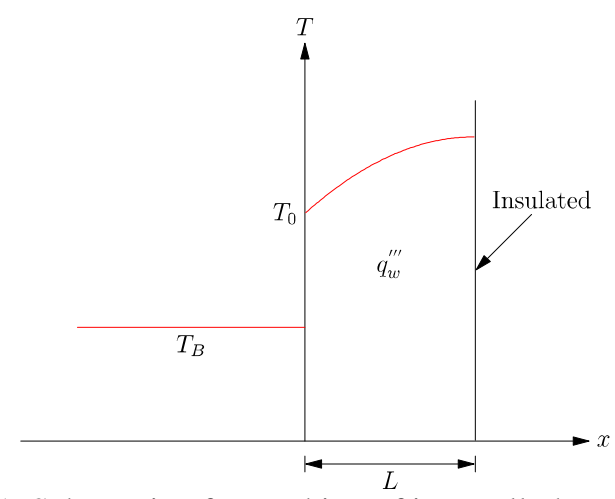

Fig. 1. Schematic of quenching of internally heated flat plate.

Heat conduction across the wall can be modeled as

$$
\frac{1}{\alpha_{w}} \frac{\partial T_{w}}{\partial t}=\frac{\partial^{2} T_{w}}{\partial x^{2}}+\frac{q_{w}^{\prime \prime \prime}}{k_{w}}, x>0,0<t<t_{0}
$$

We assume an initial steady state temperature profile

$$
T_{w}(x, 0)=\frac{q_{w}^{\prime \prime \prime}}{k_{w}}\left(L x-\frac{x^{2}}{2}\right)+T_{0}
$$

and the boundary conditions given by

$$
T_{w}(0, t)=T_{i}(t)
$$

and

$$
\left.\frac{\partial T_{w}}{\partial x}\right|_{x=L}=0
$$

Heat conduction between the "cold" liquid and the heater can be modeled as

$$
\frac{1}{\alpha_{l}} \frac{\partial T_{l}}{\partial t}=\frac{\partial^{2} T_{l}}{\partial x^{2}}, x<0,0<t<t_{0}
$$

with the following initial and boundary conditions

and

$$
\begin{gathered}
T_{l}(x, 0)=T_{B} \\
T_{l}(0, t)=T_{i}(t)
\end{gathered}
$$

$$
T_{l}(-\infty, t)=T_{B}
$$

The temperature profiles in the liquid and the heater is coupled by

$$
-\left.k_{l} \frac{\partial T_{l}}{\partial x}\right|_{x=0}=-\left.k_{w} \frac{\partial T_{w}}{\partial x}\right|_{x=0}
$$

\section{II.B.2. Analytical Solution to Heat Conduction across the} Heater

The problem of heat conduction in the heater can be partitioned into a transient term $T_{h}(x, t)$ and a steady state term $T_{s}(x)$. The latter term satisfies

$$
0=\frac{\partial^{2} T_{s}}{\partial x^{2}}+\frac{q_{w}^{\prime \prime \prime}}{k_{w}}
$$

with boundary conditions $T_{s}(0)=T_{0},\left.\frac{\partial T_{s}}{\partial x}\right|_{x=L}=0$.

The transient term satisfies the equation

$$
\frac{1}{\alpha_{w}} \frac{\partial T_{h}}{\partial t}=\frac{\partial^{2} T_{h}}{\partial x^{2}}
$$

with the initial and boundary conditions given by $T_{h}(x, 0)=0, T_{h}(0, t)=T_{i}(t)-T_{0}$ and $\left.\frac{\partial T_{h}}{\partial x}\right|_{x=L}=0$.

The solution to the steady state problem is

$$
T_{s}(x)=\frac{q_{w}^{\prime \prime \prime}}{k_{w}}\left(L x-\frac{x^{2}}{2}\right)+T_{0}
$$

The Laplace transformation of Eq. (17) leads to

$$
\frac{1}{\alpha_{w}} s \Phi_{h}(x, s)=\Phi_{h, x x}(x, s)
$$

Using the boundary conditions, the Laplacetransformed solution becomes

$$
\Phi_{h}(x, s)=\left(\psi(s)-\frac{T_{0}}{s}\right) e^{-\sqrt{\frac{s}{\alpha_{w}} x}}
$$

and

$$
\left.\frac{\partial \Phi_{h}}{\partial x}\right|_{x=0}=\left(\psi(s)-\frac{T_{0}}{s}\right)\left(-\sqrt{\frac{s}{\alpha_{w}}}\right)
$$

Note that for thick heaters we can treat the wall as semi-infinite.

\section{II.B.3. Analytical Solution to Heat Conduction in the Liquid}

The Laplace transformation of Eq. (11) leads to

$$
\frac{1}{\alpha_{l}}\left(s \Phi_{l}(x, s)-T_{B}\right)=\Phi_{l, x x}(x, s)
$$

A general solution of Eq.(22) is 
$\Phi_{l}(x, s)=c_{1}(s) e^{\sqrt{\frac{s}{\alpha_{l}}} x}+c_{2}(s) e^{-\sqrt{\frac{s}{\alpha_{l}}} x}+\frac{T_{B}}{s}$

Applying the boundary condition leads to

$$
\Phi_{l}(x, s)=\left[\psi(s)-\frac{T_{B}}{s}\right] e^{\sqrt{\frac{s}{\alpha_{l}} x}}+\frac{T_{B}}{s}
$$

and

$$
\left.\frac{\partial \Phi_{l}}{\partial x}\right|_{x=0}=\left[\psi(s)-\frac{T_{B}}{s}\right] \sqrt{\frac{s}{\alpha_{l}}}
$$

\section{II.B.4. Coupling the Liquid and Heater Solutions}

The Laplace transformation of Eq. (15) leads to

$$
\begin{aligned}
-\left.k_{l} \frac{\partial \Phi_{l}}{\partial x}\right|_{x=0} & =-\left.k_{w} \frac{\partial \Phi_{w}}{\partial x}\right|_{x=0} \\
& =-k_{w}\left(\frac{q_{w}^{\prime \prime \prime} L}{k_{w}} \frac{1}{s}+\left.\frac{\partial \Phi_{h}}{\partial x}\right|_{x=0}\right)
\end{aligned}
$$

Using Eq. (21) and Eq. (25), we obtain

$$
\psi(s)=\frac{1}{\mathcal{R}}\left[\frac{\mathcal{X}}{s}+q_{w}^{\prime \prime \prime} L \frac{1}{s^{3 / 2}}\right]
$$

where

$$
\mathcal{R}=\frac{k_{l}}{\sqrt{\alpha_{l}}}+\frac{k_{w}}{\sqrt{\alpha_{w}}}
$$

and

$$
x=\frac{k_{l} T_{B}}{\sqrt{\alpha_{l}}}+\frac{k_{w} T_{0}}{\sqrt{\alpha_{w}}}
$$

The inverse Laplace transform leads to

$$
T_{i}(t)=T_{+}+\frac{q_{w}^{\prime \prime \prime} L}{\mathcal{R}} \frac{2 \sqrt{t}}{\sqrt{\pi}}
$$

where

$$
T_{+}=\frac{X}{\mathcal{R}}
$$

\section{II.C. Internally Heated Wall of Cylindrical Pipe}

\section{II.C.1. Problem Formulation}

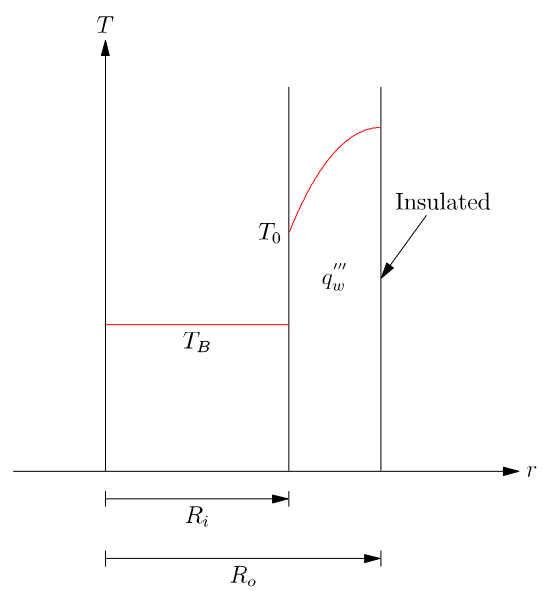

Fig. 2. Schematic of quenching of internally heated pipe.
The heat conduction across the internally heated wall can be modeled as

$$
\frac{1}{\alpha_{w}} \frac{\partial T_{w}}{\partial t}=\frac{1}{r} \frac{\partial}{\partial r}\left(r \frac{\partial T_{w}}{\partial r}\right)+\frac{q_{w}^{\prime \prime \prime}}{k_{w}}, R_{i}<r<R_{o}, 0<t<t_{0}
$$

It can be assumed that the initial temperature profile is given by

$$
T_{w}(r, 0)=\frac{q_{w}^{\prime \prime \prime}}{k_{w}} \frac{R_{i}^{2}-r^{2}}{4}+\frac{q_{w}^{\prime \prime \prime} R_{o}^{2}}{2 k_{w}} \ln \left(\frac{r}{R_{i}}\right)+T_{0}
$$

and the boundary conditions are

and

$$
T_{w}\left(R_{i}, t\right)=T_{i}(t)
$$

$$
\left.\frac{\partial T_{w}}{\partial r}\right|_{r=R_{o}}=0
$$

Heat conduction in the liquid can be modeled as

$$
\frac{1}{\alpha_{l}} \frac{\partial T_{l}}{\partial t}=\frac{\partial^{2} T_{l}}{\partial r^{2}}+\frac{1}{r} \frac{\partial T_{l}}{\partial r}, r<R_{i}, \mathrm{~J}<t<t_{0}
$$

with initial and boundary conditions as

$$
\begin{gathered}
T_{l}(r, 0)=T_{B} \\
T_{l}\left(R_{i}, t\right)=T_{i}(t) \\
T_{l}(0, t)=T_{B}
\end{gathered}
$$

The coupling between the liquid and heater temperatures is expressed as

$$
-\left.k_{l} \frac{\partial T_{l}}{\partial r}\right|_{r=R_{i}}=-\left.k_{w} \frac{\partial T_{w}}{\partial r}\right|_{r=R_{i}}
$$

\section{II.C.2. Analytical Solution to Heat Conduction in the} Heater

As before, the heat conduction in the heater can be split into a steady state term, $T_{s}(r)$, and a transient term $T_{h}(r, t)$, which can respectively be modeled as

$$
\frac{\partial^{2} T_{s}}{\partial r^{2}}+\frac{1}{r} \frac{\partial T_{s}}{\partial r}+\frac{q_{w}^{\prime \prime \prime}}{k_{w}}=0
$$

with the boundary conditions: $T_{s}\left(R_{i}, t\right)=T_{0}$ and $\left.\frac{\partial T_{s}}{\partial r}\right|_{r=R_{O}}=0$, and

$$
\frac{1}{\alpha_{w}} \frac{\partial T_{h}}{\partial t}=\frac{\partial^{2} T_{h}}{\partial r^{2}}+\frac{1}{r} \frac{\partial T_{h}}{\partial r}
$$

with the initial and boundary conditions: $T_{h}(r, 0)=0$, $T_{h}\left(R_{i}, t\right)==T_{i}(t)-T_{0}$, and $\left.\frac{\partial T_{h}}{\partial r}\right|_{r=R_{0}}=0$.

The solution to the steady state problem is

$$
T_{s}=\frac{q_{w}^{\prime \prime \prime}}{k_{w}} \frac{R_{i}^{2}-r^{2}}{4}+\frac{q_{w}^{\prime \prime \prime} R_{o}^{2}}{2 k_{w}} \ln \left(\frac{r}{R_{i}}\right)+T_{0}
$$

A Laplace transformation of Eq. (42) leads to

$$
\frac{1}{\alpha_{w}} s \Phi_{h}=\frac{\partial^{2} \Phi_{h}}{\partial r^{2}}-\frac{1}{r} \frac{\partial \Phi_{h}}{\partial r}
$$

Using the boundary conditions given above, we obtain 


$$
\Phi_{h}(r, s)=\frac{\psi(s)-\frac{T_{0}}{s}}{K_{0}\left(\sqrt{\frac{s}{\alpha_{w}}} R_{i}\right)} K_{0}\left(\sqrt{\frac{s}{\alpha_{w}}} r\right)
$$

and

$$
\left.\frac{\partial \Phi_{h}}{\partial r}\right|_{r=R_{i}}=-\frac{\psi(s)-\frac{T_{0}}{s}}{K_{0}\left(\sqrt{\frac{s}{\alpha_{w}}} R_{i}\right)} K_{1}\left(\sqrt{\frac{s}{\alpha_{w}}} R_{i}\right) \sqrt{\frac{s}{\alpha_{w}}}
$$

In the case of "thick" pipe heaters we can assume that $R_{o} \rightarrow \infty$.

\section{II.C.3. Analytical Solution to Heat Conduction in the} Liquid

A Laplace transformation of Eq. (36) leads to

$$
\frac{1}{\alpha_{l}}\left(s \Phi_{l}-T_{B}\right)=\frac{\partial^{2} \Phi_{l}}{\partial r^{2}}+\frac{1}{r} \frac{\partial \Phi_{l}}{\partial r}
$$

A general solution of Eq.(47) is

$$
\Phi_{l}(r, s)=c_{0} I_{0}\left(\sqrt{\frac{s}{\alpha_{l}}} r\right)+c_{1} K_{0}\left(\sqrt{\frac{s}{\alpha_{l}}} r\right)+\frac{T_{B}}{s}
$$

As $T_{l}$ is finite at $r=0$, we have $c_{1}=0$. Applying the other boundary condition leads to

$$
\Phi_{l}(r, s)=\frac{\psi(s)-\frac{T_{B}}{s}}{I_{0}\left(\sqrt{\frac{s}{\alpha_{l}}} R_{i}\right)} I_{0}\left(\sqrt{\frac{s}{\alpha_{l}}} r\right)+\frac{T_{B}}{s}
$$

We thus have

$$
\left.\frac{\partial \Phi_{l}}{\partial r}\right|_{r=R_{i}}=\frac{\psi(s)-\frac{T_{B}}{s}}{I_{0}\left(\sqrt{\frac{s}{\alpha_{l}}} R_{i}\right)} I_{1}\left(\sqrt{\frac{s}{\alpha_{l}}} R_{i}\right) \sqrt{\frac{s}{\alpha_{l}}}
$$

\section{II.C.4. Coupling of Heat Conduction in Liquid and Heater}

Laplace transformation of Eq. (40) lcads to

$$
\begin{aligned}
& -\left.k_{l} \frac{\partial \Phi_{l}}{\partial r}\right|_{r=R_{i}}=-\left.k_{w} \frac{\partial \Phi_{w}}{\partial r}\right|_{r=R_{i}} \\
& =-k_{w}\left[\frac{q_{w}^{\prime \prime \prime}}{2 k_{w}}\left(\frac{R_{o}^{2}}{R_{i}}-R_{i}\right) \frac{1}{s}+\left.\frac{\partial \Phi_{h}}{\partial r}\right|_{r=R_{i}}\right]
\end{aligned}
$$
$\psi(s)$

Using Eqs. (46) and (50), we obtain

$$
=\frac{\frac{q_{w}^{\prime \prime \prime}}{2}\left(\frac{R_{0}^{2}}{R_{i}}-R_{i}\right) I_{0} K_{0}+\sqrt{s}\left(k_{l} I_{1} K_{0} \frac{T_{B}}{\sqrt{\alpha_{l}}}+k_{w} K_{1} I_{0} \frac{T_{0}}{\sqrt{\alpha_{w}}}\right)}{s^{\frac{3}{2}}\left(k_{l} I_{1} K_{0} \frac{1}{\sqrt{\alpha_{l}}}+k_{w} K_{1} I_{0} \frac{1}{\sqrt{\alpha_{w}}}\right)}
$$

where $I_{1}$ and $I_{0}$ are evaluated at $\sqrt{\frac{s}{\alpha_{l}}} R_{i}$, and $K_{1}$ and $K_{0}$ are evaluated at $\sqrt{\frac{s}{\alpha_{w}}} R_{i}$.
The analytical evaluation of the poles in Eq.(52) is practically impossible due to the transcendental function in the denominator. As we are interested in the solution behavior for small values of $t$, an approximate solution can be obtained using an asymptotic expansion of the Bessel functions for large $s \rightarrow \infty$.

Using the following series expansions

$$
\begin{gathered}
I_{0}(s) \sim \frac{e^{s}}{\sqrt{2 \pi s}}\left[1+\frac{1}{8 s}+\frac{9}{128 s^{2}}+O\left(\frac{1}{s^{3}}\right)+O\left(e^{-2 s}\right)\right] \\
I_{1}(s) \sim \frac{e^{s}}{\sqrt{2 \pi s}}\left[1-\frac{3}{8 s}-\frac{15}{128 s^{2}}+O\left(\frac{1}{s^{3}}\right)+O\left(e^{-2 s}\right)\right] \\
K_{0}(s) \sim e^{-s} \sqrt{\frac{\pi}{2 s}}\left[1-\frac{1}{8 s}+\frac{9}{128 s^{2}}+O\left(\frac{1}{s^{3}}\right)\right] \\
K_{1}(s) \sim e^{-s} \sqrt{\frac{\pi}{2 s}}\left[1+\frac{3}{8 s}-\frac{15}{128 s^{2}}+O\left(\frac{1}{s^{3}}\right)\right]
\end{gathered}
$$

yields

$$
\begin{aligned}
I_{0}\left(\sqrt{\frac{s}{\alpha_{l}}} R_{i}\right) & K_{0}\left(\sqrt{\frac{s}{\alpha_{w}}} R_{i}\right) \\
& \sim \mathcal{A}\left[1+\frac{\sqrt{\alpha_{l}}-\sqrt{\alpha_{w}}}{8 R_{i} \sqrt{s}}+O\left(s^{-1}\right)\right] \\
I_{1}\left(\sqrt{\frac{s}{\alpha_{l}}} R_{i}\right) & K_{0}\left(\sqrt{\frac{s}{\alpha_{w}}} R_{i}\right) \\
& \sim \mathcal{A}\left[1-\frac{3 \sqrt{\alpha_{l}}+\sqrt{\alpha_{w}}}{8 R_{i} \sqrt{s}}+O\left(s^{-1}\right)\right]
\end{aligned}
$$

and

$$
\begin{aligned}
K_{1}\left(\sqrt{\frac{s}{\alpha_{w}}} R_{i}\right) I_{0}\left(\sqrt{\frac{s}{\alpha_{l}}} R_{i}\right) \\
\sim c t\left[1+\frac{3 \sqrt{\alpha_{w}}+\sqrt{\alpha_{l}}}{8 R_{i} \sqrt{s}}+O\left(s^{-1}\right)\right]
\end{aligned}
$$

where

$$
\mathcal{H}=e^{\sqrt{s} R_{i}\left(\frac{1}{\left.\sqrt{\alpha_{l}}-\frac{1}{\sqrt{\alpha_{w}}}\right)}\right) \frac{\left(\alpha_{l} \alpha_{w}\right)^{1 / 4}}{2 R_{i} \sqrt{s}}}
$$

Substituting Eqs.(53)-(59) into Eq.(52), we obtain

$$
\psi(s) \sim T_{+} \frac{1}{S}+\left[\frac{\left(T_{0}-T_{B}\right) \mathcal{S}}{2 R_{i} \mathcal{R}^{2}}+\frac{q_{w}^{\prime \prime \prime}\left(R_{o}^{2}-R_{i}^{2}\right)}{2 \mathcal{R} R_{i}}\right] \frac{1}{s^{3 / 2}}+O\left(s^{-2}\right)
$$

where

$$
\mathcal{S}=k_{w} k_{l}\left(\frac{1}{\sqrt{\alpha_{l}}}+\frac{1}{\sqrt{\alpha_{w}}}\right)
$$

A Laplace-transform inversion leads to

$$
T_{i}(t) \sim T_{+}+\left[\frac{\left(T_{0}-T_{B}\right) \mathcal{S}}{2 R_{i} \mathcal{R}^{2}}+\frac{q_{w}^{\prime \prime \prime}\left(R_{o}^{2}-R_{i}^{2}\right)}{2 \mathcal{R} R_{i}}\right] 2 \sqrt{\frac{t}{\pi}}
$$


It can be easily verified that Eq. (63) reduces to Eq. (30) as $R_{i} \rightarrow \infty$ while keeping the wall thickness constant.

\section{II.D. Thin Flat Heater}

For thin heaters, we assume that thermal inertia can be neglected, so that the total heating rate is instantaneously applied to heating of liquid (see Fig. 3).

\section{II.D.1. Problem Formulation}

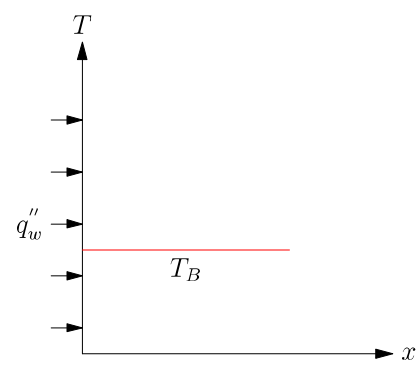

Fig. 3. Schematic of quenching of thin plate heater.

Heat conduction in the liquid can be modeled as

$$
\frac{1}{\alpha_{l}} \frac{\partial T_{l}}{\partial t}=\frac{\partial^{2} T_{l}}{\partial x^{2}}, 0<t<t_{0}, x>0
$$

with initial and boundary conditions given by

$$
\left.\frac{\partial T_{l}}{\partial x}\right|_{x=0}=-\frac{q_{w}^{\prime \prime}}{k_{l}}
$$$$
T_{l}(x, 0)=T_{B}
$$

and

$$
T_{l}(\infty, t)=T_{B}
$$

\section{II.D.2. Analytical Solution}

A Laplace transformation of Eq. (64) leads to

$$
\frac{1}{\alpha_{l}}\left({ }_{5} \Phi_{l}-T_{B}\right):-\Phi_{l, x x}
$$

A general solution of Eq.(68) is

$$
\Phi_{l}(x, s)=c_{0} e^{\sqrt{\frac{s}{\alpha_{l}}} x}+c_{1} e^{-\sqrt{\frac{s}{\alpha_{l}}} x}+\frac{T_{B}}{S}
$$

Applying the boundary conditions given by Eqs.(65)(67), we obtain

$$
\Phi_{l}(x, s)=\frac{q_{w}^{\prime \prime} \sqrt{\alpha_{l}}}{k_{l} s^{3 / 2}} e^{-\sqrt{\frac{s}{\alpha_{l}}} x}+\frac{T_{B}}{s}
$$

A Laplace-transform inversion leads to

$$
\begin{aligned}
& T_{l}(x, t) \\
& =\frac{q_{w}^{\prime \prime} \sqrt{\alpha_{l}}}{k_{l}}\left[2\left[\frac{t}{\pi} e^{-\frac{x^{2}}{4 \alpha_{l} t}}-\frac{x}{\sqrt{\alpha_{l}}} \operatorname{erfc}\left(\frac{x}{2 \sqrt{\alpha_{l} t}}\right)\right]+T_{\mathrm{B}}\right.
\end{aligned}
$$

and

$$
T_{i}(t)=T_{B}(0, t)=T_{B}+\frac{2 q_{w}^{\prime \prime}}{k_{l}} \sqrt{\frac{\alpha_{l} t}{\pi}}
$$

\section{II.E. Other Thin and Thick Heaters}

For the analysis of an internally heated annulus heater, flat and cylindrical thick walls heated by an external heater, and cylindrical thin heaters, we can follow the same idea as in II.C, II.D, and II.E. Thus, only the final results are shown in this section. It should be noted that for the cylindrical thin heaters, rigorous series solutions have been obtained. However, for practical reasons, we still adopt the asymptotic solution.

\section{II.E.1. Internally Heated Thick Annulus Heater Cooled from Outside}

For an internally heated thick annulus-shaped heater, shown in Fig.4, the wall surface variation can be expressed as

$$
T_{i}(t) \sim T_{+}+\left[\frac{\left(T_{B}-T_{0}\right) \mathcal{S}}{2 R_{o} \mathcal{R}^{2}}-\frac{q_{w}^{\prime \prime \prime}\left(R_{i}^{2}-R_{o}^{2}\right)}{2 R_{o} \mathcal{R}}\right] 2 \sqrt{\frac{t}{\pi}}
$$

It can be easily verified that Eq. (73) reduces to Eq.(30) as $R_{o} \rightarrow \infty$.

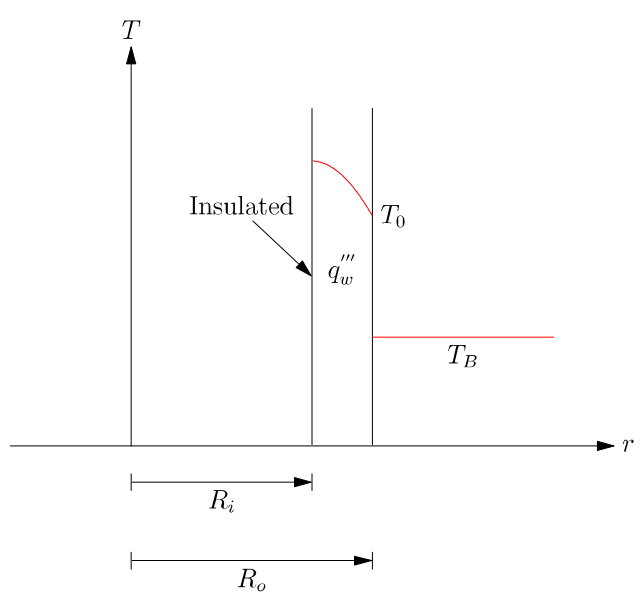

Fig. 4. Schematic of quenching of internally heated annulus

\section{II.E.2. Externally Heated Thick Flat Wall}

For an externally heated flat thick wall, shown in Fig. 5, the heat flux is be applied to the surface in contact with the fluid.

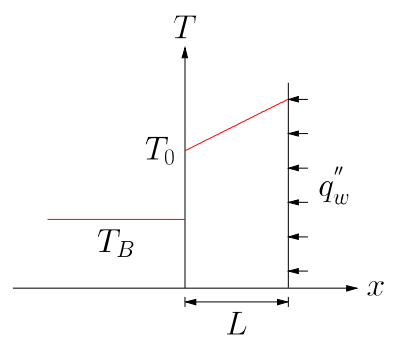

Fig. 5. Schematic of quenching of externally heated plate. 
as

In this case, the wall surface variation can be expressed

$$
T_{i}(t)=\frac{x}{\mathcal{R}}+\frac{q_{w}^{\prime \prime}}{\mathcal{R}} \frac{2 \sqrt{t}}{\sqrt{\pi}}
$$

\section{II.E.3. Externally Heated Thick Cylindrical Wall}

For, the geometry is shown in Figure 6, the timedependent temperature of the inner surface is given by

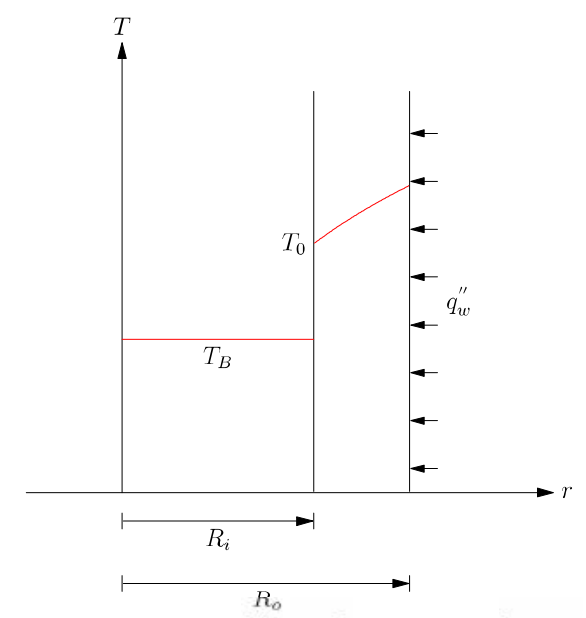

Fig. 6. Schematic of quenching of externally heated pipe.

$$
T_{i}(t)=T_{+}+\left[\frac{\left(T_{0}-T_{B}\right) \mathcal{S}}{2 R_{i} \mathcal{R}^{2}}+\frac{q_{w}^{\prime \prime} R_{o}}{\mathcal{R} R_{i}}\right] 2 \sqrt{\frac{t}{\pi}}
$$

It can be easily verified that Eq. (75) reduces to Eq.(74) as $R_{i} \rightarrow \infty$.

\section{II.E.4. Cylindrical Tube Wall Heated by a Heater Placed} Inside

The geometry is shown in Figure 7.

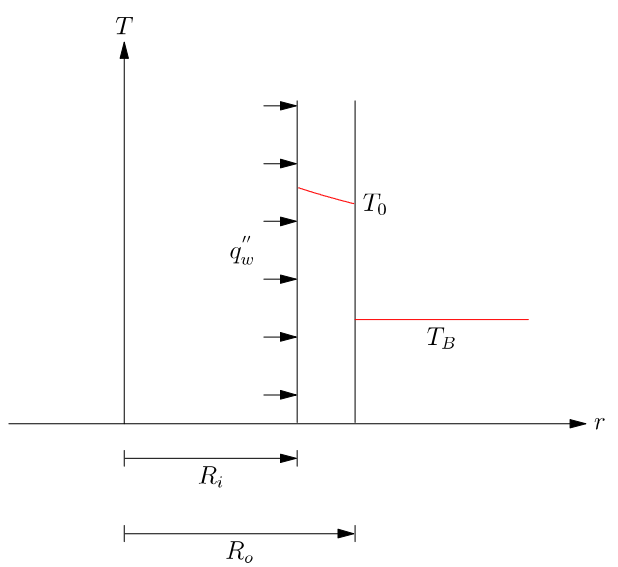

Fig. 7. Schematic of quenching of cylindrical wall heated from inside.

The wall surface variation can be expressed as

$$
T_{i}(t)=T_{+}+\left[\frac{\left(T_{B}-T_{0}\right) \mathcal{S}}{2 R_{o} \mathcal{R}^{2}}+\frac{q_{w}^{\prime \prime} R_{i}}{R_{o} \mathcal{R}}\right] 2 \sqrt{\frac{t}{\pi}}
$$

Again, Eq. (76) reduces to Eq. (74) as $R_{o} \rightarrow \infty$.

\section{II.E.5. Thin Cylindrical Heater Cooled from Outside}

In the case of a thin cylindrical heater shown in Fig. 8, the time-dependent temperature of the heater is given by

$$
T_{i}(t)=\frac{2 q_{w}^{\prime \prime}}{k_{l}} \sqrt{\frac{\alpha_{l} t}{\pi}}+T_{B}+\frac{q_{w}^{\prime \prime} \alpha_{l}}{2 k_{l} R} t
$$

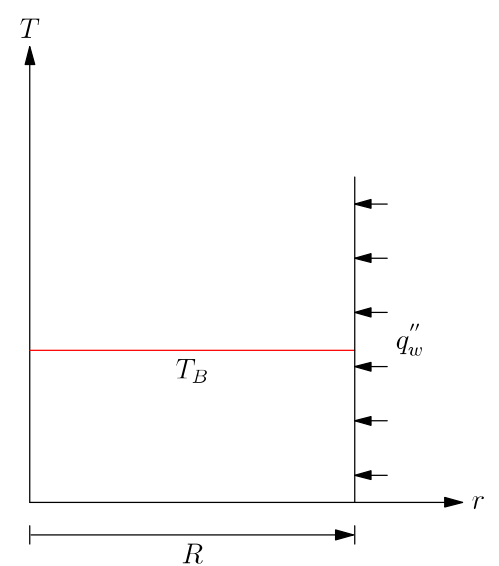

Fig. 8. Schematic of quenching of thin pipe heater cooled from outside.

It can be readily shown that Eq. (77) reduces to Eq.(72) as $R \rightarrow \infty$.

\section{II.E.6. Thin Cylindrical Heater Cooled from Inside}

The geometrical configuration is shown in Fig. 9.

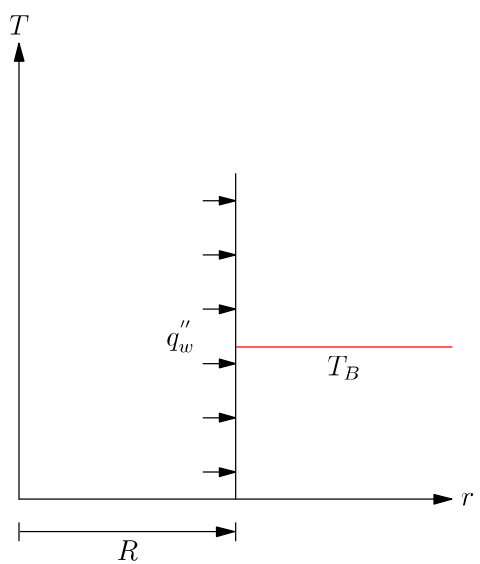

Fig. 9. Schematic of quenching of thin cylindrical heater cooled from inside.

The wall surface variation can be expressed as 


$$
T_{l}\left(R_{o}, t\right)=\frac{2 q_{w}^{\prime \prime}}{k_{l}} \sqrt{\frac{\alpha_{l} t}{\pi}}-\frac{q_{w}^{\prime \prime} \alpha_{l}}{2 k_{l} R} t+T_{B}
$$

As before, Eq. (78) reduces to Eq. (72) as $R \rightarrow \infty$.

\section{Results and Analysis}

\section{III.A. Verification of Cylindrical Heater Analysis}

A parametric study has been performed to demonstrate the modeling consistency by showing that as the radius of the cylindrical wall (Steel AISI 4340, with the inner radius, $R_{i}$, and outer radius, $R_{o}$ ) increases, the solution approaches that for a solid plate of the same thickness $\left(L=R_{o}-R_{i}=\right.$ $5 \mathrm{~mm}$ ) and of the same surface area (in contact with fluid).

The same heating power $Q$ has been applied to the pipe/annulus heaters and the flat plate heaters. Saturated water under atmospheric pressure has been used to repeatedly quench the heater. Initially, the heater is at steady state with one surface (in contact with fluid) at temperature $T_{0}$ and the other insulated. Other parameters for the current test case are shown in Table 1.

Table 1. Parametric Test Parameters

\begin{tabular}{ccc}
\hline$k_{w}(\mathrm{~W} / \mathrm{m} \cdot \mathrm{K})$ & $\rho_{w}\left(\mathrm{~kg} / \mathrm{m}^{3}\right)$ & $c_{p, w}(\mathrm{~J} / \mathrm{kg} \cdot \mathrm{K})$ \\
44.5 & 7850 & 475 \\
\hline$k_{l}(\mathrm{~W} / \mathrm{m} \cdot \mathrm{K})$ & $\rho_{l}\left(\mathrm{~kg} / \mathrm{m}^{3}\right)$ & $c_{p, l}(\mathrm{~J} / \mathrm{kg} \cdot \mathrm{K})$ \\
0.675 & 966 & 420 \\
\hline$T_{0}-T_{B}\left({ }^{\circ} \mathrm{C}\right)$ & $q_{w}^{\prime \prime}\left(\mathrm{W} / \mathrm{m}^{2}\right)$ & $t_{0}(\mathrm{~s})$ \\
15 & $1.4 \times 10^{5}$ & 0.04 \\
\hline
\end{tabular}

It should be noted that $t_{0}$ is chosen such that (see Eq.(6))

$$
L \gg 4.6 \sqrt{\frac{t_{0} \alpha_{w}}{\pi}}
$$

To prevent the volumetric heating rate from decreasing to zero as the diameter of the pipe/annulus heater increases, we fix the wall surface (in contact with fluid) heat flux to assure the heating power of pipe/annulus heaters and plate heaters are the same and finite.

\section{III.A.1. Internally Heated Pipe and the Corresponding Plate}

The volumetric heating rate for the pipe and the plate heater can be expressed by

$$
\begin{gathered}
Q=q_{w}^{\prime \prime} 2 \pi R_{i} \cdot 1 \\
q_{w, \text { plate }}^{\prime \prime \prime}=\frac{q_{w}^{\prime \prime}}{L}
\end{gathered}
$$

$$
q_{w, p i p e}^{\prime \prime \prime}=\frac{q_{w}^{\prime \prime} 2 R_{i}}{R_{o}^{2}-R_{i}^{2}}
$$

\section{III.A.2. Internally Heated Annulus and Corresponding Plate}

The expressions for the volumetric heating rates for both the pipe and the plate heater are

$$
\begin{gathered}
Q=q_{w}^{\prime \prime} 2 \pi R_{o} \cdot 1 \\
q_{w, \text { plate }}^{\prime \prime \prime}=\frac{q_{w}^{\prime \prime}}{L} \\
q_{w, \text { annulus }}^{\prime \prime \prime}=\frac{q_{w}^{\prime \prime} 2 R_{O}}{R_{o}^{2}-R_{i}^{2}}
\end{gathered}
$$

\section{III.A.3. Results and Analysis}

As shown in Fig. 10 and Fig. 11, the solutions for the pipe/annulus heaters approach that of the plate heater as the radius of the cylindrical heaters increases. This, in turn demonstrates the consistency of the complicated solutions for the cylindrical geometry heaters.

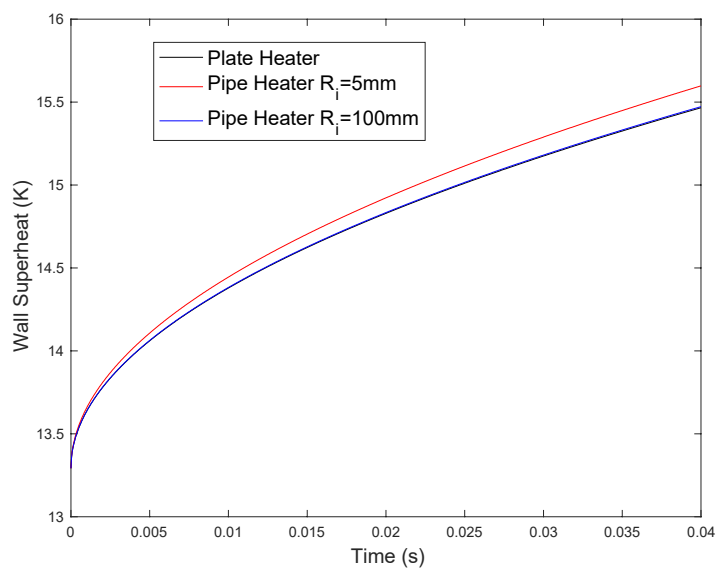

Fig. 10. Verification of thick pipe heater model.

It is interesting to note that the wall surface temperatures of all heaters drop to the same value at the moment of quenching. However, the subsequent increases (due to heating), differ from each other. The wall surface temperature of the plate heater is higher than that of the annulus-shaped heater, but lower than that of the pipe heater. For the pipe heater, the area perpendicular to the heat flux direction in the liquid decreases with the radius, which increases the thermal resistance in the liquid; in turn, the wall surface temperature increases faster than that of plate heater. A similar argument can be made for the annulus heater. 


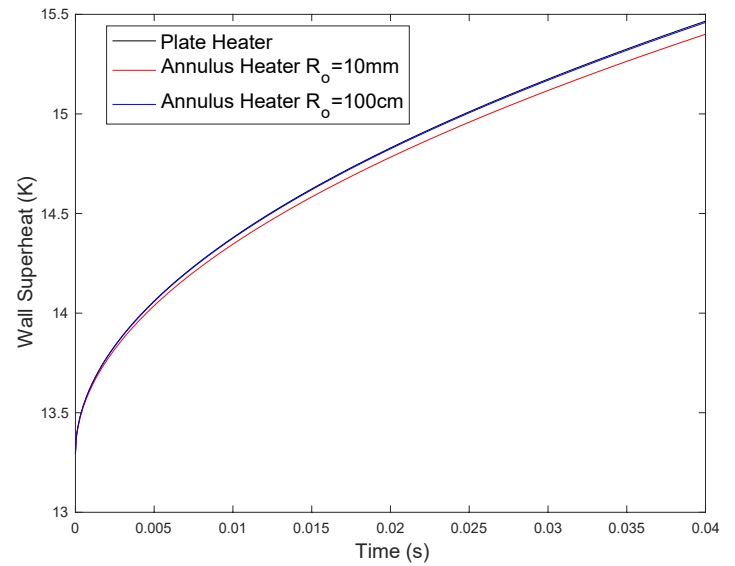

Fig. 11. Verification of thick annulus heater model.

\section{III.B. Validation against Experimental Data}

The models discussed above have been validated against selected experimental data, in which the time for bubble growth and departure is a very small fraction of the total bubble ebullition cycle, such that the average wall superheat is mainly controlled by the temperature history during the waiting period. Multiple sets of data have been used to demonstrate the generality of the model.

\section{III.B.1. Saturated Pool Boiling by Duan ${ }^{10}$}

Duan et al. (Ref. 10) performed an experimental study of saturated pool boiling at atmospheric pressure. The heater was a thin $(<1 \mathrm{~m})$ horizontal $\left(20 \times 10 \mathrm{~mm}^{2}\right)$, resistively-heated, indium-thin-oxide (ITO) film, vacuumdeposited on a sapphire substrate (250 m thick).

The properties of the materials used in the experiments are shown in Table 2.

Table 2. Parameters of Data Set 1

\begin{tabular}{ccc}
\hline$k_{w}(\mathrm{~W} / \mathrm{m} \cdot \mathrm{K})$ & $\rho_{w}\left(\mathrm{~kg} / \mathrm{m}^{3}\right)$ & $c_{p, w}(\mathrm{~J} / \mathrm{kg} \cdot \mathrm{K})$ \\
30 & 3980 & 760 \\
\hline$k_{l}(\mathrm{~W} / \mathrm{m} \cdot \mathrm{K})$ & $\rho_{l}\left(\mathrm{~kg} / \mathrm{m}^{3}\right)$ & $c_{p, l}(\mathrm{~J} / \mathrm{kg} \cdot \mathrm{K})$ \\
0.665 & 958.5 & 4217 \\
\hline$T_{B}\left({ }^{\circ} \mathrm{C}\right)$ & $q_{w}^{\prime \prime}\left(\mathrm{kW} / \mathrm{m}^{2}\right)$ & $t_{0}(\mathrm{~s})$ \\
100 & 28.7 & 0.21 \\
\hline
\end{tabular}

The critical thickness to be treated as a thick heater is

$$
\delta_{\text {crit }}=4.6 \sqrt{\frac{t_{0} \alpha_{w}}{\pi}}=3.7 \mathrm{~mm}>\delta_{w}=0.25 \mathrm{~mm}
$$

A comparison between the predictions using the present models and the experimental data for Set-1 is shown in Figure 12.

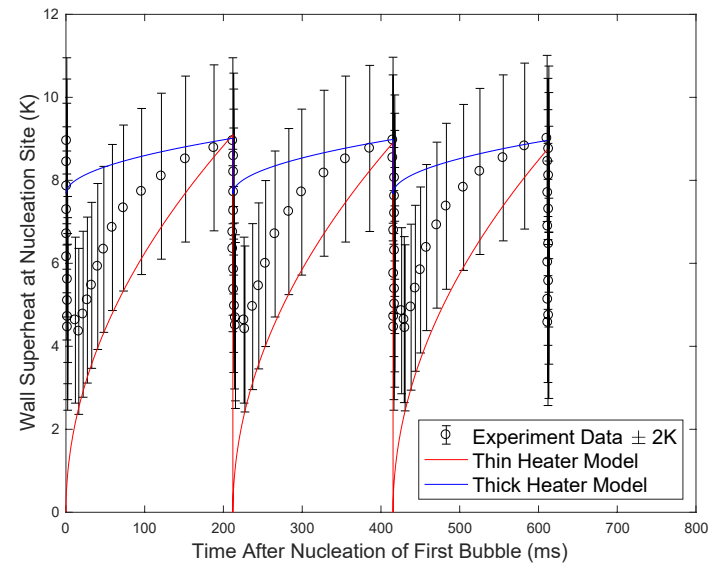

Fig. 12. Comparison between model predictions and experimental measurements for Data Set 1.

The parameters for another data set are shown in Table 3 and the corresponding results of simulations by the proposed models are presented in Fig. 13.

Table 3. Parameters of Data Set 2

\begin{tabular}{ccc}
\hline$k_{w}(\mathrm{~W} / \mathrm{m} \cdot \mathrm{K})$ & $\rho_{w}\left(\mathrm{~kg} / \mathrm{m}^{3}\right)$ & $c_{p, w}(\mathrm{~J} / \mathrm{kg} \cdot \mathrm{K})$ \\
30 & 3980 & 760 \\
\hline$k_{l}(\mathrm{~W} / \mathrm{m} \cdot \mathrm{K})$ & $\rho_{l}\left(\mathrm{~kg} / \mathrm{m}^{3}\right)$ & $c_{p, l}(\mathrm{~J} / \mathrm{kg} \cdot \mathrm{K})$ \\
0.665 & 958.5 & 4217 \\
\hline$T_{B}\left({ }^{\circ} \mathrm{C}\right)$ & $q_{w}^{\prime \prime}\left(\mathrm{kW} / \mathrm{m}^{2}\right)$ & $t_{0}(\mathrm{~s})$ \\
100 & 36 & 0.069 \\
\hline
\end{tabular}

The critical thickness beyond which the heater can be treated as "thick" is the same as before, i.e., $0.25 \mathrm{~mm}$.

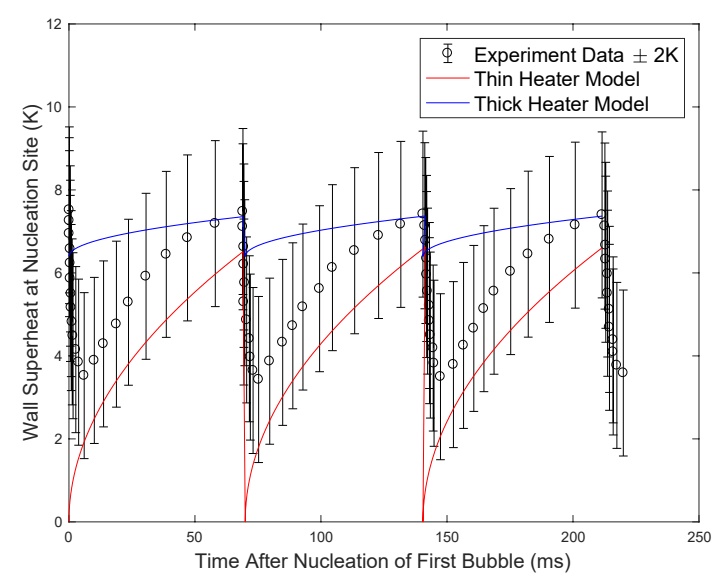

Fig. 13. Comparison between model predictions and measurements for Data Set 2. 


\section{III.B.2. Subcooled Pool Boiling by Jung ${ }^{11}$}

Jung et al. studied single-bubble nucleate boiling in a pool of water subcooled by $3^{\circ} \mathrm{C}$ under atmospheric pressure. A 50-mm-diameter $\mathrm{CaF}_{2}$ substrate, $10 \mathrm{~mm}$ in thickness, was used as a base plate. A 700-nm-thick ITO film heater $\left(8 \times 15 \mathrm{~mm}^{2}\right)$ was fabricated on the $\mathrm{CaF}_{2}$ plate. The corresponding material properties are shown in Table 4.

Table 5. Experimental Parameters

\begin{tabular}{ccc}
\hline$k_{w}(\mathrm{~W} / \mathrm{m} \cdot \mathrm{K})$ & $\rho_{w}\left(\mathrm{~kg} / \mathrm{m}^{3}\right)$ & $c_{p, w}(\mathrm{~J} / \mathrm{kg} \cdot \mathrm{K})$ \\
9.7 & 3180 & 854 \\
\hline$k_{l}(\mathrm{~W} / \mathrm{m} \cdot \mathrm{K})$ & $\rho_{l}\left(\mathrm{~kg} / \mathrm{m}^{3}\right)$ & $c_{p, l}(\mathrm{~J} / \mathrm{kg} \cdot \mathrm{K})$ \\
0.665 & 958.5 & 4217 \\
\hline$T_{B}\left({ }^{\circ} \mathrm{C}\right)$ & $q_{w}^{\prime \prime}\left(\mathrm{kW} / \mathrm{m}^{2}\right)$ & $t_{0}(\mathrm{~s})$ \\
108 & 53 & 0.15 \\
\hline
\end{tabular}

A comparison between the predictions using the present models and the experimental data for Set-1 is shown in Figure 14.

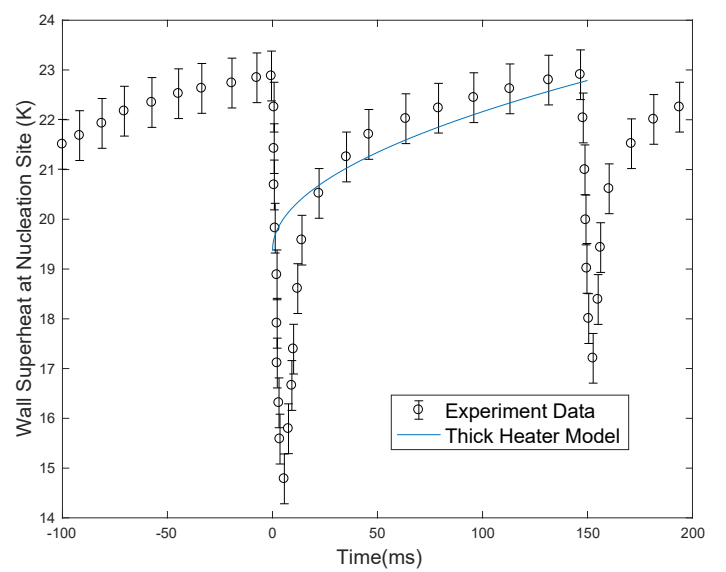

Fig. 14. Comparison between model predictions and experimental data of Jung ${ }^{11}$.

\section{III.B.4. Analysis}

As can be seen in Figs. 12-14, a good agreement between model predictions and experimental data was achieved. It should be noted that the temperature of the fluid replacing the volume evacuated by departed bubbles has been assumed to be the saturation temperature. It may be somewhat higher in the experiments by Jung et al. considering the relatively high wall superheat required for nucleation. This may explain why the model under-predicts the wall superheat by about $2 \mathrm{~K}$.
Since the actual heater geometries are normally neither very thick or extremely thin, both thick-heater and thinheater model have been used in the comparisons against the experiments of Duan ${ }^{1}$. As can be seen in Figs. 12 and 13, the experimental data of reference are placed between these two limited cases. Furthermore, the predictions by both models are inside the experimental error bars.

\section{CONCLUSIONS}

A consistent analytical model of transient heat transfer between solid walls and the surrounding coolant during the waiting period of bubble ebullition cycle has been presented. The model covers a large spectrum of geometries pertaining to both experimental boiling test sections and nuclear reactor fuel assemblies. The new models have been parametrically tested and validated against experimental data. The agreement between the model prediction and experimental data is good.

Future work includes the numerical implementation of the new models in the NPHASE-CMFD solver, and model application to evaluate the heated wall temperature and quenching heat flux forced-convection in nuclear reactor fuel channels.

\section{ACKNOWLEDGMENTS}

The authors would like to acknowledge the financial support provided to this study by the CASL program of the U.S. Department of Energy.

\section{REFERENCES}

1. Podowski, R. M., D. A. Drew, R. T. Lahey Jr, and M. Z. Podowski. "A mechanistic model of the ebullition cycle in forced convection subcooled boiling." In Eighth international topical meeting on nuclear reactor thermal-hydraulics. 1997.

2. Podowski, Michael Z., and Raf M. Podowski. "Mechanistic multidimensional modeling of forced convection boiling heat transfer." Science and Technology of Nuclear Installations 2009 (2008).

3. Del Valle, Victor H., and D. B. R. Kenning. "Subcooled flow boiling at high heat flux." International Journal of Heat and Mass Transfer 28, no. 10 (1985): 1907-1920.

4. N. Kurul and M. Z. Podowski. "Multidimensional effects in forced convection subcooled boiling." In Proceedings of the Ninth International Heat Transfer Conference, vol. 2, pp. 19-24. New York: Hemisphere Publishing, 1990.

5. Basu, Nilanjana, Gopinath R. Warrier, and Vijay K. Dhir. "Wall heat flux partitioning during subcooled flow boiling: Part 1-model development." Journal of heat Transfer 127, no. 2 (2005): 131-140. 
6. Gilman, Lindsey Anne. "Development of a general purpose subgrid wall boiling model from improved physical understanding for use in computational fluid dynamics." PhD diss., Massachusetts Institute of Technology, 2014.

7. Zeyong Wang, Dillon R. Shaver, and Michael Z. Podowski. "On the Modeling of Wall Heat Flux Partitioning in Subcooled Flow Boiling." Transactions of the American Nuclear Society, 114(2016): 881-883.

8. Moore, Franklin D., and Russell B. Mesler. "The measurement of rapid surface temperature fluctuations during nucleate boiling of water." AIChE Journal 7, no. 4 (1961): 620-624.

9. Demiray, Fatih, and Jungho Kim. "Microscale heat transfer measurements during pool boiling of FC-72: effect of subcooling." International Journal of Heat and Mass Transfer 47, no. 14 (2004): 3257-3268.

10. Gerardi, Craig Douglas. "Investigation of the pool boiling heat transfer enhancement of nano-engineered fluids by means of high-speed infrared thermography." PhD diss., Massachusetts Institute of Technology, 2009.

11. Jung, Satbyoul, and Hyungdae Kim. "An experimental method to simultaneously measure the dynamics and heat transfer associated with a single bubble during nucleate boiling on a horizontal surface." International Journal of Heat and Mass Transfer 73 (2014): 365375.

12. Shai, I., and Warren M. Rohsenow. "The mechanism of and stability criterion for nucleate pool boiling of sodium." Journal of Heat Transfer 91, no. 3 (1969): 315-328. 


\title{
Effect of Spacer Grids on Local Flow and Boiling Heat Transfer in Reactor Fuel Rod Bundles
}

\author{
B. M. Waite, M. Z. Podowski \\ Center for Multiphase Research, Rensselaer Polytechnic Institute \\ $1108^{\text {th }}$ Street, Troy NY, 12180 USA \\ waiteb2@rpi.edu, podowm@rpi.edu
}

\begin{abstract}
Nuclear reactor spacer grids offer complex geometries that have a large effect on coolant distribution in the reactor core. Over the years, the nuclear power industry has optimized spacer designs to improve reactor performance during both normal and accident conditions. A commonly used approach to PWR spacers, which has been extensively tested for single-phase flow conditions, is concerned with the addition of mixing vanes to enhance the local thermal performance. However, since the effects of the spacer grids on flow and heat transfer at multiphase flow conditions are considerably more complicated than those in single-phase flows, such situations introduce several new challenges to both experimental and theoretical investigations. The current paper documents the recent results of a study which has been conducted for some time. The overall work focus has been on developing, testing, and validating a consistent multidimensional model of dispersed bubbly flow along heated PWR coolant channels.

The specific objective of this paper is to give an overview of the two-phase flow velocity, void fraction and boiling heat transfer effects around and downstream of spacer grids using mechanistic modeling concepts. The proposed model has been implemented in a state-of-the-art computational multiphase fluid dynamics code NPHASE-CMFD [1], parametrically tested and validated. The paper focuses on the effects of obstructions on heat transfer and void distribution for both BWR-type ring-type spacers and PWR spacers with mixing vanes. A boiling model has been combined with the original two-phase flow model, and used to study the effect of the ring-type spacer grids on local phenomena governing subcooled boiling. The model's predictions for PWR spacers with mixing vanes have been compared against the adiabatic atmospheric-pressure air/water experimental data reported by Ylönen [3] and then subsequently applied to simulate velocity and void fraction distributions at actual PWR conditions. The results have provided important insight helping to improve our understanding of the effect of pressure on model scalability.
\end{abstract}

\section{KEYWORDS}

Reactor spacer grids, mixing vanes, mechanistic two-fluid model of gas/liquid flows, local void fraction predictions

\section{ACKNOWLEDGMENTS}

This research was performed under the appointment of the first author as a recipient of the Rickover Fellowship Program in Nuclear Engineering sponsored by Naval Reactors Division of the U.S. Department of Energy. The authors would also like to thank the CASL program of the U.S. Department of Energy for their support.

\section{REFERENCES}

1. B.M. Waite, D.R. Shaver and M.Z. "Podowski, Mechanistic Modeling of Two-Phase Flow Around Spacer Grids with Mixing Vanes", Proceedings of NURETH-16, Chicago, IL (2015)

2. B.M. Waite and M.Z. Podowski, "Mechanistic Predictions of the Effect of Spacer Grids with Mixing Vanes on Local Void Fraction Distribution in PWR Reactor Rod Bundles", Proceedings of NUTHOS-11, Gyeongju, Korea (2016).

3. A. Ylönen, "High-resolution flow structure measurements in a Rod bundle", PhD Thesis, NO 20961, ETH Zurich, (2013) 